\title{
Personalized Management of Post-Thrombotic Syndrome
}

Citation for published version (APA):

Amin, E. (2019). Personalized Management of Post-Thrombotic Syndrome. [Doctoral Thesis, Maastricht University]. Maastricht University. https://doi.org/10.26481/dis.20190207ea

Document status and date:

Published: 01/01/2019

DOI:

10.26481/dis.20190207ea

Document Version:

Publisher's PDF, also known as Version of record

\section{Please check the document version of this publication:}

- A submitted manuscript is the version of the article upon submission and before peer-review. There can be important differences between the submitted version and the official published version of record.

People interested in the research are advised to contact the author for the final version of the publication, or visit the DOI to the publisher's website.

- The final author version and the galley proof are versions of the publication after peer review.

- The final published version features the final layout of the paper including the volume, issue and page numbers.

Link to publication

\footnotetext{
General rights rights.

- You may freely distribute the URL identifying the publication in the public portal. please follow below link for the End User Agreement:

www.umlib.nl/taverne-license

Take down policy

If you believe that this document breaches copyright please contact us at:

repository@maastrichtuniversity.nl

providing details and we will investigate your claim.
}

Copyright and moral rights for the publications made accessible in the public portal are retained by the authors and/or other copyright owners and it is a condition of accessing publications that users recognise and abide by the legal requirements associated with these

- Users may download and print one copy of any publication from the public portal for the purpose of private study or research.

- You may not further distribute the material or use it for any profit-making activity or commercial gain

If the publication is distributed under the terms of Article $25 \mathrm{fa}$ of the Dutch Copyright Act, indicated by the "Taverne" license above, 


\section{Personalized Management of Post-Thrombotic Syndrome}


The research presented in this thesis was funded by the Netherlands Organization for Health Research and Development (ZonMw), grant number 171102007.

(c) Elham Amin, Maastricht 2019

ISBN 9789082980127

No part of this book may be reproduced or transmitted in any form or by any means, without permission of the author. For all article the copyright has been transferred to the respective publisher.

$\begin{array}{ll}\text { Cover picture (unedited) } & : \text { Adobe Stock } \\ \text { Other pictures } & : \text { Adobe Stock } \\ \text { Printing } & : \text { GVO drukkers \& vormgevers, Ede, The Netherlands }\end{array}$ 


\title{
Personalized Management of Post-Thrombotic Syndrome
}

\author{
DISSERTATION \\ To obtain the degree of Doctor at Maastricht University, \\ on the authority of the Rector Magnificus, Prof. Dr. Rianne M. Letschert, \\ in accordance with the decision of the Board of Deans, \\ to be defended in public \\ on Thursday 07 February 2019, at 14:00 hours
}

by

\section{Elham Ella Amin}


The research presented in this thesis was conducted at:

CAPHRI Care and Public Health Research Institute, Department of Clinical Epidemiology and Medical Technology Assessment of Maastricht University. CAPHRI participates in the Netherlands School of Public Health and Care Research CaRe.

CARIM Cardiovascular Research Institute Maastricht, Department of Biochemistry of Maastricht University.

\section{Promotores}

Prof. dr. H. ten Cate

Prof. dr. M. A. Joore

\section{Co-promotor}

Dr. A.J. ten Cate-Hoek

\section{Assessment Committee}

Prof. dr. C. D. Dirksen (chair)

Prof. dr. C.H. A. Wittens

Prof. dr. M. V. Huisman (LUMC, Leiden)

Dr. T.A.V. van Asselt (UMCG, Groningen)

Dr. E.G. Gerrits 


\section{CONTENTS}

Chapter 1 General Introduction 1

$\begin{array}{lll}\text { PART I } & \text { PREVENTION \& PREDICTION } & 11\end{array}$

Chapter 2 Compression to Prevent PTS: A Controversy? 13

Chapter 3 Development and Validation of a Practical Two-Step 31

Prediction Model and Clinical Risk Score for Post-Thrombotic

Syndrome

PART II COMPARATIVE \& COST EFFECTIVENESS 53

Chapter 4 Individualised versus Standard Duration of Elastic Compression 55

Therapy for Prevention of Post-thrombotic Syndrome (IDEAL

DVT): a Multicentre, Randomised, Single-Blind, Allocation-

Concealed, Non-Inferiority Trial

Chapter 5 Individually Shortened Duration versus Standard Duration of

Elastic Compression Therapy for Prevention of Post-Thrombotic

Syndrome: a Cost-Effectiveness Analysis

Chapter 6 Clinical and Economic Impact of Immediate Compression in the Acute Phase of Deep Vein Thrombosis

Chapter 7 Residual vein occlusion in Relation to Immediate Compression and Post-Thrombotic-Syndrome in Deep Vein Thrombosis

$\begin{array}{llr}\text { PART III } & \text { SUMMARY \& GENERAL DISCUSSION } & 147 \\ \text { Chapter } 8 & \text { Summary and General Discussion } & 149 \\ \text { PART IV } & \text { ADDENDUM } & 165 \\ & \text { Summary in Dutch } & 167 \\ & \text { Valorization } & 177 \\ & \text { List of publications } & 185 \\ & \text { About the author } & 189 \\ & \text { Acknowledgements } & 191\end{array}$





\section{CHAPTER 1}

General Introduction 
CHAPTER 1 
Post-thrombotic syndrome (PTS) is the most common complication of deep vein thrombosis (DVT), occurring in $20 \%$ to $50 \%$ of the patients within two years, of which the majority is diagnosed within six months after DVT. ${ }^{(1-3)}$ PTS is a chronic compilation of subjective leg complaints and/or objectively confirmable signs. The subjective complaints include pain, cramps, heaviness, itching and tingling. The objective signs are oedema, redness, skin indurations, hyperpigmentation, venectasia, pain upon calf compression and in the most severe cases venous ulcerations that develops in $5 \%$ of the patients. $(2,4)$ The exact pathophysiology of PTS is not clarified yet. It has been hypothesized that PTS develops as a consequence of venous outflow restriction due to the obstructing thrombus in combination with the inflammation process that is elicited during the acute phase of thrombus degradation and venous remodelling in DVT. Inflammation leads to damage to the venous valves and reflux, and the combination of reflux and outflow restriction eventually lead to venous hypertension. This chain of events is assumed to be the main cause of PTS signs and symptoms. ${ }^{(5-7)}$ No gold standard diagnostic tool for PTS exists so far and the clinical diagnosis is mostly based on the Villalta score. The Villalta score is one of six clinical scores that is used for PTS diagnosis; the Widmer classification, the CEAP classification, the venous clinical severity scale, the Ginsburg scale, and the Brandjes classification. ${ }^{(8)}$ In order to establish a standardized mode of diagnosis, in 2008 the scientific and standardization committee (SSC) of the International Society on Thrombosis and Haemostasis (ISTH), reached consensus on the preferred use of the Villalta score (Table 1). Each of the signs and symptoms of PTS are scored on severity and are assigned absent if the item is not present, mild (if the item score is one point), moderate (if the item score is two points) and severe in case three points are scored. There are 11 items to be scored; the extreme total score is 33 in case all items are scored as being severe or if there is venous ulceration of a history of venous ulceration. A sum score of $\geq 5$ at least six months after DVT is classified as PTS. ${ }^{(9)}$ 
Table 1: Items of the Villalta score

\section{Subjective Symptoms}

pain, itching, cramps,

tingling, heaviness

\section{Objective signs}

edema, redness, hyperpigmentation, venous ectasia, indurations, pain on calf compression, ulceration

Scoring per item Villalta score: 0 (not present), 1 (mild), 2 (moderate), 3 (severe), 33 (Active or healed ulcer). Score $\geq 5=$ PTS (5-9 mild, 10-14 moderate, $\geq 15$ severe)

This definition of the diagnosis differs from how the score was originally intended to define PTS. Previously, two consecutive Villalta sum scores of $\geq 5$ with at least three months in between was required to define PTS. This is known as the Prandoni definition of PTS. ${ }^{(10)}$

Not only a gold standard method for PTS diagnosis is lacking, also a clear-cut treatment in the acute and subacute phase absent. Invasive and non-invasive surgical techniques, as well as pharmacotherapy have been studied, however thus far no conclusive answers are obtained. ${ }^{(11-15)}$ Because curative options are missing, prevention takes a prominent place in PTS management. Compression therapy is the cornerstone of PTS prevention. Two randomized trials showed an absolute risk reduction of PTS of $23-39 \%$ in patients with DVT who wore elastic compression stockings (ECS) for two years in comparison with patients who did not wear ECS. $(1,16)$ The outcomes of these studies led to the adoption of ECS therapy in PTS management. In 2014 the results of a large randomized trial, in which the effect of ECS was compared to placebo stockings, were published; no benefit of ECS was found. ${ }^{(17)}$ Because the study was criticized for methodological shortcomings and lack of patients' therapy compliance, the European guidelines did not alter their recommendations for the use of ECS in PTS management. Moreover, between 2014 and 2017 one other randomized controlled trial, as well as a subsequent meta-analysis, found beneficial effects of ECS in PTS prevention. ECS could achieve $30 \%$ reduction in PTS occurrence. ${ }^{(18,19)}$ 


\section{The impact of PTS and PTS management on the individual patient and the society at large}

PTS can be a debilitating condition and affect patients' quality of life to a great extent. ${ }^{(20)}$ At the same time PTS prevention with ECS can be a burden to the patient as well. ECS prescribed in PTS prevention consist of class III stockings which means that the exerted pressure around the ankle equals to $35 \mathrm{mmHg}$. Part of the patients will not be able of to take the stockings on and off themselves; they require daily home care for the duration of ECS use. Moreover, ECS use can be bothersome in general and during warm days in particular; also aesthetics could play a role. Not all patients experience leg complaints and so might not belief to benefit from ECS which could result in less therapy compliance. A discrete choice experiment in patients with ECS showed that patients were willing to accept $29 \%$ increase in PTS risk if they would be able to put on the stockings without the help of others. ${ }^{(21)}$ These results emphasize the importance of autonomy and the impact that ECS use has on it. Because PTS can be debilitating and home care needs to be offered to a proportion of patients, PTS also affects the society at large. Apart from productivity loss and costs related to (para) medical care demand for leg complaints, substantial costs are induced due to ECS and homecare use. In the Netherlands, the annual costs of ECS therapy are an estimated $€ 23.5$ million. (22-24)

\section{What still needs to be known in PTS management}

Several aspects in PTS management still need to be elucidated. First, the optimal duration of ECS therapy. Because the majority of patients develop PTS within two years, ECS are prescribed for two years, regardless of the signs and symptoms. It is unclear whether it is safe and cost-effective to shorten the current two year time frame of ECS in a subset of patients, without substantial increase in PTS risk. Second, preventive therapy options in the acute phase i.e. time-frame between DVT diagnosis and the start of ECS is not determined. The 
question is which option is the most effective and what are the associated costs and effects on quality of life. Third, despite the fact that some established and possible predictors for PTS are known, thus far it is not possible to predict the individual patient risk of PTS development. If the individual risk of a patient is known, preventive measures can be adjusted to the personal need of the patient. As personalized preventive medicine is becoming a key term in medical practice, there is a need for prediction rules for PTS. Another thus far unclarified aspect is the role of residual vein occlusion in PTS occurrence. And finally, it is still unclear what role surgical procedures and pharmacotherapeutic interventions may play in future PTS prevention.

\section{Aims and outline of the present thesis}

The aim of the present thesis is to investigate and establish a personalized management of PTS in which the focus is put on a non-invasive approach. This could enable physicians to allocate targeted preventive measures to patients. Because the measures would be individually tailored, patient compliance could be improved. As patients are offered the best suited options, cost-effectiveness as well as risk-benefit trade-off may be improved. Apart from the role of invasive and pharmacotherapeutic measures, the mentioned aspects that still need to be known in PTS prevention will be tackled in one or more chapters of the current thesis.

Part I of the thesis describes the risk of PTS and the effect of ECS in more detail. This part consists of two chapters:

In chapter 2 the leading theory in pathophysiology of PTS is explained. In light of the pathophysiological mechanism the mechanistic substrate for the effectiveness of compression therapy is discussed. Then, emphasize is placed on what constitutes the individual baseline risk. Following the risk factors and indicators, the chapter continues to elaborate on alternative forms of preventive 
therapies that could be used in addition or as substitute to ECS. The review concludes with reflection upon costs aspects and implications for quality of life.

Chapter $\mathbf{3}$ describes the development and external validation of a two-step prediction model and simplified clinical risk score for PTS. The developmental phase is performed for two definitions of PTS, the current ISTH definition and the original Prandoni definition. The efficiency of the prediction model with the two definitions is explored.

Part II involves three chapters on comparative and cost-effectiveness:

Chapter 4 describes the results of the IDEAL DVT study, a multi-center randomized controlled non-inferiority trial in which individually tailored duration of ECS is compared to the standard duration of two years. In this chapter besides pts prevention as the main effect, patient outcomes (health-related quality of life) as well as costs are considered.

Chapter $\mathbf{5}$ evaluates whether a personalized management of PTS is desirable from society's perspective in monetary terms and from patients perspective in terms of patient outcomes. To answer this question cost-effectiveness of the IDEAL DVT study is performed.

Chapter 6 places the focus back on the acute phase of DVT, immediately after the diagnosis and before the start of ECS use. Although in Europe application of compression bandaging in that time frame has been customary, no large or longterm studies have explored the effect of compression therapy in the acute phase of DVT. To this end, this chapter investigates the effect of compression therapy in the acute phase of DVT on signs and symptoms of PTS whereby the influence of compression on costs and quality of life is presented.

Chapter $\mathbf{7}$ aims to elucidate the association between immediate compression therapy prior to ECS and the presence of residual vein occlusion at least six and 24 months after DVT. Subsequently, the presence of residual vein occlusion is studied in relation to PTS occurrence. 
Part III of the thesis is chapter $\mathbf{8}$ that presents a summary and a general discussion of the main findings and their implications. The chapter concludes with a reflection upon the limitations and directions for future research. 


\section{References}

1. Brandjes DP, Buller HR, Heijboer $H$, Huisman MV, de Rijk M, Jagt $H$, et al. Randomised trial of effect of compression stockings in patients with symptomatic proximal-vein thrombosis. Lancet. 1997;349(9054):759-62.

2. Prandoni $P$, Lensing $A W$, Cogo $A$, Cuppini $S$, Villalta $S$, Carta $M$, et al. The long-term clinical course of acute deep venous thrombosis. Ann Intern Med. 1996;125(1):1-7.

3. Kahn SR, Shrier I, Julian JA, Ducruet T, Arsenault L, Miron MJ, et al. Determinants and time course of the postthrombotic syndrome after acute deep venous thrombosis. Ann Intern Med. 2008;149(10):698-707.

4. Kahn SR, Shbaklo H, Lamping DL, Holcroft CA, Shrier I, Miron MJ, et al. Determinants of health-related quality of life during the 2 years following deep vein thrombosis. J Thromb Haemost. 2008;6(7):1105-12.

5. Phillips LJ, 2nd, Sarkar R. Molecular characterization of post-thrombotic syndrome. J Vasc Surg. 2007;45 Suppl A:A116-22.

6. Henke PK, Comerota AJ. An update on etiology, prevention, and therapy of postthrombotic syndrome. J Vasc Surg. 2011;53(2):500-9.

7. Ten Cate-Hoek AJ, Henke PK, Wakefield TW. The post thrombotic syndrome: Ignore it and it will come back to bite you. Blood Rev. 2015.

8. Kolbach DN, Neumann HA, Prins MH. Definition of the post-thrombotic syndrome, differences between existing classifications. European journal of vascular and endovascular surgery : the official journal of the European Society for Vascular Surgery. 2005;30(4):404-14.

9. Kahn SR, Partsch H, Vedantham S, Prandoni P, Kearon C. Definition of post-thrombotic syndrome of the leg for use in clinical investigations: a recommendation for standardization. J Thromb Haemost. 2009;7(5):879-83.

10. Villalta S, Bagatella, P., Piccioli, A., Lensing, A., Prins, M. \& Prandoni, P. Assessment of validity and reproducibility of a clinical scale for the post-thrombotic syndrome Haemostasis. 1994;24(158a).

11. Haig Y, Enden T, Grotta O, Klow NE, Slagsvold CE, Ghanima W, et al. Post-thrombotic syndrome after catheter-directed thrombolysis for deep vein thrombosis (CaVenT): 5 year follow-up results of an open-label, randomised controlled trial. The Lancet Haematology. 2016;3(2):e64-71.

12. Vedantham S, Goldhaber SZ, Julian JA, Kahn SR, Jaff MR, Cohen DJ, et al. Pharmacomechanical Catheter-Directed Thrombolysis for Deep-Vein Thrombosis. The New England journal of medicine.2017;377(23):2240-52.

13. Hull RD, Pineo GF, Brant R, Liang J, Cook R, Solymoss S, et al. Home therapy of venous thrombosis with long-term LMWH versus usual care: patient satisfaction and postthrombotic syndrome. Am J Med. 2009;122(8):762-9 e3.

14. Luzzi R, Belcaro G, Dugall M, Hu S, Arpaia G, Ledda A, et al. The efficacy of sulodexide in the prevention of postthrombotic syndrome. Clin Appl Thromb Hemost. 2014;20(6):5949.

15. Ippolito E, Belcaro G, Dugall M, Cesarone MR, Feragalli B, Errichi BM, et al. Venoruton(R): post thrombotic syndrome. Clinical improvement in venous insufficiency (signs and symptoms) with Venoruton(R). A five-year, open-registry, efficacy study. Panminerva Med. 2011;53(3 Suppl 1):13-9. 
16. Prandoni $\mathrm{P}$, Lensing AW, Prins $\mathrm{MH}$, Frulla $\mathrm{M}$, Marchiori $\mathrm{A}$, Bernardi $\mathrm{E}$, et al. Below-knee elastic compression stockings to prevent the post-thrombotic syndrome: a randomized, controlled trial. Ann Intern Med. 2004;141(4):249-56.

17. Kahn SR, Shapiro S, Wells PS, Rodger MA, Kovacs MJ, Anderson DR, et al. Compression stockings to prevent post-thrombotic syndrome: a randomised placebo-controlled trial. Lancet. 2014;383(9920):880-8.

18. Mol GC, van de Ree MA, Klok FA, Tegelberg MJ, Sanders FB, Koppen S, et al. One versus two years of elastic compression stockings for prevention of post-thrombotic syndrome (OCTAVIA study): randomised controlled trial. BMJ (Clinical research ed). 2016;353:i2691.

19. Appelen D, van Loo E, Prins MH, Neumann MH, Kolbach DN. Compression therapy for prevention of post-thrombotic syndrome. Cochrane Database Syst Rev. 2017;9:Cd004174.

20. Kahn SR, Ducruet T, Lamping DL, Arsenault L, Miron MJ, Roussin A, et al. Prospective evaluation of health-related quality of life in patients with deep venous thrombosis. Arch Intern Med. 2005;165(10):1173-8.

21. Bouman AC, Ten Cate-Hoek AJ, Dirksen CD, Joore MA. Eliciting patients' preferences for elastic compression stocking therapy after deep vein thrombosis: potential for improving compliance. J Thromb Haemost. 2016;14(3):510-7.

22. Blattler W. [Aspects of cost effectiveness in therapy of acute leg/pelvic vein thrombosis]. Wiener medizinische Wochenschrift (1946). 1999;149(2-4):61-5.

23. Gelderblom G, Hagedoorn-Meuwissen, EAV. Kousen uittrekhulpmiddel Easy-Lever. Een onderzoek naar bruikbaarheid, effecten en belemmeringen. in opdracht van ZonMw. 2005.

24. Raju S, Hollis K, Neglen P. Use of compression stockings in chronic venous disease: patient compliance and efficacy. Ann Vasc Surg. 2007;21(6):790-5. 


\section{PART I}

\section{PREVENTION \& PREDICTION}




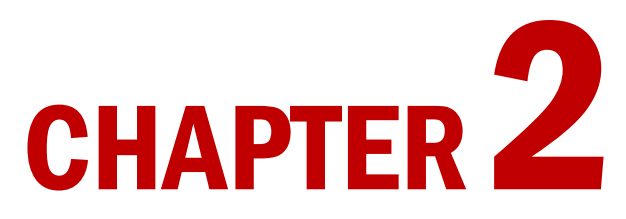

Compression to Prevent PTS: A Controversy?
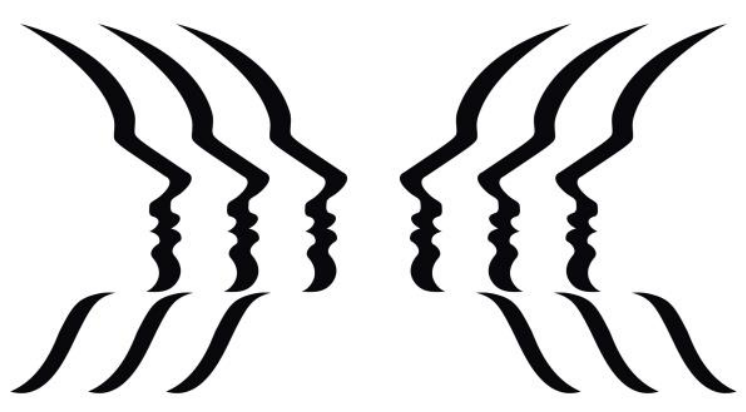

Amin E, Joore MA, ten Cate-Hoek AJ.

Phlebology. 2016 Mar; 31 (1 Suppl): 41-7 


\section{Abstract}

Compression therapy, prescribed as elastic compression stockings, is the cornerstone in the management of post-thrombotic syndrome. The effectiveness of elastic compression stockings has recently been called into question in a large randomized placebo-controlled trial. The findings however may be less contradictory than assumed and presented. The mechanistic substrate for the effectiveness of compression therapy is based on its ability to counteract venous hypertension, which is a central aspect in the pathophysiology of post-thrombotic syndrome. Nevertheless, despite elastic compression stockings a significant percentage $(20-50 \%)$ of patients develops post-thrombotic syndrome, suggesting that there are other factors to be considered next to compression. Every patient has an individual baseline risk value, constituted of non-modifiable and modifiable risk factors (i.e. age, sex, bodyweight etcetera). Straining patients at risk is therefore crucial. Exploring additional or alternative forms of therapy is desirable as well since these are in addition to the risk factors, costs aspects and quality of life, puzzle pieces in the management of post-thrombotic syndrome, which once pieced together enables multifactorial yet individualized therapy. 


\section{Introduction}

Post-thrombotic syndrome (PTS) is a serious long-term complication of deep venous thrombosis (DVT), which occurs in $25-50 \%$ of patients, mostly within 2 years, after DVT diagnosis. ${ }^{1,2}$ As the name indicates, PTS is diagnosed on the basis of a compilation of signs and symptoms including pain, edema and ulceration, rather than a specific disease entity. The exact aetiology of PTS, and hence the best strategy in prevention of PTS, has not been elucidated yet. For a long period of time, applying elastic compression stockings (ECS) has been considered the best approach to prevent PTS. ${ }^{3}$ Recently, however, the effectiveness of ECS is called into question. In this review, we seek to outline the controversies concerning compression therapy, thereby focussing on pathophysiological aspects of PTS and mitigating patient factors. Moreover, we will explore additional treatment options and will make a proposal for optimization of PTS management, balancing clinical effectiveness,cost aspects and implications for quality of life.

\section{Contradictory findings?}

ECS therapy used to be recommended for the prevention of PTS by several guidelines based on high-quality evidence. ${ }^{3}$ This evidence was primarily based on two randomized controlled studies, both of which showed a reduction in the incidence of PTS by $50 \%{ }^{1,2}$ However, in a fairly recent large $(\mathrm{N}=806)$ placebo controlled trial no effect of ECS on the incidence of PTS was observed. ${ }^{4}$ Since its publication, the trial results have stirred the discussion on the effectiveness of ECS. At the same time the trial has been criticized on many aspects, such as the lack of patient compliance, the use of placebo stockings, which might have had some therapeutic value and/or influence on the quality of life, the characteristics of the study population that possibly are not comparable to the previously mentioned studies and the fact that no instruction regarding the stockings was given to the patients by a physician. ${ }^{5}$ These factors could have undermined the 
validity of the outcomes. Therefore, findings regarding the effectiveness of ECS may be less contradictory than assumed and presented. Nevertheless, in addition to compression as a measure to counteract venous pressure, other factors may be of equal or perhaps even greater value for the prevention of PTS.

\section{Pathophysiology of PTS, risk factors and indicators}

Although the pathophysiological mechanisms underlying PTS have not been entirely clarified, venous hypertension is assumed to play a leading role. ${ }^{5,6}$ In the acute phase of DVT, the formed thrombus blocks the venous outflow causing the pressure in the vein to rapidly increase. At the same time, inflammatory processes aimed at resolving the thrombus take place. ${ }^{7-9}$ The process of thrombus resolution almost invariably causes collateral vein wall damage, and because of the preferred location of the thrombus in the area approximating the venous valves, in many cases the valves will also be damaged. In the sub-acute phase, vein-wall remodeling takes place resulting in vein-wall stiffness and thus less compliance of the vein wall. ${ }^{10}$ Vein-wall remodeling and valvular damage both contribute to venous hypertension.

Moreover, if the thrombus resolution is incomplete, and this is the case in $50 \%$ of the patients, the residual thrombus also adds to increased venous hypertension and decreased flow. ${ }^{11}$ The venous hypertension overloads the capillaries and provokes capillary leakage. As a consequence, edema is formed and subsequently followed by impaired microcirculation and hypoxia of the tissues, leading to various symptoms including skin ulceration and sensation of pain. 5,6 


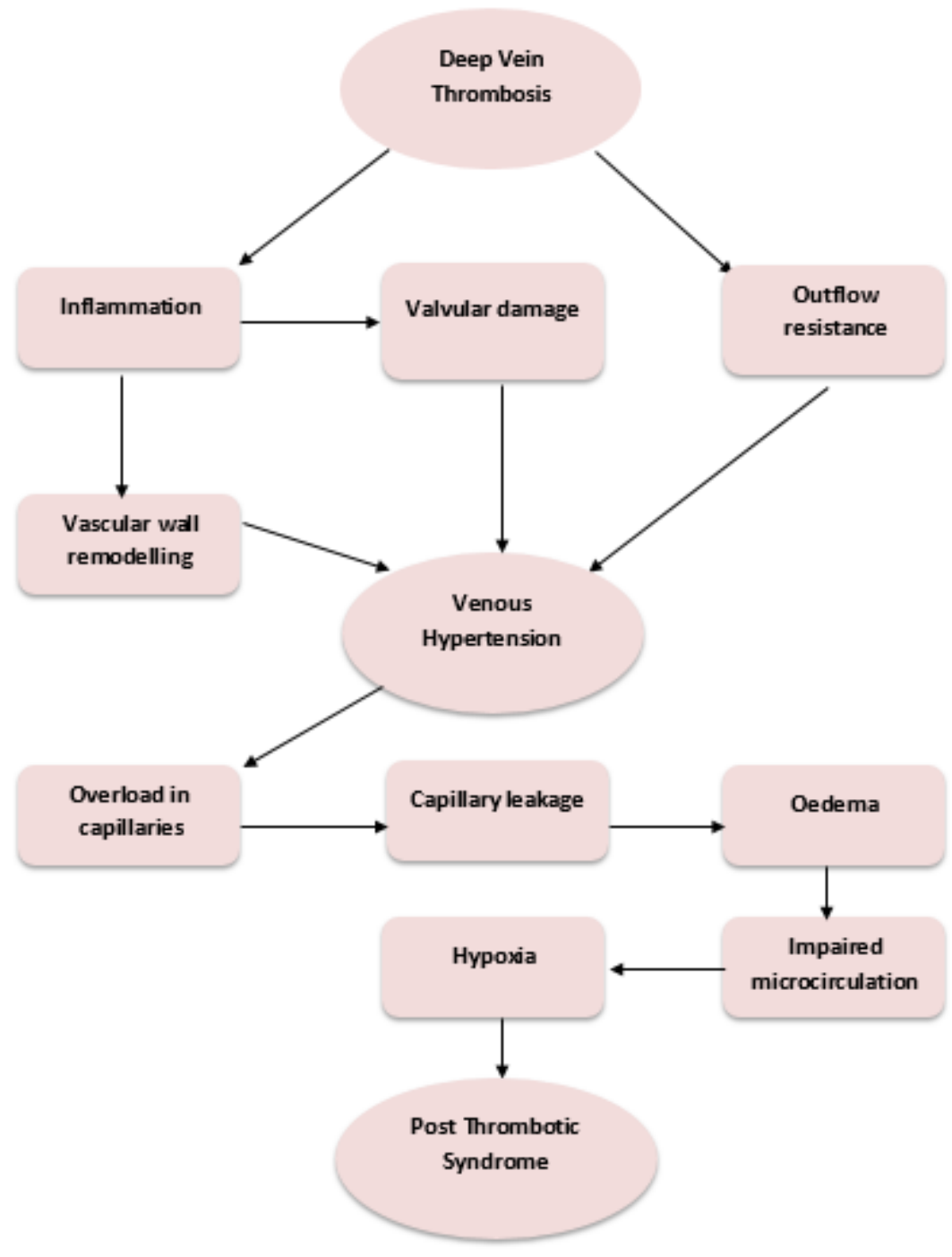

Figure 1. Schematic representation of the pathophysiology of PTS. 


\section{The mechanistic substrate for the effectiveness of compression} therapy

Compression therapy is aimed at improving the venous outflow as it counteracts venous hypertension, thereby reducing capillary leakage and edema development, which in its turn leads to improved microcirculation in the skin. In addition compression therapy supports muscle compression also reducing the diameter of the (deep) veins. Subsequently, the venous flow accelerates and the venous ejection fraction improves. ${ }^{12}$ Venous flow has shown to influence the process of thrombus resolution; animal experimental studies show that reduced flow is associated with pronounced inflammatory reactions and causes excess remodeling of the vein wall and poor thrombus resolution. ${ }^{13}$ On the other hand improving venous flow diminished the inflammatory reactions. There are, however, uncertainties as to the starting point of the ECS as well as to the optimal duration of the therapy. ${ }^{14} \mathrm{~A}$ randomized controlled clinical study on individually tailored duration of ECS is currently being performed (NCT01429714). ${ }^{15}$ The sample size for inclusion (864) was reached in July 2015; the results of this study are to be expected autumn 2017. Despite the many indications for a probable mode of action of compression in the prevention of PTS, its success most likely will depend on the interplay with additional patientrelated factors. Not all patients diagnosed with DVT will develop PTS and not all patients who receive compression therapy after DVT will benefit from it. We propose that every patient diagnosed with DVT will have an individual baseline risk value for the development of PTS. This baseline risk value may be expressed by age, gender, lifestyle-associated aspects, levels of biomarkers related to PTS etc. 


\section{What constitutes the individual baseline risk value?}

Some risk factors such as age and gender are non-modifiable. Older people are more prone to thrombosis and therefore also to PTS. Men are at increased risk for both thrombosis and PTS. In addition it was observed in several studies that ECS therapy was less successful in men. ${ }^{16,17}$ A risk factor that has the possibility to be modified is varicosities. Varicosities have been linked to increased risk of thrombosis as well as increased risk for PTS. ${ }^{18}$ Removal of superficial varicose veins may therefore decrease the risk of PTS. Lifestyle is an important moderator of risk, as it affects risk factors such as smoking status, physical activity and obesity. Not only obesity but being overweight already increases the risk of PTS. A body mass index (BMI) of $>25 \mathrm{~kg} / \mathrm{m} 2$ increases the risk 1.5 times, while a $\mathrm{BMI}$ $>28 \mathrm{~kg} / \mathrm{m} 2$ has been shown to increase the risk to $3.5-4$ fold. ${ }^{16,19}$ However, one study also suggested an OR of 4.7 when the BMI amounted $>22 \mathrm{~kg} / \mathrm{m}^{2}$. Several explanations have been postulated on the mechanism constituting this risk. First, abdominal fat may exert pressure on superficial veins, in turn deteriorating the venous flow, which promotes reflux.

Second, overweight and obesity could indicate a lower level of physical activity, that has a negative influence on the calf muscle pump function. ${ }^{16}$ It is a two-sided sword for as the symptoms of PTS become prominent the level of physical activity lowers and is followed by weight gain. ${ }^{16}$ Furthermore, adipose tissue may promote inflammatory responses by stimulating various pro-inflammatory cytokines that alter adhesion molecules and affects the vascular wall. Finally, adipose tissue can act as an endocrine organ and produce leptin, which induces a thrombotic state. ${ }^{20}$ Excessive abdominal fat expressed as a high waist circumference increases the risk of PTS almost three-fold. ${ }^{21}$

Henceforth, interventions aimed at reducing the BMI should gain more attention. Promotion of physical activity will serve two purposes; it will concomitantly induce weight loss as well as improve the calf muscle pump function. More extended thrombosis reaching into the iliofemoral 
tract (IFDVT) is found to be a risk factor for PTS, increasing both the risk of PTS by two-fold and the risk of recurrent DVT. Recurrent DVT increases the risk of PTS, but it also holds true the other way around as PTS increases the risk of recurrent DVT. ${ }^{22,23}$ In case of an increased risk of recurrence, hypercoagulability could very well be the underlying risk factor. Although thrombophilia has never been implicated as a risk factor for PTS, levels of D-dimer have been found to be two-fold increased in patients with PTS. ${ }^{24}$ Several studies have identified various inflammatory biomarkers in association with PTS. Strong associations were found between levels of CRP and PTS. ${ }^{25}$ In addition to these markers, associations with PTS were also found for interleukin (IL) 6, IL 8 and intracellular adhesion molecule 1(ICAM-1).26 (26) Due to extended heterogeneity between studies and differences in timing of blood sampling meta-analysis could not yet be performed for these biomarkers. 


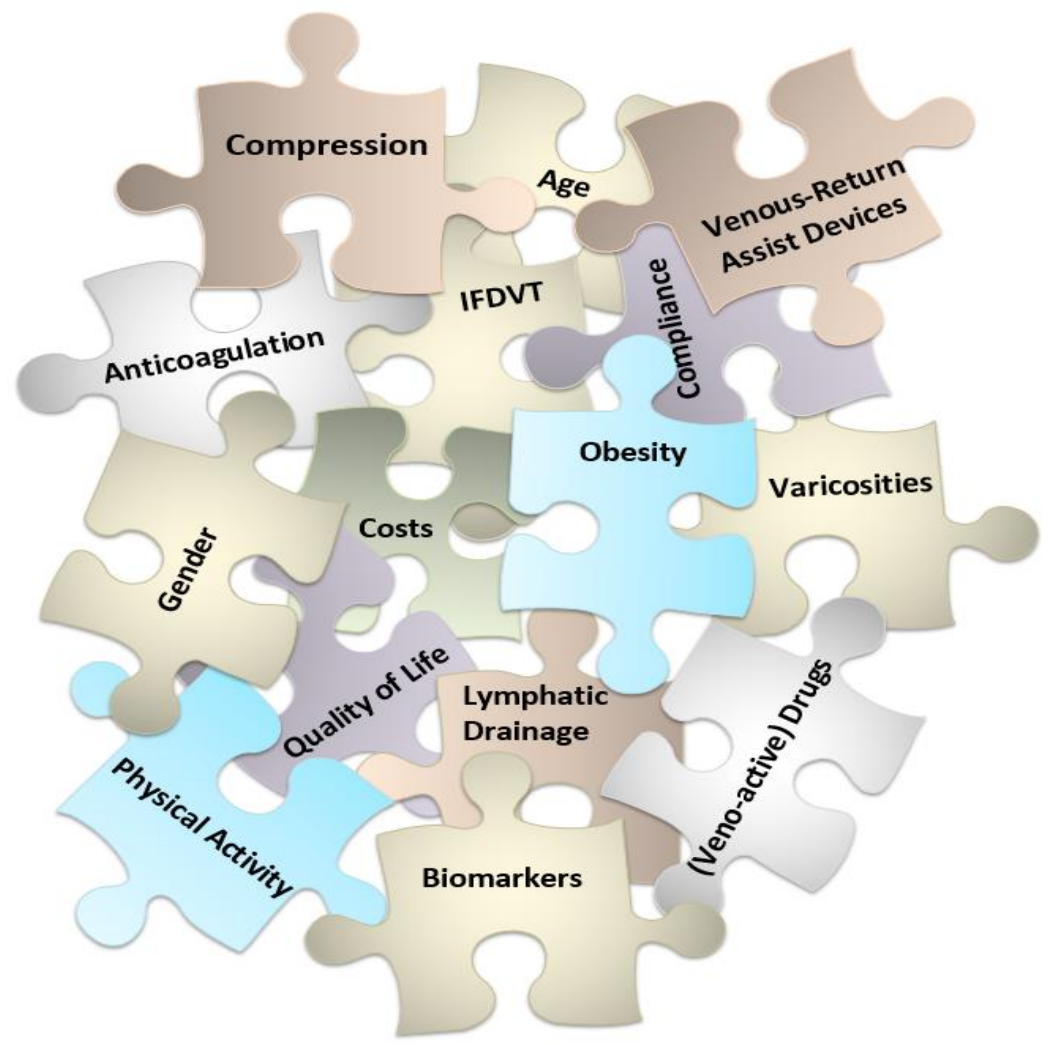

Figure 2: Pieces of the puzzle for PTS: modifiable and non-modifiable risk factors, treatment options, patient related outcomes.

\section{Alternate forms of therapy or additional therapies to compression}

Although physicians may be hesitant to prescribe physical activity during the acute phase of DVT, because blood flow increases and this may worsen the symptoms, exercise does not seem to be associated with exacerbation of symptoms or increased rate of recurrent VTE. ${ }^{(27,28)}$ Physical activity has actually shown to be beneficial for symptom relieve. Also in the sub-acute and chronic phase exercise may be beneficial. Padberg and colleagues conducted a trial in 31 patients with chronic venous insufficiency in which the intervention group was 
offered a 6 months exercise program (3 months supervised and 3 months unsupervised). The results showed that the calf muscle pump function was returned to normal and improvement in muscle strength occurred. (29) The intervention was offered on top of regular therapy consisting of ECS and oral anti coagulation. Another trial showed that the application of ECS in patients with a history of DVT during the actual exercise sessions had no effect. (30)

Besides physical activity, devices directed at improving the muscle pump function are noteworthy. $O^{\prime}$ Donnel and colleagues investigated a wavegenerating device in relation to PTS severity and found that the quality of life improved significantly in patients wearing the device. There was no significant difference in clinical effectiveness. The authors conclude based on the improvement of quality of life that venowave may therefore be applied in addition to compression therapy or as stand-alone. ${ }^{(31)}$

As another alternative option in PTS treatment, lymphatic drainage could be also considered. This intervention has been investigated in the management of venous insufficiency and is aimed at stimulating venous blood flow and the lymphatic vessels, to remove excessive interstitial fluid. As a consequence edema and its related symptoms are reduced. Lymphatic drainage and ECS might have comparable effects. ${ }^{(32)}$

Pharmacotherapeutic interventions are underestimated and understudied alternatives forms of preventive therapy for PTS. Six possible candidate drugs may be considered. Some are known as veno-active drugs (VADs): rutosides and micronized purified flavonoid fraction (MPFF). Other drugs are currently used for other indication but may be used for PTS prevention. These drugs comprises: sulodexide, low molecular weight heparins (LMWH), anti-inflammatory drugs and statins. Table 1 summarizes the pharmacotherapeutic options and their effects. Rutosides are drugs derived from horse chestnut that is traditionally prescribed in treatment of edema in patients with chronic venous disease (CVD). Based on its edema-reducing characteristics, it is assumed that rutosides may be of benefit in treatment of PTS. Rutosides causes vasoconstriction through 
stimulation of alpha-a1 receptor and are found to reduce the calf circumference in patients with PTS. ${ }^{(33)}$ In patients with CVD, rutoside appeared to lower the number of ulcerations in addition to reduction of edema. ${ }^{(34)}$ MPFF, act as edema reductive agents by inhibiting hypoxia induced endothelial activation as consequence of impaired microcirculation. MPFF improve the lymphatic drainage and shortens ulceration healing time. ${ }^{(35)}$

Sulodexide is a vasculoprotective drug and comprises glycosaminoglycans including LMWH and dermatan sulfate. Its effectiveness is based on its ability to protect the vascular glycocalix and hence the endothelium, as the glycocalix plays a role in the permeability of the endothelium. Sulodexide, in addition to compression, was observed to reduce the PTS incidence in patients with DVT.36 Moreover, sulodexide after anticoagulant treatment showed association with reduced rate of VTE recurrence. ${ }^{36} \mathrm{LMWH}$, in addition to their antithrombotic effect, is another group of endothelium-protective drugs that are shown to attenuate the symptoms of PTS. ${ }^{37}$ Of anti-inflammatory drugs and statins it is assumed that they might play a role in PTS prevention; however, thus far little is known on what their actual effect might be. Anti-inflammatory drugs have not been studied in relation to PTS. Statins have been investigated in the context of venous thrombosis and were shown to have anti-inflammatory effects; the expression of the biomarkers IL6, IL8, CRP, as well as tissue factor, plasminogen activator inhibitor-1 and monocyte chemotactic protein1 (MCP-1) was reduced by the use of statins. Elevated levels of the latter is linked to vein wall fibrosis which in turn is associated with PTS. ${ }^{38}$ All drugs mentioned might prove useful as adjunctive therapeutic options in the management of PTS. However, welldesigned studies, preferably with a multifactorial design, are required to elucidate their exact role. 


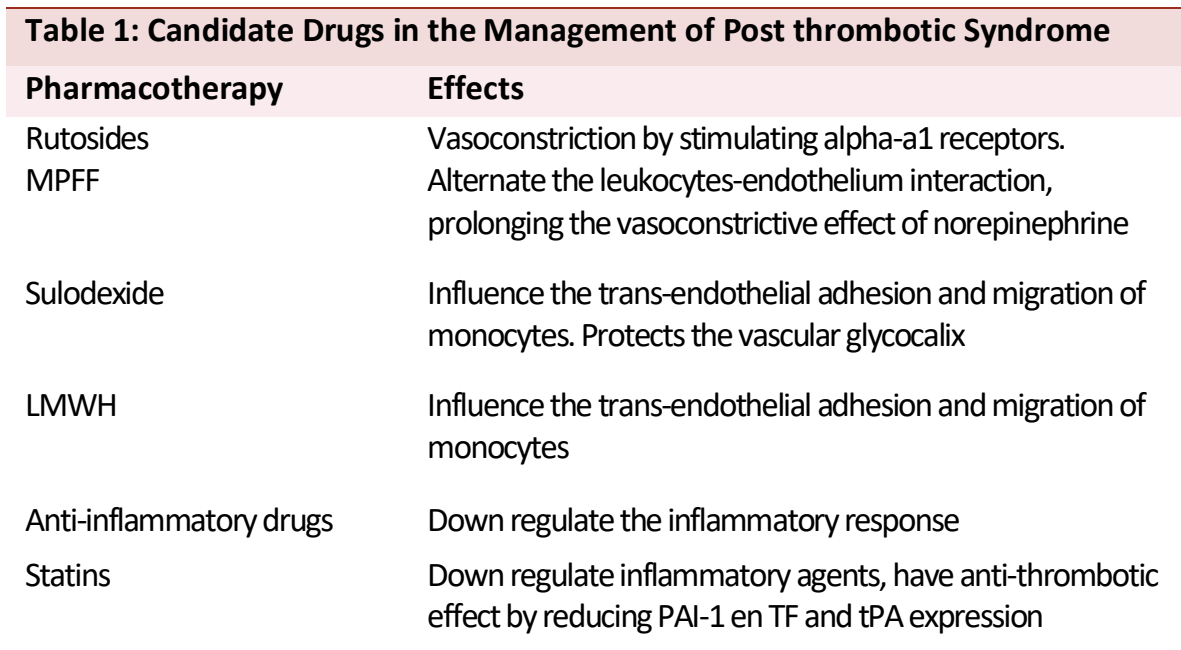

MPFF; Micronized Purified Flavonoid Fraction, LMWH; Low Molecular Weight Heparin, PAI-1; Plasminogen Activator Inhibitor-1 TF; Tissue Factor, tPA; Tissue Plasmingen Activator.

\section{Cost aspects and implications for Quality of life}

Severe PTS is associated with substantial disability, work absenteeism, reduced quality of life and increased health care costs. ${ }^{39-42}$ There is a dose-dependent association between PTS severity and quality of life, where quality of life worsens with increasing severity of PTS. ${ }^{39}$ Therefore it is of the utmost importance to assess the influence of the different forms of therapy that are suggested for the prevention and treatment of PTS on patient-reported outcomes (symptoms, signs, functioning and ultimately quality of life). This includes not only the influence on (prevention of) PTS but also the potential harms in terms of side effects. The latter includes the tolerability of pharmacological treatment and the impact of elastic compression therapy on autonomy in persons who are unable to put on the stockings themselves. A 15-year retrospective cohort study conducted in Sweden estimated the costs of a primary DVT to be $\$ 6000$ and the average costs of treating its complications \$4659; this suggests that medical care-related expenditure in a patient with DVT who develops complications, 
including PTS, is approximately $\$ 10,000$ over a period of 15 years. ${ }^{40} \mathrm{~A}$ cost analysis of treatment of PTS in Brazil showed more or less similar results: the average annual costs per patients ranged from \$426 in those with mild PTS to $\$ 1188$ in those with severe PTS. ${ }^{42}$ A literature-based Markov model was developed for estimation of direct medical costs related to long-term complications of primary DVT in USA. The model indicated that PTS-associated discounted costs are about $\$ 7000$ per patient. ${ }^{41}$ Investing in new therapeutic options for the prevention of PTS is therefore a very attractive scenario. The population at risk is large (20-50\% of all patients with DVT) and the potential benefits both for the increase in quality of life and for the decrease in costs are substantial.

\section{Conclusion}

In this review, we have elaborated on the controversies of ECS in the treatment and the prevention of PTS. We have mentioned the yet unclear aspects such as the timing and duration of compression therapy and the possible mode of action in relation to PTS pathophysiology. In addition we have touched upon the risk markers, discussed the possible alternative treatments and reflected on quality of life and cost aspects. All these aspects can be seen as pieces of the puzzle for the management of PTS (Figure 2). These puzzle pieces stand on their own and some may not even have substantial influence when regarded solely, together however, they might work synergistically. We argue that piecing this puzzle is the future direction, in which the management of PTS is multifactorial, yet individualized (Figure 3). To this end, it is essential that for each and every patient the individual risk for PTS occurrence is established. Because diagnostic methods and (preventive) therapies differ from one another in regard to costs and burden placed on patients, it is of importance to take these aspects into account as well. 


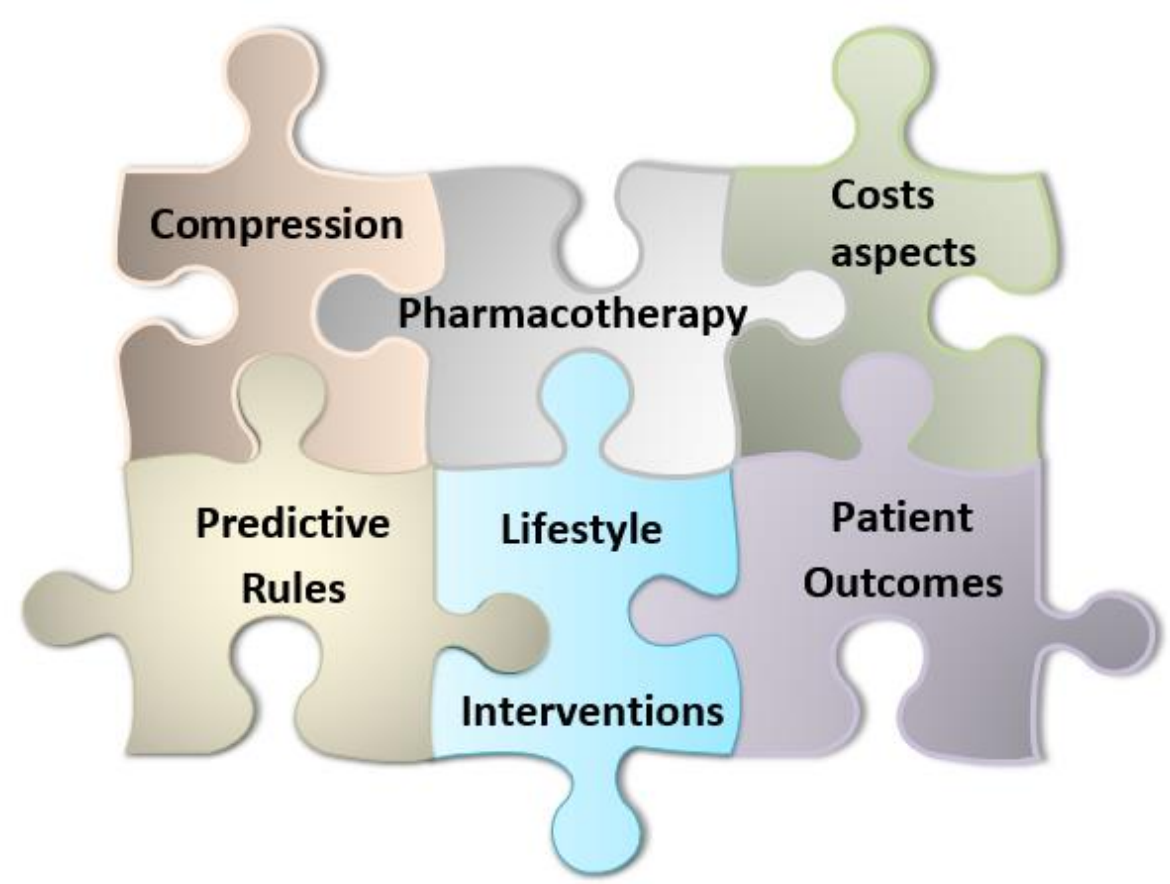

Figure 3. Multifaceted approach weighing individual risks (predictive rules), combining therapeutic options (compression, pharmacotherapy(including anticoagulation) and lifestyle interventions), considering cost aspects, and patient related outcomes (QOL). 


\section{References}

1. Prandoni $\mathrm{P}$, Lensing AW, Cogo A, Cuppini S, Villalta S, Carta $M$, et al. The long-term clinical course of acute deep venous thrombosis. Ann Intern Med. 1996;125(1):1-7.

2. Brandjes DP, Buller HR, Heijboer $H$, Huisman MV, de Rijk $M$, Jagt $H$, et al. Randomised trial of effect of compression stockings in patients with symptomatic proximal-vein thrombosis. Lancet. 1997;349(9054):759-62.

3. Kearon C, Kahn SR, Agnelli G, Goldhaber S, Raskob GE, Comerota AJ. Antithrombotic therapy for venous thromboembolic disease: American College of Chest Physicians Evidence-Based Clinical Practice Guidelines (8th Edition). Chest. 2008;133(6 Suppl):454S-545S.

4. Kahn SR, Shapiro S, Wells PS, Rodger MA, Kovacs MJ, Anderson DR, et al. Compression stockings to prevent post-thrombotic syndrome: a randomised placebo-controlled trial. Lancet. 2014;383(9920):880-8.

5. Perrin M, Eklof B. Does prescription of medical compression prevent development of post-thrombotic syndrome after proximal deep venous thrombosis? Phlebology. 2015.

6. Phillips LJ, 2nd, Sarkar R. Molecular characterization of post-thrombotic syndrome. J Vasc Surg. 2007;45 Suppl A:A116-22.

7. Stewart GJ. Neutrophils and deep venous thrombosis. Haemostasis. 1993;23 Suppl 1:127-40.

8. Varma MR, Varga AJ, Knipp BS, Sukheepod P, Upchurch GR, Kunkel SL, et al. Neutropenia impairs venous thrombosis resolution in the rat. J Vasc Surg. 2003;38(5):1090-8.

9. Arpaia G, Cimminiello C, Mastrogiacomo O, de Gaudenzi E. Efficacy of elastic compression stockings used early or after resolution of the edema on recanalization after deep venous thrombosis: the COM.PRE Trial. Blood Coagul Fibrinolysis. 2007;18(2):131-7.

10. Ten Cate-Hoek AJ, Henke PK, Wakefield TW. The post thrombotic syndrome: Ignore it and it will come back to bite you. Blood Rev. 2015.

11. Ginsberg JS, Hirsh J, Julian J, Vander LaandeVries M, Magier D, MacKinnon B, et al. Prevention and treatment of postphlebitic syndrome: results of a 3-part study. Arch Intern Med. 2001;161(17):2105-9.

12. ten Cate-Hoek AJ. [Post thrombotic syndrome: are elastic stockings on their last legs? The role of compression in prevention and treatment]. Ned Tijdschr Geneeskd. 2015;159:A8726.

13. Cooley BC, Chen CY, Hess R, Schmeling G. Incomplete resolution of deep vein thrombosis under reduced flow conditions. Thromb Res. 2013;131(1):55-8.

14. Bouman A, Cate-Hoek AT. Timing and duration of compression therapy after deep vein thrombosis. Phlebology. 2014;29(1 suppl):78-82.

15. Ten Cate-Hoek AJ, Bouman AC, Joore MA, Prins M, Ten Cate H. The IDEAL DVT study, individualised duration elastic compression therapy against long-term duration of therapy for the prevention of post-thrombotic syndrome: protocol of a randomised controlled trial. BMJ Open. 2014;4(9):e005265.

16. Tick LW, Kramer MH, Rosendaal FR, Faber WR, Doggen CJ. Risk factors for postthrombotic syndrome in patients with a first deep venous thrombosis. J Thromb Haemost. 2008;6(12):2075-81.

17. Kahn SR, Shrier I, Julian JA, Ducruet T, Arsenault L, Miron MJ, et al. Determinants and time course of the postthrombotic syndrome after acute deep venous thrombosis. Ann Intern Med. 2008;149(10):698-707. 
18. Ten Cate-Hoek AJ, Ten Cate H, Tordoir J, Hamulyak K, Prins MH. Individually tailored duration of elastic compression therapy in relation to incidence of the postthrombotic syndrome. J Vasc Surg. 2010;52(1):132-8.

19. Ageno W, Piantanida E, Dentali F, Steidl L, Mera V, Squizzato A, et al. Body mass index is associated with the development of the post-thrombotic syndrome. Thromb Haemost. 2003;89(2):305-9.

20. Blokhin IO, Lentz SR. Mechanisms of thrombosis in obesity. Curr Opin Hematol. 2013;20(5):437-44.

21. Rattazzi M, Callegari E, Sponchiado A, Galliazzo S, Pagliara V, Villalta S, et al. Visceral obesity, but not metabolic syndrome, is associated with the presence of postthrombotic syndrome. Thromb Res. 2015;136(2):225-8.

22. Stain M, Schonauer V, Minar E, Bialonczyk C, Hirschl M, Weltermann A, et al. The postthrombotic syndrome: risk factors and impact on the course of thrombotic disease. $J$ Thromb Haemost. 2005;3(12):2671-6.

23. Rodger MA, Kahn SR, Wells PS, Anderson DA, Chagnon I, Le Gal G, et al. Identifying unprovoked thromboembolism patients at low risk for recurrence who can discontinue anticoagulant therapy. CMAJ. 2008;179(5):417-26.

24. Latella J, Desmarais S, Miron MJ, Roussin A, Joyal F, Kassis J, et al. Relation between Ddimer level, venous valvular reflux and the development of post-thrombotic syndrome after deep vein thrombosis. J Thromb Haemost. 2010;8(10):2169-75.

25. Bouman AC, Smits JJ, Ten Cate H, Ten Cate-Hoek AJ. Markers of coagulation, fibrinolysis and inflammation in relation to post-thrombotic syndrome. J Thromb Haemost. 2012;10(8):1532-8.

26. Rabinovich A, Cohen JM, Kahn SR. Predictive value of markers of inflammation in the postthrombotic syndrome: a systematic review: inflammatory biomarkers and PTS. Thromb Res. 2015;136(2):289-97.

27. Isma N, Johanssson E, Bjork A, Bjorgell O, Robertson F, Mattiasson I, et al. Does supervised exercise after deep venous thrombosis improve recanalization of occluded vein segments? A randomized study. J Thromb Thrombolysis. 2007;23(1):25-30.

28. Shrier I, Kahn SR, Steele RJ. Effect of early physical activity on long-term outcome after venous thrombosis. Clin J Sport Med. 2009;19(6):487-93.

29. Padberg FT, Jr., Johnston MV, Sisto SA. Structured exercise improves calf muscle pump function in chronic venous insufficiency: a randomized trial. J Vasc Surg. 2004;39(1):7987.

30. Kahn SR, Azoulay L, Hirsch A, Haber M, Strulovitch C, Shrier I. Effect of graduated elastic compression stockings on leg symptoms and signs during exercise in patients with deep venous thrombosis: a randomized cross-over trial. J Thromb Haemost. 2003;1(3):494-9.

31. O'Donnell MJ, McRae S, Kahn SR, Julian JA, Kearon C, Mackinnon B, et al. Evaluation of a venous-return assist device to treat severe post-thrombotic syndrome (VENOPTS). A randomized controlled trial. Thromb Haemost. 2008;99(3):623-9.

32. Holmes CE, Bambace NM, Lewis P, Callas PW, Cushman M. Efficacy of a short course of complex lymphedema therapy or graduated compression stocking therapy in the treatment of post-thrombotic syndrome. Vasc Med. 2014;19(1):42-8.

33. de Jongste $A B$, Jonker JJ, Huisman MV, ten Cate JW, Azar AJ. A double blind three center clinical trial on the short-term efficacy of 0 -(beta-hydroxyethyl)-rutosides in patients with post-thrombotic syndrome. Thromb Haemost. 1989;62(3):826-9.

34. Ippolito E, Belcaro G, Dugall M, Cesarone MR, Feragalli B, Errichi BM, et al. Venoruton(R): post thrombotic syndrome. Clinical improvement in venous insufficiency (signs and 
symptoms) with Venoruton(R). A five-year, open-registry, efficacy study. Panminerva Med. 2011;53(3 Suppl 1):13-9.

35. Katsenis K. Micronized purified flavonoid fraction (MPFF): a review of its pharmacological effects, therapeutic efficacy and benefits in the management of chronic venous insufficiency. Curr Vasc Pharmacol. 2005;3(1):1-9.

36. Luzzi R, Belcaro G, Dugall M, Hu S, Arpaia G, Ledda A, et al. The efficacy of sulodexide in the prevention of postthrombotic syndrome. Clin Appl Thromb Hemost. 2014;20(6):5949.

37. Hull RD, Pineo GF, Brant R, Liang J, Cook R, Solymoss S, et al. Home therapy of venous thrombosis with long-term LMWH versus usual care: patient satisfaction and postthrombotic syndrome. Am J Med. 2009;122(8):762-9 e3.

38. Rodriguez AL, Wojcik BM, Wrobleski SK, Myers DD, Jr., Wakefield TW, Diaz JA. Statins, inflammation and deep vein thrombosis: a systematic review. J Thromb Thrombolysis. 2012;33(4):371-82.

39. Kahn SR, Ducruet T, Lamping DL, Arsenault L, Miron MJ, Roussin A, et al. Prospective evaluation of health-related quality of life in patients with deep venous thrombosis. Arch Intern Med. 2005;165(10):1173-8.

40. Bergqvist $D$, Jendteg $S$, Johansen L, Persson U, Odegaard K. Cost of long-term complications of deep venous thrombosis of the lower extremities: an analysis of a defined patient population in Sweden. Ann Intern Med. 1997;126(6):454-7.

41. Caprini JA, Botteman MF, Stephens JM, Nadipelli V, Ewing MM, Brandt S, et al. Economic burden of long-term complications of deep vein thrombosis after total hip replacement surgery in the United States. Value Health. 2003;6(1):59-74.

42. Ramacciotti E, Gomes M, de Aguiar ET, Caiafa JS, de Moura LK, Araujo GR, et al. A cost analysis of the treatment of patients with post-thrombotic syndrome in Brazil. Thromb Res. 2006;118(6):699-704. 


\section{CHAPTER 3}

\section{Development and Validation of a Practical Two- step Prediction Model and Clinical Risk Score for Post-Thrombotic Syndrome}

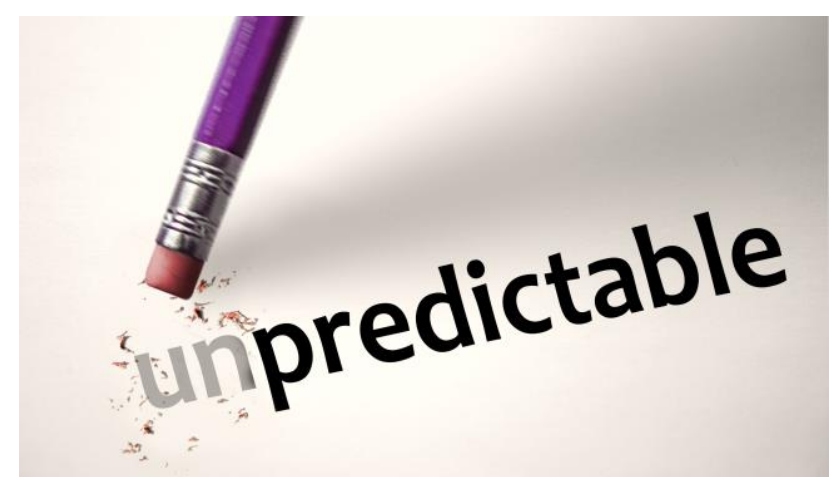

Amin EE, van Kuijk SMJ, Joore MA, Prandoni $\mathrm{P}$, ten Cate $\mathrm{H}$, ten Cate-Hoek AJ.

Thrombosis \& Haemostasis. 2018 Jul; 118(7): 1242-1249 


\section{Summary}

Background Post-thrombotic syndrome (PTS) is a common chronic consequence of deep vein thrombosis that affects the quality of life and is associated with substantial costs. In clinical practice, it is not possible to predict the individual patient risk. We develop and validate a practical two-step prediction tool for PTS in the acute and subacute phase of deep vein thrombosis.

Methods Multivariable regression modelling with data from two prospective cohorts in which 479 (derivation) and 1107 (validation) consecutive patients with objectively confirmed deep vein thrombosis of the leg, from thrombosis outpatient clinic of Maastricht University Medical Centre, the Netherlands (derivation), and Padua University hospital in Italy (validation) were included. PTS was defined as a Villalta score of $\geq 5$ at least six months after acute thrombosis.

Results Variables in the baseline model in the acute phase were: age, body mass index, sex, varicose veins, history of venous thrombosis, smoking status, provoked thrombosis and thrombus location. For the secondary model the additional variable was residual vein obstruction. For optimism-corrected AUCs were 0.71 for the baseline model and 0.60 for the secondary model. Calibration plots showed well calibrated predictions. External validation of the derived clinical risk scores was successful; AUC 0.66 (95\% Cl 0.63 to 0.70$)$ and 0.64 (95\% $\mathrm{Cl} 0.60$ to 0.69$)$.

Conclusion Individual risk for PTS in the acute phase of deep vein thrombosis can be predicted based on readily accessible baseline clinical and demographic characteristics. The individual risk in the subacute phase can be predicted with limited additional clinical characteristics. 


\section{Introduction}

Post-thrombotic syndrome (PTS) is a chronic condition that develops in $25 \%$ to $50 \%$ of the patients after deep vein thrombosis (DVT) of the leg $(1,2)$. It is a compilation of signs and symptoms varying from pain and oedema to venous ulcerations. The presence of (severe) PTS is associated with 3-fold higher medical and total costs compared to DVT in the absence of PTS ${ }^{(3,4)}$. Moreover, quality of life declines as PTS becomes worse ${ }^{(1,2)}$. Although the exact pathophysiology of the condition is not fully understood, a number of modifiable and nonmodifiable risk factors have previously been identified as established or potential predictors: (Ipsilateral) DVT recurrence ${ }^{(2,5)}$, poor regulation of INR ${ }^{6}$, 7), proximal DVT ${ }^{(3,8,9)}$, higher body mass index ${ }^{(8,10)}$, presence of varicose veins ${ }^{(9,}$ ${ }^{11)}$, presence of residual thrombosis ${ }^{(3,12)}$, older age ${ }^{(5,9)}$, gender ${ }^{(8)}$, elevated levels of biomarkers CRP, D-dimer, FVIII, IL6, IL8 and ICAM-1 ${ }^{(13-15)}$, and type and quality of anticoagulant prescribed ${ }^{6,7,16)}$. Thus far however, it is not possible in clinical practice to combine these factors and predict the risk of PTS despite the need to identify patients at high risk.

One of the most important hurdles for development of a prediction model for PTS is the absence of a gold standard for the diagnosis. The diagnosis is based on one of the several clinical scores that have been developed over the years $(1,17$ 19). In 2008, the International Society for Thrombosis and Hemostasis (ISTH) subcommittee for standardisation recommended the Villalta score as the preferred clinical score ${ }^{(18)}$.

In the absence of effective therapies for PTS preventive measures remain warranted. To this end, elastic compression stockings are widely applied and although the effectiveness has been disputed, a recent meta-analysis showed a $30 \%$ reduction in occurrence of PTS achieved by compression stockings ${ }^{(20)}$. In addition, other measures such as physical activity, lymphatic drainage, the use of venous-return assist devices and veno-active drugs that were found to enhance the efficacy of compression therapy in patients with PTS, might if 
initiated at an earlier point in time in selected patients, potentially prevent PTS (12, 21-24). Moreover, in patients with highest risk of PTS catheter directed thrombolysis might be considered. $(25,26)$ If the individual risk of patients is known treatment can be personalized and hence expected to be more efficient. We therefore developed and externally validated a two-step prediction model for PTS and derived simplified clinical risk scores that could serve as a tool for identification of patients at increased risk of PTS, as well as for better targeting of therapy. Additionally, we externally validated the clinical risk scores.

\section{Methods}

\section{Derivation cohort}

For the development of the two-step prediction model data from a prospective DVT cohort were used. Data were collected from June 2003 until June 2013. This cohort was part of medical care evaluation in a clinical care pathway within the Maastricht University Medical Center+ (MUMC+) in the Netherlands (registration number medical ethical approval (METC) 15-4-256) and was comprised of adult patients who were followed up for two years after DVT had been objectively confirmed. There were no exclusion criteria. A medical doctor assessed the signs and symptoms of PTS using the Villalta score at the 3, 6, 12, and 24 months post DVT. Baseline measurements (first office visit within 2 to 3 weeks following acute presentation and treatment for thrombosis) included: height, weight, medical history, current health status, presence of venous insufficiency, hypertension, smoking status, family history for thrombosis, and appraisal of the triggering factors for deep vein thrombosis such as immobilisation, surgery, oral contraceptive use or presence of malignancy. Follow-up measurements included: assessment of residual vein obstruction when discontinuation of anticoagulation was considered, and plasma levels of D-dimer, levels of factor VIII and C reactive protein (CRP) . All patients received 
anticoagulation treatment for a minimum of 3 months and compression therapy for at least 6 months.

\section{Sample size}

The occurrence of post thrombotic syndrome is between $20 \%$ and $50 \%$. A conservative percentage of $35 \%$, was chosen for the sample size calculation. We followed the suggested sample size calculation for logistic regression ${ }^{(27)}$. Where $p$ is the smallest of the proportions of negative or positive cases in the population and $\mathrm{k}$ the number of covariates (the number of independent variables), then the minimum number of cases to include is: $N=10 \mathrm{k} / \mathrm{p}$. We had 12 covariates to include in the model and the proportion of positive cases in the population is approximately 0.35 (35\%). The minimum number of cases required is therefore $\mathrm{N}=10 \times 12 / 0.35=343$. This would implicate that a cohort of 343 patients is required for our 12 candidate predictors.

\section{Outcome measure}

The outcome was PTS defined as a single Villalta score of $\geq 5$ as of six months after diagnosis of DVT. The Villalta score is comprised of several items of leg complaints and/or objectively confirmable signs. The items include pain, cramps, heaviness, itching, tingling, oedema, redness, skin indurations, hyperpigmentation, venectasia, pain on calf compression, and in the most severe cases venous ulcerations. Depending on the severity, each item is scored on a 4-point scale. The presence or history of a venous ulcer is scored as 33 points. ${ }^{(28)}$

\section{Candidate predictors}

As candidate predictors, we included predictors that are reported in the literature except for interleukin-6 and-8, intercellular adhesion molecule 1 and type of anticoagulant because data on these predictors were not available from the derivation cohort. We also included type of DVT (provoked) as a candidate predictor. 


\section{Model development}

We developed a two-step model consisting of a model to be applied at baseline in order to predict the probability of developing PTS at 6 months, and a model to be applied at 6 months to predict the probability of PTS 24 months after initial thrombosis for those patients who did not develop PTS till then. The first model included only baseline demographics and clinical characteristics. The second model was similar to the baseline model with the addition of the following potential predictor variables: levels of plasma biomarkers D-dimer, FVIII and CRP, INR regulation during the first three months following acute DVT, and presence of residual vein obstruction. Incomplete data were completed based on medical records if possible.

Multiple imputation was used to impute the incomplete records, since using only complete records may cause a considerable loss of precision and is more likely to bias results ${ }^{(29)}$. Sensitivity analysis was performed to exclude significant differences between results of the imputed and the original data. Variable selection in the final models was performed using backward stepwise elimination in multivariable logistic regression analysis. A p-value of 0.3 was chosen for excluding variables from the model so that potentially important predictors were not erroneously deleted ${ }^{(30)}$.

First, all analyses were performed with continuous variables as such. In order to develop simple and practical models, continuous variables were subsequently dichotomized based on cut-off values derived from literature or, if no information was available, based on the data. Models with and without the addition of biomarkers were assessed. The discriminative ability of the models was expressed as the magnitude of the area under the receiver operating characteristic curve (AUC). The ability of the models (baseline model and secondary model) to generate predicted probabilities comparable to observed outcome frequencies was determined by visually assessing calibration curves. The analyses were performed using SPSS version 23. $R$ version 3.1.3 was used to perform the internal validation of the models and to obtain calibration plots. The 
predictive performance of the models was explored. Based on the regression coefficients of the models a practical clinical score was estimated. These clinical scores for the baseline and secondary models were externally validated.

\section{Internal validation}

To internally validate the two-step model we used bootstrapping techniques ${ }^{(30)}$. We drew 1000 bootstrap samples from the original data set and re-estimated the model on each sample. The average differences in performance measures of those models on the bootstrap sample and the original data are estimators of optimism in the model performance. We subtracted the measures of optimism from the initial performance measures (i.e. AUC) to obtain optimism-corrected measures of performance. In addition, we computed a shrinkage factor. The regression coefficients were subsequently multiplied by this shrinkage factor. These shrunk coefficients combined with a re-estimated intercept render future predictions less extreme, and counteract the effect of overfitting a prediction model. The individual probability estimation for patients can be performed using the following equation: Probability = $1 /(1+\exp (-$ LP), in which LP is the linear combination of the intercept and all coefficients multiplied by their respective patient values.

\section{External validation}

The validation cohort consisted of 1107 adult patients from Padua University hospital outpatient clinic in Italy who were diagnosed with proximal DVT of the leg. Exclusion criteria were: ipsilateral deep vein thrombosis less than two years ago, thrombectomy, arterial thrombotic events, active cancers, deficiencies in natural anticoagulants or medical conditions leading to prolonged immobilization. All patients received anticoagulation. The duration of anticoagulation depended on international guidelines, patients' preferences and risk profile. All patients received compression therapy for at least 6 months. PTS was assessed at 3, 6, 12, 18 and 24 months after DVT diagnosis. Three months 
after DVT compression ultrasonography was performed to determine the presence of residual thrombosis. All variables of the original model except for smoking status were present in the validation cohort. There were no missing values for the available variables. Model performance was quantified as the AUC. Because we validated clinical risk scores derived from the prediction models, calibration would not have additional value as the resulting scores do not reflect probabilities. External validation was performed with SPSS version 23.

\section{Reporting}

This study adhered to the Transparent Reporting of a multivariable prediction model for Individual Prognosis Or Diagnosis (TRIPOD) statement for reporting. (31)

\section{Results}

The derivation cohort consisted of 479 patients of whom 28 were eventually excluded from the analysis due to large amount of missing information on follow up visits. All 1107 patients in the validation cohort were included in the analyses. Table 1 shows the baseline demographic and clinical characteristics of both study populations.

In the derivation cohort, at 6 months after deep vein thrombosis $22.8 \%$ developed PTS. Of the remaining patients who did not develop PTS until 6 months post DVT, $29.6 \%$ developed PTS in the 18 months following the initial period of 6 months. At the end of the 24 months follow up $45.7 \%$ of the entire cohort was diagnosed with PTS. 
Table 1: Baseline and clinical characteristics of the study populations

\section{Derivation cohort Validation cohort \\ $\mathrm{N}=451 \quad \mathrm{~N}=1107$}

\begin{tabular}{lrr} 
Characteristic & \\
\hline Age>56, $\mathrm{n}(\%)$ & $239(53.0)$ & $726(65.6)$ \\
Male sex, n (\%) & $228(50.6)$ & $545(49.2)$ \\
Smoker, $\mathrm{n}(\%)$ & $103(22.8)$ & Unknown \\
Varicose veins, n (\%) & $67(14.9)$ & $355(32.1)$ \\
Body mass index>30, n (\%) & $132(29.3)$ & $127(11.5)$ \\
Previous deep vein thrombosis, n (\%) & $91(20.2)$ & $164(14.8)$ \\
Provoked thrombosis, $\mathrm{n}(\%)$ & $242(53.7)$ & $526(47.5)$ \\
Iliofemoral thrombosis, $\mathrm{n}(\%)$ & $220(48.8)$ & $585(52.8)$ \\
\hline
\end{tabular}

\section{Model development}

Table 2 illustrates the final reduced prediction models with the dichotomized predictors based on backward elimination, before and after internal validation. The bootstrapping procedure yielded shrinkage factors between 0.81 and 0.86 . 
Table 2: Prediction model for post thrombotic syndrome

\begin{tabular}{|c|c|c|c|}
\hline \multirow[b]{2}{*}{ Variable } & \multicolumn{2}{|c|}{ Initial model } & \multirow{2}{*}{$\begin{array}{r}\text { Internally validated } \\
\text { model } \\
\text { Regression } \\
\text { coefficient }^{\mathrm{a}}\end{array}$} \\
\hline & $\begin{array}{l}\text { Regression } \\
\text { coefficient }\end{array}$ & OR $(95 \% \mathrm{Cl})$ & \\
\hline \multicolumn{4}{|l|}{ Baseline model } \\
\hline Intercept & -2.593 & - & -2.428 \\
\hline Age $>56$ & 0.779 & $2.18(1.30-3.66)$ & 0.694 \\
\hline Body mass index $>30$ & 0.801 & $2.22(1.36-3.66)$ & 0.713 \\
\hline Varicose veins & 1.505 & $4.50(2.51-8.08)$ & 1.339 \\
\hline Smoking & 0.551 & $1.74(1.01-3.03)$ & 0.490 \\
\hline History of DVT & 0.573 & $1.77(1.01-3.11)$ & 0.510 \\
\hline Male sex & -0.429 & $0.65(0.39-1.08)$ & -0.382 \\
\hline Iliofemoral thrombosis & 0.556 & $1.74(0.99-3.06)$ & 0.495 \\
\hline Provoked DVT & 0.345 & $1.41(0.84-2.37)$ & 0.307 \\
\hline \multicolumn{4}{|l|}{ Secondary model } \\
\hline Intercept & -1.521 & - & -1.393 \\
\hline Age $>56$ & 0.369 & $1.45(0.89-2.35)$ & 0.299 \\
\hline Body mass index $>30$ & 0.391 & $1.48(0.87-2.53)$ & 0.317 \\
\hline Varicose veins & 1.032 & $2.81(1.36-5.80)$ & 0.836 \\
\hline Smoking & 0.477 & $1.61(0.91-2.84)$ & 0.387 \\
\hline $\begin{array}{l}\text { Residual vein } \\
\text { obstruction }\end{array}$ & 0.342 & $1.41(0.86-2.31)$ & 0.277 \\
\hline History of DVT & & & - \\
\hline Male sex & - & - & - \\
\hline Iliofemoral thrombosis & - & - & - \\
\hline Provoked DVT & - & - & - \\
\hline
\end{tabular}

The discriminative ability of the models is represented as the area under the curve (AUC). The AUCs for the baseline model followed by the secondary model were 0.71 and 0.60 after internal validation. Sensitivity analysis showed no difference in model performance between using only complete cases and the imputed data. The differences between the baseline models based on continuous and dichotomized variables were negligible. For the secondary model the differences were also small, the highest values of $A U C(0.67,95 \% \mathrm{Cl}$ 0.61-0.73) was reached for the model with continuous variables and containing 
all biomarkers. The calibration plots are presented in Figure 1. Visual inspection shows that the calibration plots closely follow the 45-degree line thereby indicating good calibration. Table 3 shows model characteristics for several cutoff values of predictive probabilities for PTS. Efficiency of the models can be read from the table by dividing the denominator found in the column $\mathrm{N}$ under negative predictive value, by $\mathrm{N}$ for the corresponding model. For example, at a threshold of 15\%, 146 out of 451 (32.4\%) are allocated to a low risk for PTS and might be excluded from extra interventions, at the cost of $9.9 \%$ missed PTS.

A

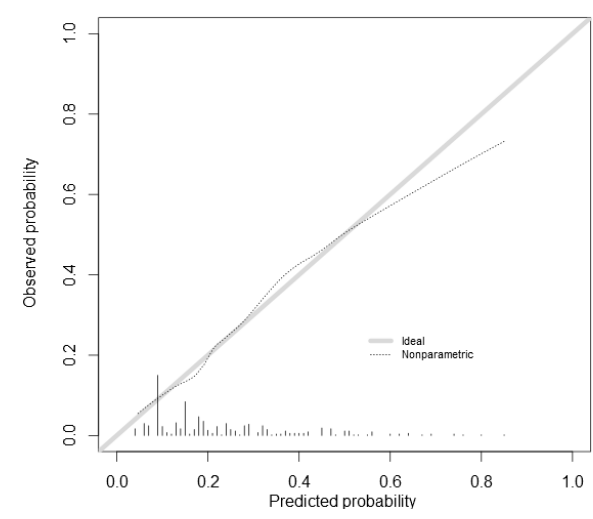

B

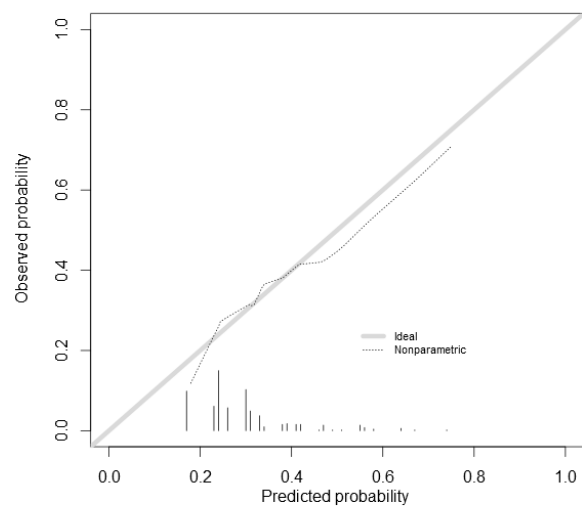

Figure 1: Shown are the calibration plots of the baseline model $(A)$ and the secondary model (B) for post thrombotic syndrome 


\section{Table 3: Model characteristics}

\begin{tabular}{|c|c|c|c|c|c|c|c|c|}
\hline \multirow[b]{2}{*}{ Threshold } & \multicolumn{2}{|c|}{ Sensitivity } & \multicolumn{2}{|c|}{ Specificity } & \multicolumn{3}{|c|}{ PPV } & NPV \\
\hline & $\mathrm{N}$ & $\%$ & $\mathrm{~N}$ & $\%$ & $\mathrm{~N}$ & $\%$ & $\mathrm{~N}$ & $\%$ \\
\hline \multicolumn{9}{|c|}{ Baseline model } \\
\hline 2.5 & $103 / 103$ & 100 & - & - & $103 / 451$ & 22.8 & - & 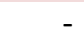 \\
\hline 5 & $103 / 103$ & 100 & $9 / 348$ & 2.6 & $103 / 442$ & 23.3 & $9 / 9$ & 100 \\
\hline 7.5 & $103 / 103$ & 100 & $25 / 348$ & 7.2 & $103 / 426$ & 24.2 & $25 / 25$ & 100 \\
\hline 10 & $91 / 103$ & 88.3 & $106 / 348$ & 30.5 & $91 / 333$ & 27.3 & $106 / 118$ & 89.8 \\
\hline 12.5 & $90 / 103$ & 87.4 & $121 / 348$ & 34.8 & $90 / 317$ & 28.4 & $121 / 134$ & 90.3 \\
\hline 15 & $87 / 103$ & 84.5 & $146 / 348$ & 42.0 & $87 / 289$ & 30.1 & $146 / 162$ & 90.1 \\
\hline 17.5 & $78 / 103$ & 75.7 & $191 / 348$ & 54.9 & $78 / 235$ & 33.2 & $191 / 216$ & 88.4 \\
\hline 20 & 73/103 & 70.9 & $231 / 348$ & 66.4 & $73 / 190$ & 38.4 & $231 / 261$ & 88.5 \\
\hline 22.5 & $70 / 103$ & 68.0 & $249 / 348$ & 71.6 & $70 / 169$ & 41.4 & $249 / 282$ & 88.3 \\
\hline 25 & $63 / 103$ & 61.2 & $260 / 348$ & 74.7 & $63 / 151$ & 41.7 & $260 / 300$ & 86.7 \\
\hline \multicolumn{9}{|c|}{ Seconary model } \\
\hline 2.5 & $103 / 103$ & 100 & - & - & $103 / 348$ & 29.6 & - & 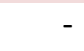 \\
\hline 5 & $103 / 103$ & 100 & - & - & $103 / 348$ & 29.6 & - & - \\
\hline 7.5 & $103 / 103$ & 100 & - & - & $103 / 348$ & 29.6 & - & - \\
\hline 10 & $103 / 103$ & 100 & - & - & $103 / 348$ & 29.6 & - & - \\
\hline 12.5 & $103 / 103$ & 100 & - & - & $103 / 348$ & 29.6 & - & - \\
\hline 15 & $103 / 103$ & 100 & - & - & $103 / 348$ & 29.6 & - & - \\
\hline 17.5 & $103 / 103$ & 100 & - & - & $103 / 348$ & 29.6 & - & - \\
\hline 20 & $97 / 103$ & 94.2 & $44 / 245$ & 18.0 & $97 / 298$ & 32.6 & $44 / 50$ & 88.0 \\
\hline 22.5 & $97 / 103$ & 94.2 & $44 / 245$ & 18.0 & $97 / 298$ & 32.6 & $44 / 50$ & 88.0 \\
\hline 25 & $70 / 103$ & 68.0 & $124 / 245$ & 50.6 & $70 / 191$ & 36.6 & $124 / 157$ & 79.0 \\
\hline
\end{tabular}

$P P V$, positive predictive value; NPV, negative predictive value

Table 4 presents the simplified clinical risk scores for the baseline and secondary model with PTS. A score of $\leq 2$ points is associated with a $10 \%$ risk for the development of PTS, a score of 3 or 4 points indicates a risk of $20 \%$, and a score of $\geq 5$ points is associated with a risk of $40 \%$. The AUC of the models with the clinical risk scores equalled 0.73 ( $95 \% \mathrm{Cl} 0.67$ to 0.78 ) for the baseline model and 0.62 (95\% $\mathrm{Cl} 0.55$ to 0.68 ) for the secondary model. 
Table 4: Clinical risk scores for post thrombotic syndrome

\section{Baseline risk}

assessment
Risk assessment in the subacute phase

a

\section{Variable}

Age $>56$

Body mass index $>30$

2

1

2

Varicose veins

$4 \quad 3$

Smoking

1

$-$

Residual thrombosis

1

1

1

1

Risk of post thrombotic syndrome development:

Baseline model: Score $0-2$ points $10 \%, 3-4$ points $20 \%, \geq 5$ points $40 \%$

Secondary model: Score $0-2$ points $25 \%, 3-4$ points $45 \%, \geq 5$ points $60 \%$

a Subacute phase $=6$ months after diagnosis of deep vein thrombosis

\section{External validation}

The occurrence of PTS at 6 months in the validation cohort was $20.6 \%$ and in the following 18 months another $22.4 \%$ of the remaining patients developed PTS. Validation of the simplified clinical risk scores without one predictor (smoking status) showed an AUC of 0.66 ( $95 \% \mathrm{Cl} 0.63$ to 0.70$)$ for the baseline model and 0.64 (95\% $\mathrm{Cl} 0.60$ to 0.69 ) for the secondary model.

\section{Discussion}

We developed a baseline prediction model (clinical risk score) for PTS that is practical and easy to use. The model has good predictive performance with an AUC of 0.71 and an AUC of 0.73 for the derived risk score. Risk assessment can be performed in the acute phase as soon as the patient is diagnosed with DVT, and is based on only those variables that are readily available at baseline. The secondary model and clinical risk score can subsequently be applied in the 
subacute phase ( 6 months after venous thrombosis) and could be used to identify those patients that may either stop preventive therapy or are in need of continued or adjunctive therapy. The secondary prediction model discriminates moderately between patients at high risk and low risk for PTS with AUCs of 0.60 (AUC clinical risk score 0.62). The addition of biomarkers did not improve the models' discriminative ability and had overall very little influence on the results. This might be due to the fact that the biomarkers available from the derivation cohort were measured in the chronic phase of DVT. It could therefore very well be that biomarkers measured in the acute phase of DVT may have additional predictive value and might thereby improve the models' performance ${ }^{(32)}$.

The efficiency of the models was the greatest for the baseline model at a threshold of $15 \%$ in which $32.4 \%$ of patients are classified as low risk at the cost of $9.9 \%$ missed cases. In previously published studies margins set even as high as $10 \%$ were deemed acceptable ${ }^{(33)}$. It needs however to be determined which threshold is more desirable both from a medical perspective (accurate identification of patients at risk for PTS) and which is more desirable from a societal perspective (most efficient selection of patients that can be excluded from further treatment). It would require decision analytical modelling to compare the savings associated with the treatment of fewer patients, to the health benefits forgone associated with the percentage of patient that was erroneously left untreated.

Validation of the baseline and secondary clinical risk scores in a new large set of patients in which the predictor smoking status was absent, showed to be successful. The baseline risk score corresponded to an AUC of 0.66 and the secondary risk score showed an AUC of 0.64 , which was slightly better than in the derivation cohort. This indicates that the risk scores could also be applied to other patient populations with thrombosis. To our knowledge no externally validated prediction models for PTS exist so far, therefore comparison is not possible. End of November 2017 one study on development of a prediction model for PTS has been published ${ }^{(34)}$. The study used data from a randomized 
controlled trial that compared the effect of elastic compression stockings to placebo stockings for prevention of PTS in patients with proximal deep vein thrombosis. Because the prediction model was developed in a trial with several inclusion and exclusion criteria, and the diagnosis of post thrombotic syndrome was based on the Ginsberg criteria rather than the current consensus supported Villalta score, it is not likely that the model could be readily applied to all patients with DVT. Moreover, this prediction model has not yet been externally validated. Consequently, it is not directly suitable for clinical use.

The most important limitation for the development of the models was the lack of gold standard for PTS. Another limitation is that biomarkers were measured at a later stage after DVT and that no biomarkers were available for the acute phase of DVT. Inflammatory markers in the acute phase might have offered better predictive value for PTS and thereby have increased the discriminative ability of our models. The strength of our models and clinical risk scores is that they are derived from a cohort of patients with DVT in which all consecutive patients were included; this will likely increase the generalizability of the models as was shown in the external validation phase. Another strength is the simplicity of the models/risk scores. The application of the baseline model is anticipated to be easy because the predictors are dichotomized and are commonly available at baseline, so this model can be used at no additional costs since no expensive diagnostic measurements are required. Even for the secondary model costs are expected to be moderate, as only the additional assessment of residual vein obstruction is needed.

Our two-step model has the potential to both improve patient care and at the same time reduce costs. At time of DVT diagnosis, based on readily accessible baseline clinical characteristics, clinicians can predict the individual patients' risk for developing PTS at 6 months after DVT. In the subacute phase the individual risk can be estimated with the additional assessment of residual thrombosis. Therapy can thus be allocated to those who will likely benefit the most, which could also result in a better cost-effectiveness balance. 


\section{References}

1. Brandjes DP, Buller HR, Heijboer $\mathrm{H}$, et al. Randomised trial of effect of compression stockings in patients with symptomatic proximal-vein thrombosis. Lancet. 1997;349(9054):759-62.

2. Prandoni $P$, Lensing AW, Cogo $A$, et al. The long-term clinical course of acute deep venous thrombosis. Ann Intern Med. 1996;125(1):1-7.

3. Kahn SR, Shrier I, Julian JA, et al. Determinants and time course of the postthrombotic syndrome after acute deep venous thrombosis. Ann Intern Med. 2008;149(10):698707.

4. Guanella R, Ducruet T, Johri M, et al. Economic burden and cost determinants of deep vein thrombosis during 2 years following diagnosis: a prospective evaluation. J Thromb Haemost. 2011;9(12):2397-405.

5. Prandoni $\mathrm{P}$, Lensing AW, Prins $\mathrm{MH}$, et al. Below-knee elastic compression stockings to prevent the post-thrombotic syndrome: a randomized, controlled trial. Ann Intern Med. 2004;141(4):249-56.

6. van Dongen $\mathrm{CJ}$, Prandoni P, Frulla M, Marchiori A, Prins MH, Hutten BA. Relation between quality of anticoagulant treatment and the development of the postthrombotic syndrome. J Thromb Haemost. 2005;3(5):939-42.

7. Chitsike RS, Rodger MA, Kovacs MJ, et al. Risk of post-thrombotic syndrome after subtherapeutic warfarin anticoagulation for a first unprovoked deep vein thrombosis: results from the REVERSE study. J Thromb Haemost. 2012;10(10):2039-44.

8. Stain $\mathrm{M}$, Schonauer $\mathrm{V}$, Minar $\mathrm{E}$, et al. The post-thrombotic syndrome: risk factors and impact on the course of thrombotic disease. J Thromb Haemost. 2005;3(12):2671-6.

9. Tick LW, Kramer MH, Rosendaal FR, Faber WR, Doggen CJ. Risk factors for postthrombotic syndrome in patients with a first deep venous thrombosis. J Thromb Haemost. 2008;6(12):2075-81.

10. Ageno W, Piantanida E, Dentali F, et al. Body mass index is associated with the development of the post-thrombotic syndrome. Thromb Haemost. 2003;89(2):305-9.

11. Ten Cate-Hoek AJ, Ten Cate H, Tordoir J, Hamulyak K, Prins MH. Individually tailored duration of elastic compression therapy in relation to incidence of the postthrombotic syndrome. J Vasc Surg. 2010;52(1):132-8.

12. Prandoni $P$, Frulla $M$, Sartor $D$, Concolato $A$, Girolami $A$. Vein abnormalities and the post-thrombotic syndrome. J Thromb Haemost. 2005;3(2):401-2.

13. Latella J, Desmarais S, Miron MJ, et al. Relation between D-dimer level, venous valvular reflux and the development of post-thrombotic syndrome after deep vein thrombosis. J Thromb Haemost. 2010;8(10):2169-75.

14. Bouman AC, Smits JJ, Ten Cate H, Ten Cate-Hoek AJ. Markers of coagulation, fibrinolysis and inflammation in relation to post-thrombotic syndrome. J Thromb Haemost. 2012;10(8):1532-8.

15. Rabinovich A, Cohen JM, Cushman M, et al. Inflammation markers and their trajectories after deep vein thrombosis in relation to risk of post-thrombotic syndrome. J Thromb Haemost. 2015;13(3):398-408.

16. Ziegler S, Schillinger M, Maca TH, Minar E. Post-thrombotic syndrome after primary event of deep venous thrombosis 10 to 20 years ago. Thromb Res. 2001;101(2):23-33.

17. Villalta S, Bagatella P, Piccioli A, Lensing A, Prins MH \& Prandoni P. Assessment of validity and reproducibility of a clinical scale for the post-thrombotic syndrome Haemostasis. 1994;24(158a). 
18. Kearon C, Kahn SR, Agnelli G, Goldhaber S, Raskob GE, Comerota AJ. Antithrombotic therapy for venous thromboembolic disease: American College of Chest Physicians Evidence-Based Clinical Practice Guidelines (8th Edition). Chest. 2008;133(6 Suppl):454S-545S.

19. Ginsberg JS, Hirsh J, Julian J, et al. Prevention and treatment of postphlebitic syndrome: results of a 3-part study. Arch Intern Med. 2001;161(17):2105-9.

20. Appelen D, van Loo E, Prins MH, Neumann MH, Kolbach DN. Compression therapy for prevention of post-thrombotic syndrome. Cochrane Database Syst Rev. 2017;9:Cd004174.

21. Padberg FT, Jr., Johnston MV, Sisto SA. Structured exercise improves calf muscle pump function in chronic venous insufficiency: a randomized trial. J Vasc Surg. 2004;39(1):7987.

22. O'Donnell MJ, McRae S, Kahn SR, et al. Evaluation of a venous-return assist device to treat severe post-thrombotic syndrome (VENOPTS). A randomized controlled trial. Thromb Haemost. 2008;99(3):623-9.

23. Ippolito $E$, Belcaro $G$, Dugall $M$, et al. Venoruton(R): post thrombotic syndrome. Clinical improvement in venous insufficiency (signs and symptoms) with Venoruton(R). A fiveyear, open-registry, efficacy study. Panminerva Med. 2011;53(3 Suppl 1):13-9.

24. Kahn SR, Shrier I, Shapiro S, et al. Six-month exercise training program to treat postthrombotic syndrome: a randomized controlled two-centre trial. CMAJ. 2011;183(1):37-44.

25. Haig Y, Enden T, Grotta O, K et al. Post-thrombotic syndrome after catheter-directed thrombolysis for deep vein thrombosis (CaVenT): 5-year follow-up results of an openlabel, randomised controlled trial. The Lancet Haematology. 2016;3(2):e64-71.

26. Vedantham S, Goldhaber SZ, Julian JA, et al. Pharmacomechanical Catheter-Directed Thrombolysis for Deep-Vein Thrombosis. The New England journal of medicine. 2017;377(23):2240-52.

27. Peduzzi P, Concato J, Kemper E, Holford TR, Feinstein AR. A simulation study of the number of events per variable in logistic regression analysis. Journal of clinical epidemiology. 1996;49(12):1373-9.

28. Kahn SR, Partsch H, Vedantham S, Prandoni P, Kearon C. Definition of post-thrombotic syndrome of the leg for use in clinical investigations: a recommendation for standardization. J Thromb Haemost. 2009;7(5):879-83.

29. van Kuijk SMJ, Viegtbauer W, Peeters LL \& Smits L. Bias in regression coefficient estimates when assumptions for handling missing data are violated: a simulation study. Epidemiology Biostatistics and Public Health 2016;13(1):e11598-1.

30. Steyerberg EW. Clinical Prediction Models: A Practical Approach to Development, Validation, and Updating New York: Springer-Verlag 2009.

31. Collins GS, Reitsma JB, Altman DG, Moons KG. Transparent reporting of a multivariable prediction model for individual prognosis or diagnosis (TRIPOD): the TRIPOD statement. BMJ (Clinical research ed). 2015;350:g7594.

32. Ten Cate-Hoek AJ, Henke PK, Wakefield TW. The post thrombotic syndrome: Ignore it and it will come back to bite you. Blood Rev. 2015.

33. Kahn SR, Shapiro S, Wells PS, et al. Compression stockings to prevent post-thrombotic syndrome: a randomised placebo-controlled trial. Lancet. 2014;383(9920):880-8.

34. Rabinovich A, Ducruet T, Kahn SR. Development of a clinical prediction model for the postthrombotic syndrome in a prospective cohort of patients with proximal deep vein thrombosis. J Thromb Haemost. 2017. 


\section{Supplementary appendix}

\section{Secondary analysis}

As a secondary analysis in the derivation cohort we explored whether differences in PTS definition affected the models' performance. We compared the ISTH consensus definition to the original Prandoni definition of PTS (two consecutive Villalta scores of $\geq 5$ with at least 3 months between the assessments). Results are presented in this supplementary appendix.

Based on the Prandoni definition, PTS occurrence at 6 months after DVT was $14.0 \%$ and $14.7 \%$ in the following 18 months. The differences between the models based on continuous and dichotomized variables with Prandoni definition of PTS were relatively small. The highest values of AUC $(0.75,95 \%$ confidence interval 0.68-0.82) was observed in the model that included all continuous variables. The more conservative Prandoni definition had better discriminative properties than the one-time assessment of the ISTH definition in the subacute phase. For Prandoni definition the AUCs after internal validation were 0.69 and 0.69 for baseline and secondary models respectively. Sensitivity analysis showed no difference in model performance between using only complete cases and the imputed data.

Both definitions discriminate well between moderate, severe and mild cases.

The Prandoni definition was also better capable of distinguishing between mild and non-cases. In the acute phase both baseline models were similar, however the Prandoni definition yielded more efficient models. If the ISTH definition is chosen more patients with mild symptoms are identified as being at risk for PTS reducing the efficiency of the model compared to the models based on the Prandoni definition. On the other hand, the models based on the Prandoni definition may underestimate the percentage of patients at risk of PTS and may therefore result in a situation in which treatment is withheld unjustly. It needs to be determined which definition is more desirable both from a medical perspective (accurate identification of patients at risk for PTS) and from a 
societal perspective (most efficient selection of patients that can be excluded from further treatment). It would require decision analytical modelling to compare the savings associated with the treatment of fewer patients, to the health benefits forgone associated with the percentage of patient that were erroneously left untreated.

\begin{tabular}{|c|c|c|c|}
\hline \multirow[b]{2}{*}{ Variable } & \multicolumn{2}{|c|}{ Initial model } & \multirow{2}{*}{$\begin{array}{c}\text { Internally } \\
\text { validated model } \\
\text { Regression } \\
\text { coefficient }^{\mathrm{a}}\end{array}$} \\
\hline & $\begin{array}{l}\text { Regression } \\
\text { coefficient }\end{array}$ & OR $(95 \% \mathrm{Cl})$ & \\
\hline \multicolumn{4}{|l|}{ Baseline model } \\
\hline Intercept & $-3,254$ & - & -2.328 \\
\hline Age $>56$ & 0.762 & 2.14 (1.15-3.99) & 0.632 \\
\hline Body mass index $>30$ & 0.814 & $2.26(1.26-4.04)$ & 0.676 \\
\hline Varicose veins & 1.278 & $3.59(1.87-6.91)$ & 1.061 \\
\hline Smoking & 0.805 & $2.24(1.18-4.23)$ & 0.668 \\
\hline History of DVT & 0.509 & $1.66(0.86-3.21)$ & 0.423 \\
\hline Male sex & -0.450 & $0.64(0.35-1.16)$ & -0.373 \\
\hline Iliofemoral thrombosis & 0.498 & $1.65(0.85-3.19)$ & 0.413 \\
\hline Provoked DVT & 0.367 & $1.44(0.78-2.67)$ & 0.305 \\
\hline \multicolumn{4}{|l|}{ Secondary model } \\
\hline Intercept & -3.408 & - & -3.061 \\
\hline Age $>56$ & - & - & - \\
\hline Body mass index $>30$ & 0.603 & $1.83(0.96-3.47)$ & 0.488 \\
\hline Varicose veins & 1.620 & $\begin{array}{r}5.05(2.41- \\
10.59)\end{array}$ & 1.312 \\
\hline Smoking & 0.405 & $1.50(0.73-3.07)$ & 0.328 \\
\hline $\begin{array}{l}\text { Residual vein } \\
\text { obstruction }\end{array}$ & 0.662 & $1.94(1.05-3.58)$ & 0.536 \\
\hline History of DVT & 0.420 & $1.52(0.75-3.11)$ & 0.340 \\
\hline Male sex & 0.363 & $1.44(0.75-2.76)$ & 0.294 \\
\hline Iliofemoral thrombosis & 1.040 & $2.83(1.44-5.58)$ & 0.842 \\
\hline Provoked DVT & 0.446 & $1.56(0.83-2.95)$ & 0.361 \\
\hline
\end{tabular}




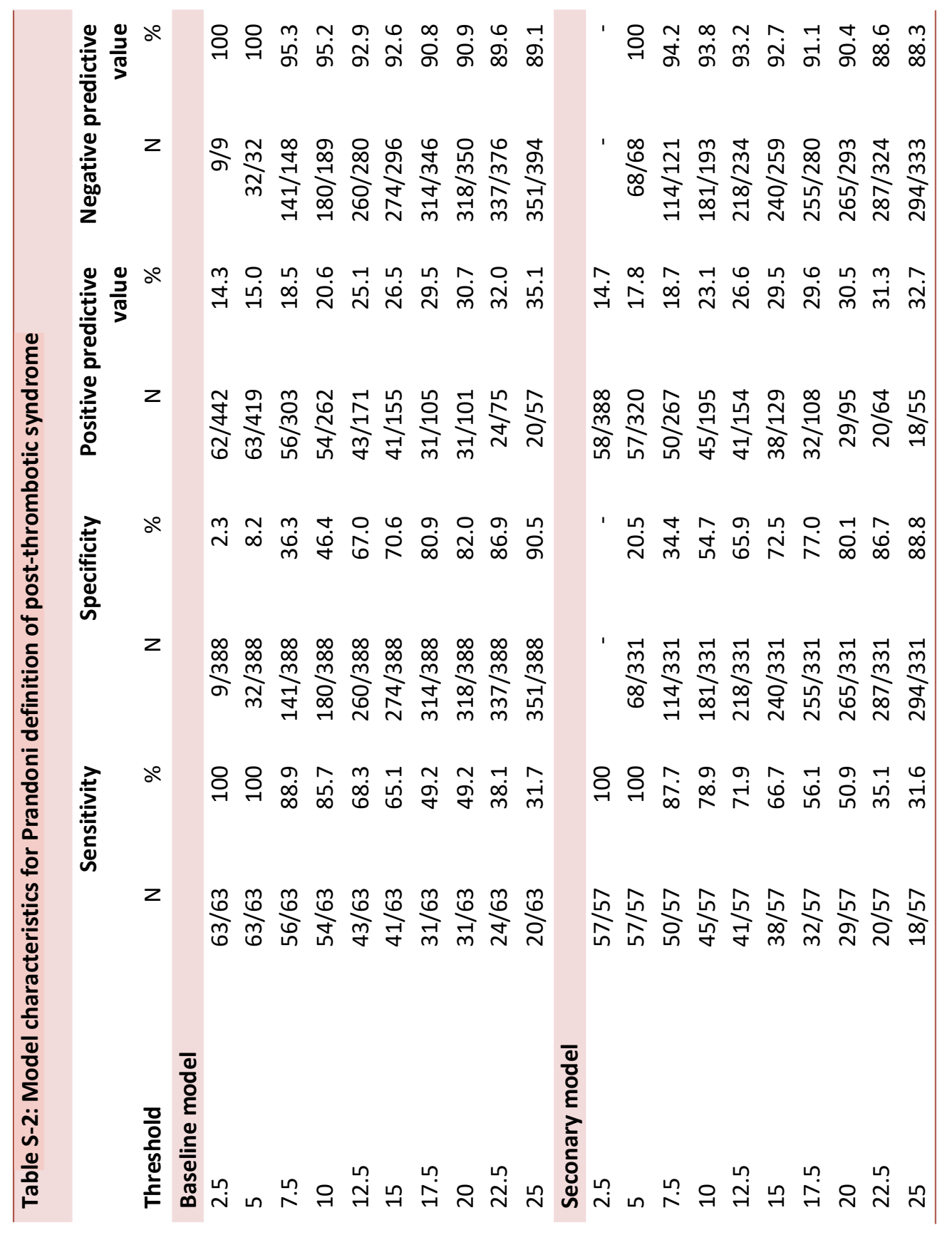




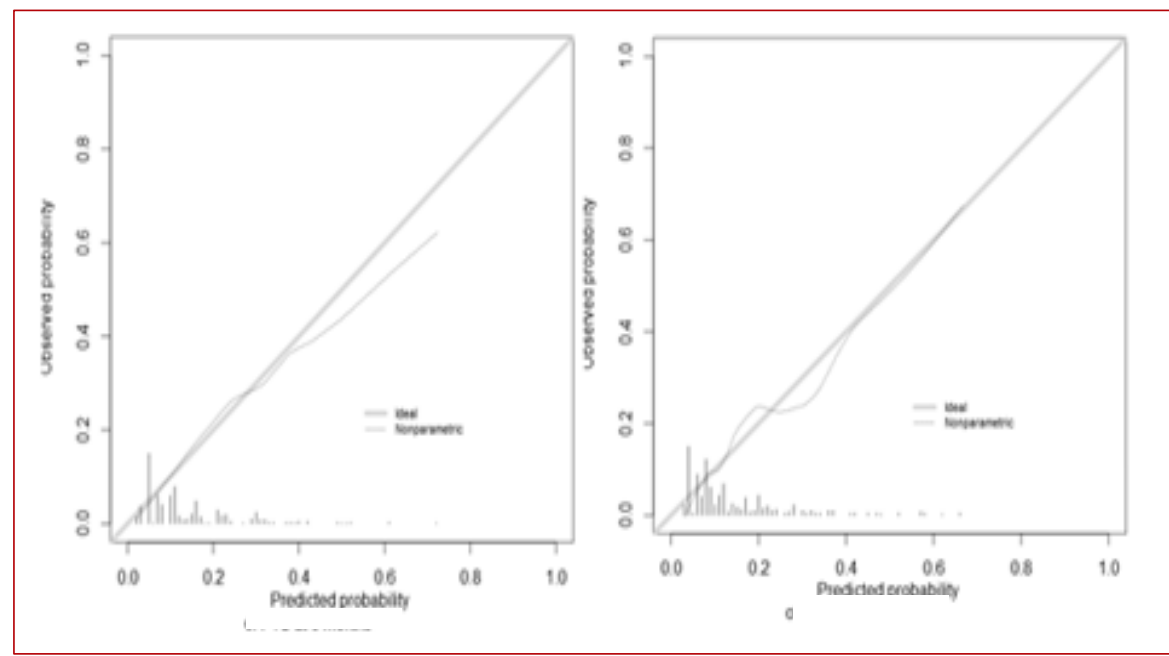

Figure 1: Shown are the calibration plots of the baseline model (left) and the secondary model (right) for PTS based on Prandoni definition of post-thrombotic syndrome

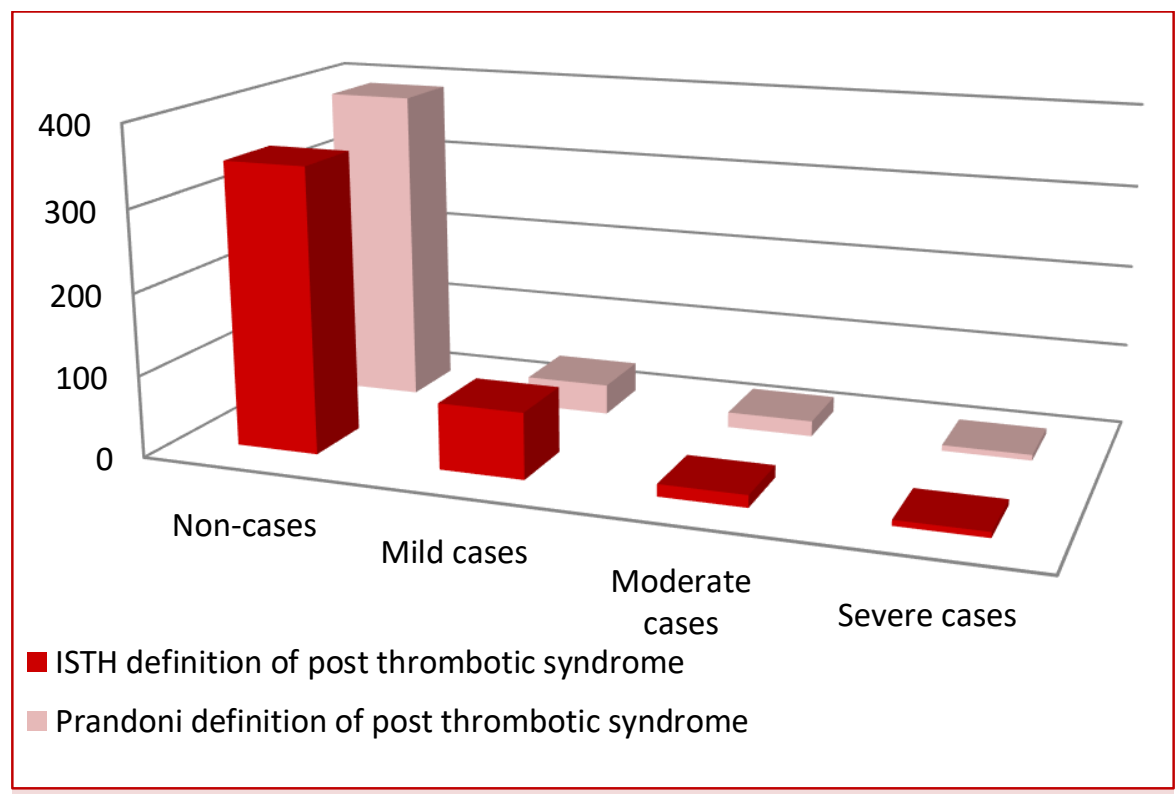

Figure 2: Differences in proportion of PTS (severity) for the ISTH and Prandoni definition six months after DVT. The differences are most pronounced for no PTS and mild post-thrombotic syndrome, proportions of moderate and severe PTS are similar for both scoring methods. 


\section{PART II}

\section{COMPARATIVE \& COST-EFFECTIVENESS}




\section{CHAPTER 4}

Individualised versus Standard Duration of Elastic Compression Therapy for Prevention of PostThrombotic Syndrome (IDEAL DVT): a Multicentre, Randomised, Single-Blind, Allocation-Concealed, NonInferiority Trial.

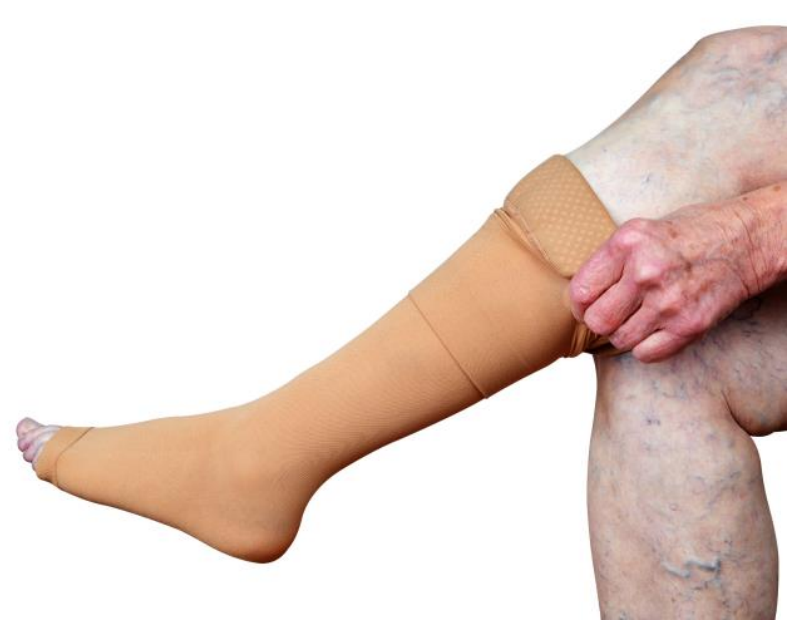

ten Cate-Hoek AJ, Amin EE, Bouman AC, Meijer K, Tick LW, Middeldorp S, Mostard GJM, ten Wolde $M$, van den Heiligenberg SM, van Wissen $S$, van de Poel MH, Villalta S, Serné EH, Otten HM, Klappe E, Bistervels IM, Lauw MN, Piersma-Wichers $M$, Prandoni $P$, Joore MA, Prins $M H$, ten Cate $H$, for the IDEAL DVT investigators.

The Lancet Haematology. 2018 Jan; 5(1): e25-e33 


\section{Abstract}

Background Therapy with elastic compression stockings has been the cornerstone for prevention of post-thrombotic syndrome for decades in patients after acute deep venous thrombosis. It is uncertain who benefits most from therapy, and what the optimum duration of therapy should be. We therefore aimed to assess the safety and efficacy of individualised duration of compression therapy versus the standard duration of 24 months following an initial treatment period of 6 months.

Methods We did a multicentre, randomised, single-blind, allocation-concealed, non-inferiority trial at 12 hospitals in the Netherlands and two in Italy. We randomly assigned patients (1:1) with acute proximal deep vein thrombosis of the leg and without pre-existent venous insufficiency (Clinical Etiological Anatomical and Pathophysiological score $<$ C3) to receive either individualised duration of elastic compression therapy or standard duration of therapy for 24 months following an initial treatment period of 6 months. Randomisation was done with a web-based automatic randomisation programme (TENALEA) and a random block size (2-12), and was stratified by centre, age, and body-mass index. In the initial phase, compression was applied within $24 \mathrm{~h}$ of diagnosis according to three prespecified protocols. All patients received elastic compression stockings $(30-40 \mathrm{~mm} \mathrm{Hg}$ ) for 6 months, and were instructed to wear them every day during ambulant hours. Thereafter treatment was tailored on the basis of clinical signs and symptoms scored according to the Villalta postthrombotic syndrome scale; patients assigned to individualised therapy with two consecutive Villalta scores of 4 or less were instructed to stop using the stockings. Patients were followed up for 2 years and assessed at five clinic visits at study inclusion, and 3, 6, 12, and 24 months after diagnosis (stocking allocation was not revealed to the assessors). The primary outcome was the proportion of patients with post-thrombotic syndrome at 24 months diagnosed according to original Villalta criteria (a score of $\geq 5$ on two consecutive occasions 
at least 3 months apart) assessed by intention to treat. The predefined noninferiority margin for the difference in success rates was set at $7 \cdot 5 \%$. This study has been completed and is registered with ClinicalTrials.gov, number NCT01429714.

Findings Between March 22, 2011, and July 1, 2015, we enrolled 865 patients and randomly assigned 437 to individualised duration compression stockings and 428 to standard duration. 283 (66\%) of 432 patients in the intervention group were advised before 24 months to stop wearing elastic compression stockings (236 [55\%] of 432).

Interpretation Individualised therapy with elastic compression stockings for the prevention of post-thrombotic syndrome was non-inferior to standard duration of therapy of 24 months. Individualising the duration is effective and could shorten the length of therapy needed, potentially enhancing patients' wellbeing.

\section{Introduction}

Post-thrombotic syndrome is a common and chronic complication of deep vein thrombosis of the leg affecting up to half of all patients. ${ }^{1}$ It is characterised by a combination of problems in the leg including tiredness of the leg, pain and oedema, and irreversible skin changes such as hyperpigmentation, venous ectasia, and in more severe cases lipodermatosclerosis and venous ulceration. ${ }^{1-3}$ Post-thrombotic syndrome negatively affects quality of life and is associated with substantial costs. ${ }^{4-6}$ Once the condition is established, treatment options are scarce. Therefore, preventive therapy with elastic compression stockings has been the cornerstone of treatment for decades since findings from two randomised trials $^{7,8}$ showed that compression therapy for 24 months reduced the risk of post-thrombotic syndrome by approximately $50 \%$. The effectiveness of elastic compression therapy was challenged by findings from the placebo-controlled SOX trial, ${ }^{9}$ which showed no difference between active and placebo stockings. 
This result affected the clinical community greatly as it gave rise to changes in some guidelines and advice against the routine application of elastic compression therapy. ${ }^{10,11}$ Other groups have been more conservative and did not value the evidence as strong enough to update their recommendations. ${ }^{12,13}$

The SOX trial had several limitations including insufficient adherence to compression therapy, which might have obscured any potential benefit of therapy in subsets of patients. ${ }^{14,15}$ Results from the OCTAVIA trial ${ }^{16}$ showed that in patients with excellent adherence to elastic compression stockings there was less post-thrombotic syndrome when the use of stockings was continued beyond 12 months. Hence, OCTAVIA re- emphasised the value of compression therapy, but also reinforced the original question that formed the basis of our study: can the duration of compression therapy be further optimised; ie, tailored on individual basis ${ }^{17,18}$ Tailoring treatment duration to individual needs could retain the effectiveness of compression therapy, enhance patients' wellbeing, and save substantial costs. ${ }^{19}$ We therefore did a study (IDEAL DVT) to compare the effectiveness of individualised duration of elastic compression therapy with standard duration of therapy of 24 months for the prevention of postthrombotic syndrome. The objective of our study was to assess whether tailoring the duration of elastic compression therapy according to signs and symptoms of an individual patient would not be inferior compared with standard duration of therapy.

\section{Methods}

\section{Study design and participants}

We did a multicentre, randomised, single-blind, allocation-concealed, noninferiority trial at 14 centres, 12 hospitals in the Netherlands and two in Italy (appendix $\mathrm{p} \mathrm{2).} \mathrm{This} \mathrm{trial} \mathrm{was} \mathrm{reviewed} \mathrm{and} \mathrm{approved} \mathrm{by} \mathrm{the} \mathrm{institutional} \mathrm{review}$ 
board at each participating centre. The study protocol was published previously. ${ }^{19}$

Eligible participants were adult patients who had an acute, objectively documented proximal thrombosis of the leg and were adequately treated within $24 \mathrm{~h}$ of diagnosis with anticoagulant treatment and initial compression therapy according to one prespecified local study protocol per hospital (appendix p 4). ${ }^{19}$ Patients were ineligible if they had a life expectancy of less than 6 months, underwent active thrombolysis, or had previous ipsilateral deep vein thrombosis of the leg; if pre-existent severe venous insufficiency was present, because signs and symptoms are similar to post-thrombotic syndrome (venous insufficiency was characterised by skin signs $\mathrm{C} 3$ to $\mathrm{C} 6$ on the Clinical Etiological Anatomical and Pathophysiological [CEAP] score ${ }^{20}$ or by pre-existent requirement of compression therapy); or if they had a contraindication for compression therapy such as intermittent claudication or clinical signs of leg ischaemia. In case of recurrent ipsilateral thrombosis within the first 6 months after diagnosis, patients were excluded from further assessment, as this new event would interfere with the Villalta assessments preceding the intervention and render patients ineligible according to the inclusion criteria. All participants gave written informed consent.

\section{Randomisation and masking}

We randomly assigned eligible patients (1:1) to either individualised duration of elastic compression therapy following an initial treatment period of 6 months followed by individualised extended duration of therapy depending on Villalta scores $^{8,19,21}$ (intervention) or an initial treatment period of 6 months followed by standard duration of therapy for 24 months (control). After obtaining consent, randomisation was done by the coordinating study centre (Maastricht University Medical Center, Maastricht, Netherlands) within 2-6 weeks after the acute onset of deep vein thrombosis through a webbased randomisation programme (TENALEA). A random block size (2-12) was used and randomisation 
was stratified for centre, age, and body-mass index (BMI). Patients were informed of treatment allocation by telephone by the coordinating study centre. Information on treatment allocation was concealed from the study nurse or the treating physician. Patients were asked to not wear the stockings at the day of their outpatient clinic visits and to not reveal their treatment allocation to the treating physician. Health-care providers were unaware of treatment allocation. Independent clinical research assistants monitored the sites. The investigators collected, maintained, and analysed the data.

\section{Procedures}

A custom-fitted, flat-knitted, knee length graduated compression stocking class III (ankle pressure 30-40 mm Hg) was prescribed for all patients. The pressure class was similar to the pressure used in six of eight previous trials assessing the value of compression in patients with deep venous thrombosis. ${ }^{7-9,16,17,22}$ The other two small trials ${ }^{23,24}$ used mixed-treatment modalities.

Compression therapy with knee length elastic compression was started immediately after the initial phase (from diagnosis until resorption of the acute oedema). In the initial phase, compression was applied within $24 \mathrm{~h}$ of diagnosis according to local prespecified protocols. ${ }^{19}$ In the individualised duration group, there were three scenarios: ${ }^{19}$ compression therapy was discontinued if the Villalta scores were 4 or less at both the 3-month and 6-month follow-up visits; compression therapy was continued for the total duration of 24 months if the Villalta score was 5 or more at both visits; or compression therapy was continued for a further 6 months if the Villalta score was 5 or more at the 3-month followup visit followed by a score of or less at the 6-month visit. Therapy was then discontinued at the 12-month visit if the score was four or less again; otherwise therapy was continued. If patients did not have two consecutive low scores within 1 year of the acute event, these patients were considered to be chronically unstable and therefore ineligible for shortened treatment duration. If a patient developed symptoms and signs of post-thrombotic syndrome after 
discontinuation of elastic compression therapy, a predefined protocol was followed (appendix). Treatment was reinstated for a week and then stopped again. In case of persistent symptoms, elastic compression was reinstated permanently. Patients were followed up for 2 years, during which they visited the outpatient clinic five times: at inclusion into the study and at 3, 6, 12, and 24 months following the diagnosis. At each follow-up visit signs of post thrombotic syndrome were recorded and scored by the study nurse or the treating physician using the objective part of the Villalta clinical scale. ${ }^{21}$ Patients filled out the subjective part of the Villalta scale either in a web-based questionnaire, for which the link was sent to them the day before the planned study visit, or in a questionnaire on paper that was sent to them by regular mail. Prescriptions for new stockings were provided by the coordinating study centre. Adherence to elastic compression therapy was assessed via specific questions in the questionnaires preceding the clinical visits, and in addition by random telephone contacts by study staff. Patients were instructed to contact their physician in case of intermittent leg complaints or signs and symptoms suggestive of recurrent venous thrombosis. Prespecified objective testing was required for these patients. ${ }^{19,25}$ Type and duration of anticoagulation treatment was left at the discretion of the treating physician.

\section{Outcomes}

The primary outcome was the proportion of patients with post-thrombotic syndrome at 24 months after the initial event. Post-thrombotic syndrome was diagnosed with the Villalta scale, as recommended by the subcommittee for standardisation of the International Society on Thrombosis and Haemostasis (ISTH).

The use of the Villalta scale was promoted as the preferred method of diagnosis for post thrombotic syndrome over other scales for the assessment of venous disease as this scale is disease-specific, widely validated, easy to apply, and sensitive to change. ${ }^{26}$ The scale assesses five patient-rated symptoms: pain, 
cramps, heaviness, paraesthesia, and itching, and six physical signs: pretibial oedema, skin induration, hyperpigmentation, pain during calf compression, venous ectasia, and redness. All items are graded for intensity on a four-point scale, 0 points when there are no deviations from normal, 1 if the signs or symptoms are mild, 2 if they are moderate, and 3 if they are severe. With 11 items a total score of 33 can be reached, a score of 5-9 is considered mild postthrombotic syndrome, 10-14 moderate, and a score of 15 or more, or presence of ipsilateral venous ulceration is considered severe post-thrombotic syndrome..$^{2,21}$ We defined post thrombotic syndrome as a Villalta score of 5 or higher at two consecutive visits that were at least 3 months apart (the original scoring method). ${ }^{8,19,21}$

Additionally, the proportion of patients with post thrombotic syndrome according to the more recently introduced ISTH consensus scoring method (a score of 5 or higher at the 6-month visit or later) was assessed. ${ }^{26}$ The use of the ISTH scoring method results in more patients diagnosed, especially those with mild post-thrombotic syndrome. The original scoring method is more conservative in diagnosing post-thrombotic syndrome. Secondary outcomes included recurrent objectively confirmed venous thromboembolism and venous thromboembolism-related death during follow-up assessed by an independent adjudication committee; health-related quality of life measured at each study visit with validated generic questionnaires (SF-36, ${ }^{27} \mathrm{EQ}-5 \mathrm{D}^{28}$ ) and venous disease-specific questionnaires (Dutch translated VEINES-QOL). ${ }^{29,30}$ Two additional secondary outcomes that were indicated in the study protocol are not presented in the current manuscript: patients' preference was assessed at an early stage of the study and was previously published in a separate manuscript, ${ }^{31}$ and costs will be analysed in the context of a cost-effectiveness study.

\section{Statistical analysis}

At a one-sided significance level of 0.05 and a power of $80 \%$, a sample size of 848 was needed in this study to provide sufficient numbers for an adequately 
powered trial. Loss to follow-up of patients was expected to be less than $2 \%$, thus 864 patients (432 per treatment arm) were needed. The study was designed to show that the effectiveness of individualised duration of elastic compression treatment for the prevention of post-thrombotic syndrome was non-inferior to elastic compression therapy for a standard duration of 24 months. We determined that preserving $70 \%$ of the therapeutic effect would allow a difference of $7 \cdot 5 \%$ (the non-inferiority margin) in the outcome between the groups. ${ }^{19,32}$ The therapeutic effect of elastic compression therapy for the standard duration of 24 months was estimated from two studies that showed a mean reduction of post-thrombotic syndrome of $26 \%$ using the original Villalta scoring method or a comparable scoring method. 7,8,33 For the primary outcome, the proportion of patients with post-thrombotic syndrome at 24 months after the deep vein thrombosis, a univariate analysis of proportions was done with logistic regression $\left(\chi^{2}\right)$ analysis, and odds ratios (OR)s and $95 \% \mathrm{Cl}$ were calculated. The efficacy analysis included all randomly assigned patients who fitted the inclusion criteria i.e. excluding those who had a recurrent deep vein thrombosis within the first 6 months and provided written informed consent (intention-to-treat population). Additionally, we used the Kaplan-Meier method to calculate the cumulative incidence of post-thrombotic syndrome, adjusted for centre to compare incidence rates between the two treatment arms. Loss to follow-up, withdrawals, and deaths were censored at the last available date. Hazard ratios (HRs) and $95 \% \mathrm{Cl}$ were calculated using Cox proportional hazards models, stratified for centre and adjusted for age, sex, and BMI, both for original Villalta scoring and ISTH consensus scoring method. ${ }^{21}$

We did descriptive analyses to assess patient characteristics, and to assess the severity of post-thrombotic syndrome, adherence to therapy, the proportion of recurrent venous thromboembolism (deep vein thrombosis of the leg and pulmonary embolism), and the proportion of (thrombosis-related) death. We applied a mixed-design analysis of variance to test for differences between the 
two treatment groups, and to assess changes over time by comparing repeated outcome measures for quality of life scores at different time points of follow-up. The minimally important difference (MID) for quality of life scores were: at least 4 points for the VEINES-QOL T score, ${ }^{34}$ at least 0.07 for the EQ-5D, and at least 0.05 for the SF-36. ${ }^{35}$ For the VEINES-QOL intrinsic score, a MID of at least 0.07 (0.5 times the SD) was assumed. ${ }^{36}$ We did a post-hoc analysis to compare the incidence of post thrombotic syndrome at 24 months for patients with a Villalta score of less than 5 at 6 months in the individualised treatment group (stop compression) and the standard treatment group (continue compression). An intention-to-treat analytical approach was used for all outcomes. For all analyses a two-sided $p$ value of 0.05 or less was considered significant. Analyses were done with SPSS software, version 23. An independent adjudication committee adjudicated causes of death in the study. This study is registered with ClinicalTrials.gov, number NCT01429714.

\section{Role of the funding source}

The funder of the study has no involvement in study design, study conduct, data collection, data analysis, data interpretation, or writing of the report. The corresponding author had full access to all the data in the study and had final responsibility for the decision to submit for publication.

\section{Results}

Between March 22, 2011, and July 1, 2015, we enrolled 865 patients and randomly assigned 437 to individualised duration of elastic compression therapy and 428 to standard duration of therapy. Patients were included in the study within a median of 18 days (IQR 17-19) of the diagnosis of acute proximal deep vein thrombosis; however, predefined compression treatment started within $24 \mathrm{~h}$ of the diagnosis (appendix $\mathrm{p} 4$ ). After the exclusion of nine patients because 
of a recurrent thrombotic event of the leg within the first 6 months after enrolment, 856 patients were included in the primary intention-to-treat analysis (figure 1).

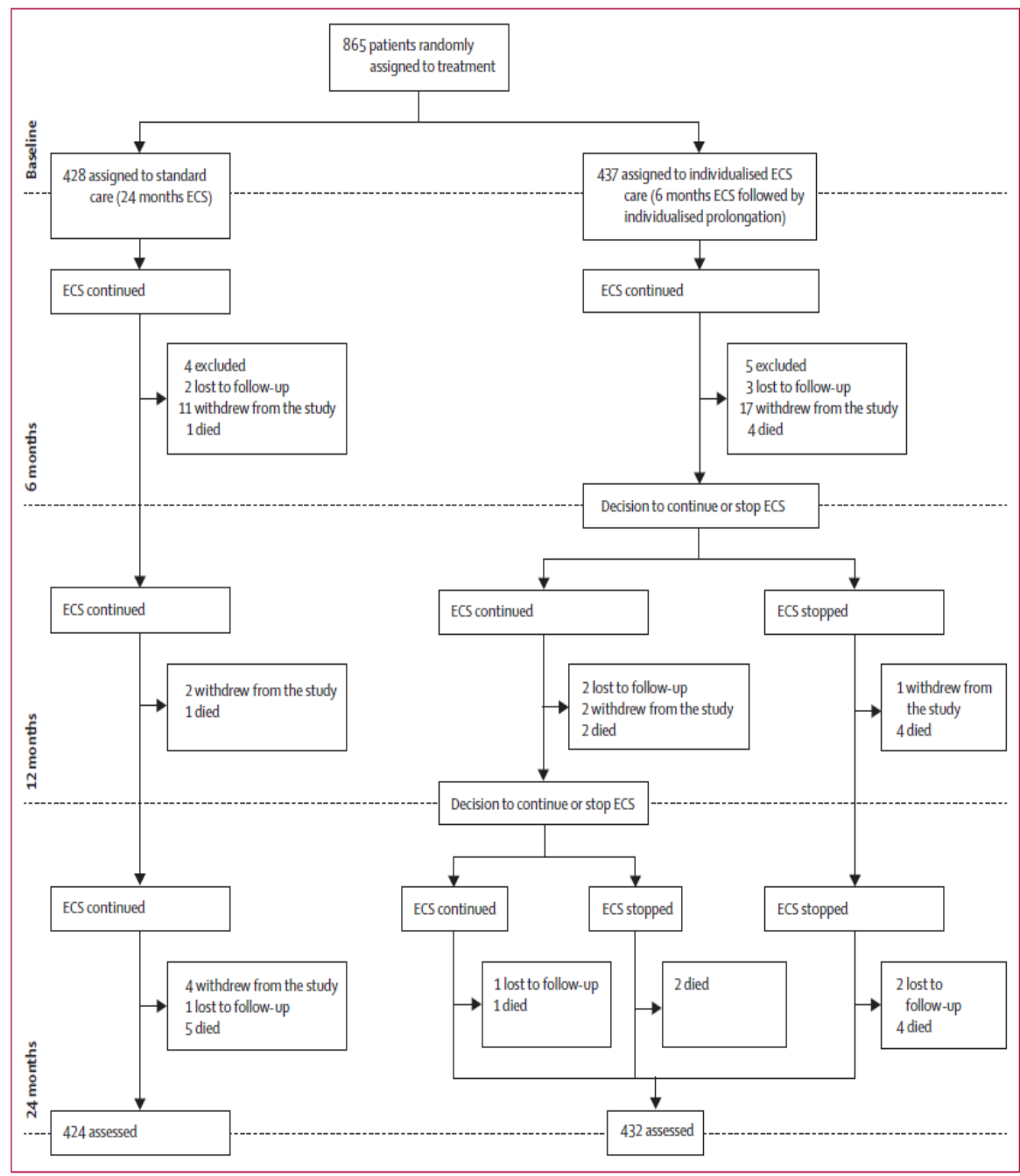

Figure 1: Trial profile. ECS=elastic compression stockings 


\begin{tabular}{|c|c|c|}
\hline & $\begin{array}{l}\text { Individualised duration } \\
\text { stockings }(n=437)\end{array}$ & $\begin{array}{l}\text { Standard duration } \\
\text { stockings }(n=428)\end{array}$ \\
\hline Age (years) & $58 \cdot 1(14 \cdot 6)$ & $56 \cdot 3(15 \cdot 7)$ \\
\hline \multicolumn{3}{|l|}{ Age category (years) } \\
\hline$<40$ & $36(8 \%)$ & $53(12 \%)$ \\
\hline 40-65years & $255(58 \%)$ & $257(60 \%)$ \\
\hline$>65$ years & $146(33 \%)$ & $117(27 \%)$ \\
\hline \multicolumn{3}{|l|}{ Sex } \\
\hline Men & $253(58 \%)$ & $251(59 \% \%)$ \\
\hline Women & $184(42 \%)$ & $177(41 \%)$ \\
\hline Body-mass index $\left(\mathrm{kg} / \mathrm{m}^{2}\right)$ & $28 \cdot 0(5 \cdot 1)$ & $27 \cdot 8(5 \cdot 4)$ \\
\hline \multicolumn{3}{|l|}{ Body-mass index category } \\
\hline$<26 \mathrm{~kg} / \mathrm{m}^{2}$ & $172(39 \%)$ & $186(43 \%)$ \\
\hline$\geq 26 \mathrm{~kg} / \mathrm{m}^{2}$ & $261(60 \%)$ & $238(56 \%)$ \\
\hline Previous DVT contralateral & $47(11 \%)$ & $34(8 \%)$ \\
\hline \multicolumn{3}{|l|}{ Characteristics of current DVT } \\
\hline Unprovoked DVT & $295(68 \%)$ & $290(68 \%)$ \\
\hline Right & $191(44 \%)$ & $191(45 \%)$ \\
\hline Left & $231(53 \%)$ & $223(52 \%)$ \\
\hline Bilateral & $2(<1 \%)$ & $2(<1 \%)$ \\
\hline \multicolumn{3}{|l|}{ Most proximal extent of DVT* } \\
\hline Popliteal vein & $215(49 \%)$ & $211(49 \%)$ \\
\hline Femoral vein & $114(26 \%)$ & $122(29 \%)$ \\
\hline Common femoral vein & $96(22 \%)$ & $90(21 \%)$ \\
\hline DVT treatment & .. & .. \\
\hline Vitamin K antagonist $\dagger$ & $400(92 \%)$ & $378(88 \%)$ \\
\hline Non-vitamin-K anticoagulantsł & $10(2 \%)$ & $18(4 \%)$ \\
\hline Investigational anticoagulants 5 & $12(3 \%)$ & $12(3 \%)$ \\
\hline Low-molecular-weight heparin & $15(3 \%)$ & $20(5 \%)$ \\
\hline \multicolumn{3}{|c|}{$\begin{array}{l}\text { Data are mean (SD) or } \mathrm{n}(\%) \text {. DVT=deep vein thrombosis, *In the case of bilateral DVT, the leg with the most proximal } \\
\text { DVT was considered to be the index leg. †All patients receiving a vitamin K antagonist had initially } 5-10 \text { days of } \\
\text { low-molecular-weight heparin. } ¥ \text { The only non-vitamin-K anticoagulant used during the study was rivaroxaban. } \\
\text { SSome patients participated in studies comparing investigational anticoagulants (warfarin vs edoxaban) and } \\
\text { low-molecular-weight heparin in patients with malignancy. }\end{array}$} \\
\hline
\end{tabular}

Baseline characteristics and anticoagulant treatment were similar for both groups (table 1). 283 (66\%) of 432 patients in the intervention group were advised before 24 months to stop wearing elastic compression stockings (236 
[55\%] of 432 patients after 6 months, and 47 [11\%] of 432 at 12 months). In nine (3\%) of 283 patients therapy was reinitiated and permanently reinstated because of persistent leg complaints. In another eight (3\%) of 283 patients elastic compression therapy was temporarily reinstated for a week, according to protocol. Adherence to treatment advice was similar in both groups with either daily or almost daily use, or no use of stockings as appropriate in 383 (96\%) of 400 patients at 3 months, 369 (93\%) of 395 at 6 months, 286 (81\%) of 354 at 12 months and 240 (77\%) of 313 at 24 months in patients receiving individualised treatment and with daily or almost daily use of stockings in 382 (96\%) of 399, $363(93 \%)$ of 390, $328(87 \%)$ of 377, and 269 (79\%) of 340 patients receiving standard therapy (appendix $\mathrm{p} 11$ ). The mean percentage of adherence registered with random telephone calls throughout the follow-up was 380 (SD 8.0; 88\%) of 432 for the intervention group and 302 (49.7; 71\%) of 424 in the control group. Post-thrombotic syndrome occurred in 125 (29\%) of 432 patients receiving individualised duration of therapy and 118 (28\%) of 424 patients who received standard duration of therapy (OR 1.06, 95\% Cl, 0.78-1.44) (figure 2, table 2). The absolute difference was $1 \cdot 1 \%(95 \% \mathrm{Cl}-5 \cdot 2$ to $7 \cdot 3)$. The cumulative incidence of post-thrombotic syndrome at 730 days was $28.9 \%(95 \% \mathrm{Cl} 24 \cdot 7-33 \cdot 5)$ in the individualised duration group versus $27 \cdot 8 \%(23 \cdot 6-32 \cdot 4)$ in the standard duration group (hazard ratio [HR] adjusted for centre $1 \cdot 13,95 \% \mathrm{Cl} 0 \cdot 88-1 \cdot 46 ; p=0 \cdot 77$ ). Distribution of severity of post-thrombotic syndrome was similar for both groups. The analysis according to the ISTH-scoring method showed higher incidences but similar relative efficacy (table 2). Per-protocol analysis showed similar results (appendix). 


\begin{tabular}{|c|c|c|c|}
\hline & $\begin{array}{l}\text { Individualised } \\
\text { duration compression } \\
\text { stockings }(n=432)\end{array}$ & $\begin{array}{l}\text { Standard duration } \\
\text { compression } \\
\text { stockings }(n=424)\end{array}$ & $\begin{array}{l}\text { Odds ratio } \\
(95 \% \mathrm{Cl})\end{array}$ \\
\hline \multicolumn{4}{|l|}{ Primary outcome } \\
\hline 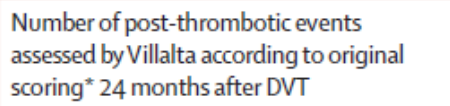 & $125(29 \%)$ & $118(28 \%)$ & $1.06(0.78-1.44)$ \\
\hline \multicolumn{4}{|l|}{ Villalta severity category (scores) } \\
\hline None $(<5)$ & $307(71 \%)$ & $305(72 \%)$ & .. \\
\hline Mild (5-9) & $84(19 \%)$ & $67(16 \%)$ & .. \\
\hline Moderate (10-14) & $32(7 \%)$ & $35(8 \%)$ & .. \\
\hline Severe (>14 or ulcer) & $9(2 \%)$ & $17(4 \%)$ & .. \\
\hline \multicolumn{4}{|l|}{ Secondary outcomes } \\
\hline $\begin{array}{l}\text { Number of post-thrombotic events } \\
\text { assessed by Villalta's criteria according to } \\
\text { ISTH scoring } 24 \text { months after DVT }\end{array}$ & $219(51 \%)$ & $192(45 \%)$ & $1.24(0.94-1.64)$ \\
\hline \multicolumn{4}{|l|}{ Villalta severity category (scores) } \\
\hline None $(<5)$ & $213(49 \%)$ & $233(55 \%)$ &.. \\
\hline Mild (5-9) & $177(41 \%)$ & $142(33 \%)$ & .. \\
\hline Moderate (10-14) & $35(8 \%)$ & $35(8 \%)$ & .* \\
\hline Severe (>14 or ulcer) & $7(2 \%)$ & $14(3 \%)$ & .. \\
\hline Ipsilateral leg ulcer & $2(<1 \%)$ & 0 & .* \\
\hline Recurrent DVT & $21(5 \%)$ & $27(6 \%)$ &. \\
\hline Recurrent pulmonary embolism & $13(3 \%)$ & $9(2 \%)$ & .. \\
\hline Death $\ddagger$ & $17(4 \%)$ & $7(2 \%)$ &. \\
\hline Malignancy related & $12(3 \%)$ & $5(1 \%)$ & .. \\
\hline Documented venous thromboembolism & 0 & 0 & .. \\
\hline $\begin{array}{l}\text { Venous thromboembolism cannot be } \\
\text { excluded }\end{array}$ & $3(<1 \%)$ & $1(<1 \%)$ &. \\
\hline Other & $2(<1 \%)$ & $1(<1 \%)$ & .. \\
\hline \multicolumn{4}{|c|}{$\begin{array}{l}\text { Of the } 865 \text { patients in the intention-to-treat analysis, } 856 \text { were included in the time-to-event analysis. Nine patients } \\
\text { (four in the standard group and five in the intervention group) were excluded because of recurrent venous thrombosis in } \\
\text { the leg within the first } 6 \text { months. DVT=deep vein thrombosis. ISTH=International Society on Thrombosis and } \\
\text { Hemostasis. *Original scoring:Villalta score of at least } 5 \text { at two consecutive visits at least } 3 \text { months apart. } \dagger \text { ISTH scoring: } \\
\text { Villalta score of at least } 5 \text { or an ulcer after the } 6 \text {-month visit. } ¥ \text { See appendix for individual causes of death (p 9). }\end{array}$} \\
\hline
\end{tabular}

The cumulative incidence of post-thrombotic syndrome for individualised treatment duration and standard treatment duration showed that most cases were identified at 6 months (87 [21\%] of 424 and 92 [21\%] of 432, respectively) and that thereafter there was a slight increase at 12 months (ten [2\%] of 424 and 
eight [2\%] of 432), and 24 months (21 [5\%] of 424 and 25 [6\%] of 432, according to the original scoring method). The proportion of patients with recurrent venous thromboembolic episodes was similar for both groups, and mortality was higher in the individualised treatment duration group (table 2). The HRs and 95\% $\mathrm{Cl}$ stratified for centre and adjusted for age, sex, and BMI category (cut-off 26) for the original Villalta scoring and the ISTH-consensus scoring method were 1.13 $(0.88-1.46)$ and $1.15(0.94-1.40)$, respectively.

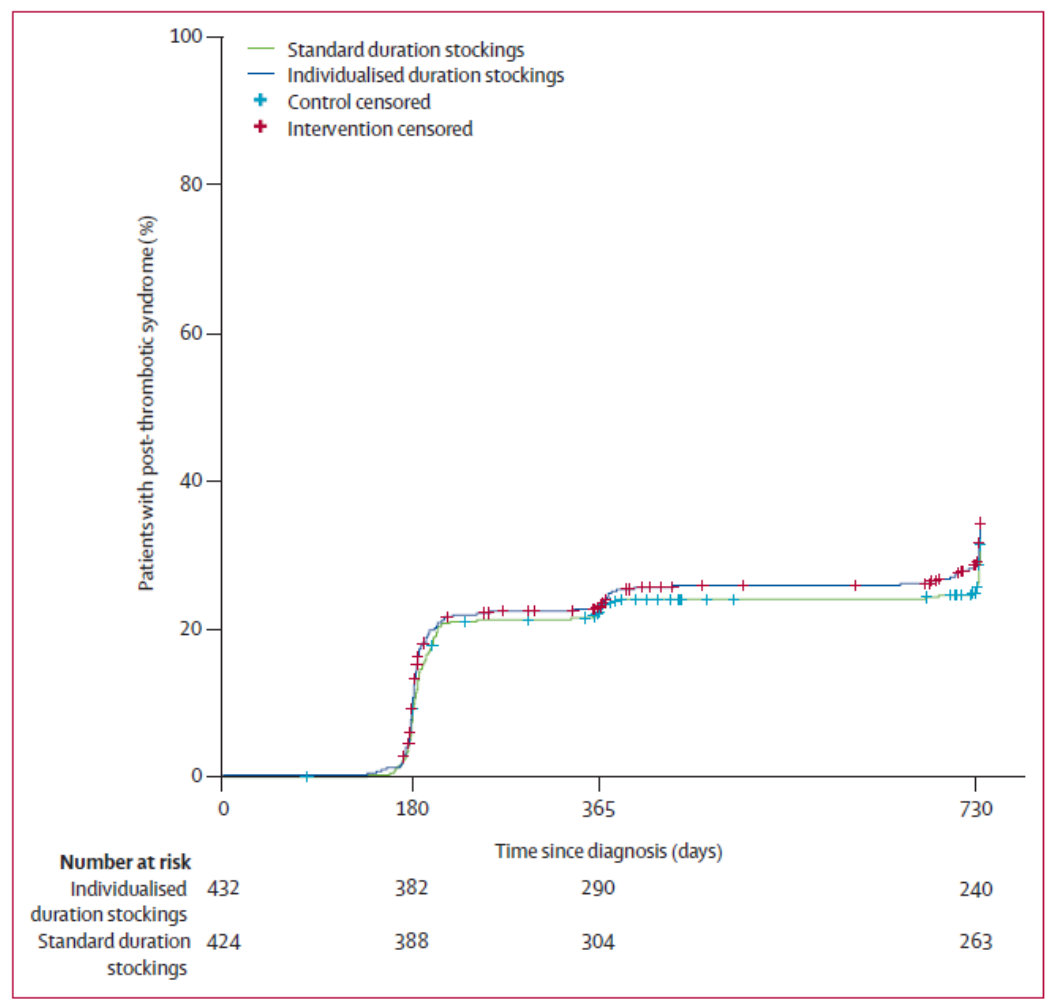

Figure 2: Cumulative incidence of post-thrombotic syndrome

The primary outcome of post-thrombotic syndrome (PTS) according to the original Villalta scoring method was first assessed at the 3-month visit and thereafter at 6, 12, and 24 months. Data from 31 patients who withdrew and four who were lost to follow-up were censored at the time of their last assessment. 
24 patients died, but no deaths were related to treatment (table S-2). Most deaths in both groups were related to cancer. No serious adverse events related to the intervention occurred.

Post-hoc analysis (including 420 patients) using the ISTH-scoring method showed an incidence of post thrombotic syndrome for individualised treatment in the group of early stoppers (those with Villalta score $<5$ at 6 months) of $36 \%$ (45 of 207 patients) compared with 22\% (76 of 213 patients) for the group that continued use of elastic compression stockings for 24 months (standard duration) with an absolute difference in incidence of post-thrombotic syndrome of $14.0 \%$; relative risk (RR) 1.6 (95\% Cl 1.2-2.3); number-needed-to-treat $7 \cdot 2$ (4.4-20·7). When the original scoring method was employed (including 419 patients) the differences were non-significant with an incidence of postthrombotic syndrome of $10 \%$ (21 of 212 patients) in the early stoppers versus 7\% (14 of 207 patients) for those that continued treatment (RR 1.52, 95\% Cl $0 \cdot 71-2 \cdot 97)$.

Generic quality of life was similar in both treatment groups: SF-36 ranged from 0.62 at 1 month to 0.82 at 24 months in patients with individualised treatment versus 0.61 to 0.82 for patients with standard therapy, $p=0.86$. EQ-5D ranged from 0.82 to 0.90 in patients receiving individualised treatment versus 0.83 to 0.88 in the standard treatment group, $p=0.51$. Disease-specific quality-of-life measures were also similar between groups: VEINES-QOL T scores ranged from 50.3 at 1 month to 50.0 at 24 months for patients with individualised treatment versus 49.8 to $50 \cdot 0$ in patients with standard treatment, $p=0 \cdot 34$. The VEINESQOL intrinsic score ranged from 0.63 to 0.76 in patients with individualised treatment versus 0.63 to 0.75 in patients with standard therapy, $p=0.64$ (appendix $p$ 13). Except for the VEINESQOL $T$ score $(p=0.88)$, all QOL measurements significantly increased over time $(p<0 \cdot 0001)$. These differences were clinically important for SF-36 and for the VEINESQOL intrinsic score in both groups. For the EQ5D score the MID of 0.07 or greater occurred in the individualised treatment group only. 


\section{Discussion}

Our study findings showed that individualised duration of elastic compression therapy is non-inferior to standard duration of treatment. Elastic compression stockings are commonly viewed as unattractive and uncomfortable; however, the expected positive effect of shorter duration of elastic compression on quality of life could not be substantiated; quality of life between treatment groups was similar for all measures, and improved over time for most measures. The observed incidence of post-thrombotic syndrome was similar to incidences reported for standard duration of elastic compression in previous landmark trials by Brandjes and colleagues ${ }^{7}$ and Prandoni and colleagues, ${ }^{8}$ indicating that individualised duration of elastic compression therapy is feasible without increasing the incidence of post-thrombotic syndrome. Moreover, individualised duration of treatment was efficient, as more than half the patients in the intervention group could stop wearing the stockings as early 6 months after the thrombosis and in only $3 \cdot 2 \%$ of cases was permanent reinstatement of treatment necessary.

The need for elastic-compression therapy was previously challenged by findings from the SOX trial ${ }^{9}$ that showed an unexpected absence of efficacy with elastic compression therapy for the prevention of post thrombotic syndrome. Nonadherence to therapy was identified as a plausible and important contributor to the negative findings of SOX. ${ }^{14}$ Apart from this one large negative trial, overall evidence suggests that elastic compression therapy is effective for around a $30 \%$ reduction of post-thrombotic syndrome. ${ }^{1,2,25,37,38}$ Findings from the OCTAVIA trial have shown that in selected patients with excellent adherence $(85 \%$ of patients using elastic compression stockings for 6-7 days a week), outcomes after stopping treatment at 12 months were inferior to standard duration of treatment, with 14 needed to treat for the extra year for the prevention of post thrombotic syndrome-highlighting the importance of therapy adherence for efficacy. ${ }^{16}$ In our study, adherence to therapy advice was high throughout the 
study (more than 90\% after 3 months and almost $80 \%$ at the last follow-up visit). These adherence values are similar to those reported in other trials that showed efficacy of compression therapy. ${ }^{7,8,16}$ A post-hoc analysis of data from our IDEAL study comparing cessation of stockings in patients in the individualised treatment group with Villalta scores less than 5 with similar patients in the standard treatment group who continued stocking therapy showed a significant benefit in the standard treatment group, with seven needed to treat for the continuation of 18 more months therapy for the prevention of post-thrombotic syndrome when using the ISTH scoring method. However, there were no significant between-group differences when the original scoring method was used. This result indicates that the treatment effect shown in the OCTAVIA trial might be directed at mild post-thrombotic syndrome. The conclusion could be that compression after around 6 or 12 months benefits mainly patients with mild post thrombotic syndrome caused by oedema. Whether it is cost-effective in the long run to provide such patients with elastic compression stockings and thus prevent further damage due to venous hypertension, or whether post thrombotic syndrome in these patients is so mild that therapy may be forgone, should be assessed by a formal cost-effectiveness analysis to estimate the longterm costs and effects of this strategy.

From a pathophysiological point of view, compression in the (sub) acute phase would be expected to be more effective for prevention of post-thrombotic syndrome than compression at a later stage. Compression counteracts the acute increase of venous pressure caused by the obstructing thrombus and might thereby prevent secondary skin changes associated with oedema and inflammation. ${ }^{39,40}$ Additionally, compression restores venous flow and improves calf muscle function, which might as a result promote thrombus resolution and reduce vein wall remodeling, and thereby prevent post-thrombotic syndrome.41-43

Our study had some potential limitations. First, our study was designed and initiated at a time of grade $1 \mathrm{~A}$ evidence for the efficacy of elastic compression 
therapy for prevention of post-thrombotic syndrome. ${ }^{44}$ Therefore assessing the effective ness of elastic compression therapy itself was not defined as one of the study objectives (there is now some uncertainty about the efficacy of elastic compression). Second, definition of a non-inferiority margin is always subjective and the clinical relevance of meeting or not meeting a criterion by just a few percentage points could be debated, when the overall incidence of the event is around $30 \%$. We can, however, be confident that the individualised intervention was truly non-inferior, since the outcomes were numerically similar in both groups. Third, mortality was unevenly distributed between groups, with an imbalance mainly related to malignancy. However, we attributed this result to chance, as there was no biological plausibility for a true effect.

What do these outcomes mean for individual patients and health-care budgets? Individualised shortening of the duration of therapy based on the original Villalta scoring method is an effective and safe strategy that might be less demanding for patients. Additionally, an individualised therapy strategy has the potential to substantially reduce costs without increasing the incidence of moderate to severe post-thrombotic syndrome. Whether continuation of compression beyond 6 months with the intention to prevent mild post-thrombotic syndrome is cost-effective needs to be assessed. To obtain a more precise estimation of its effect on health-care budgets and to assess the long-term consequences of these strategies, a formal cost-effectiveness analysis should be done.

In conclusion, individualised duration of therapy with elastic compression stockings for the prevention of post-thrombotic syndrome was non-inferior to standard duration therapy of 24 months for patients with acute proximal deep vein thrombosis of the leg. Individualised duration of therapy resulted in shortened treatment duration of only 6 months in more than $50 \%$ of patients, and was safe and effective, and is therefore likely to enhance patients' wellbeing and reduce health-care costs. 


\section{References}

1 Prandoni P, Kahn SR. Post-thrombotic syndrome: prevalence, prognostication and need for progress. Br J Haematol 2009; 145: 286-95.

2 Kahn SR, Shrier I, Julian JA, et al. Determinants and time course of the postthrombotic syndrome after acute deep venous thrombosis. Ann Intern Med 2008; 149: 698-707.

3 Pesavento R, Villalta S, Prandoni P. The postthrombotic syndrome. Intern Emerg Med 2010; 5: 185-92.

4 Lubberts B, Paulino Pereira NR, Kabrhel C, Kuter DJ, DiGiovanni CW. What is the effect of venous thromboembolism and related complications on patient reported health-related quality of life? A meta-analysis. Thromb Haemost 2016; 116: 417-31.

5 Bergqvist $D$, Jendteg $S$, Johansen $L$, Persson $U$, Odegaard K. Cost of long-term complications of deep venous thrombosis of the lower extremities: an analysis of a defined patient population in Sweden. Ann Intern Med 1997; 126: 454-57.

6 Kahn SR, Hirsch A, Shrier I. Effect of postthrombotic syndrome on health-related quality of life after deep venous thrombosis. Arch Intern Med 2002; 162: 1144-48.

7 Brandjes DP, Buller HR, Heijboer $\mathrm{H}$, et al. Randomised trial of effect of compression stockings in patients with symptomatic proximal-vein thrombosis. Lancet 1997; 349: 75962.

8 Prandoni $\mathrm{P}$, Lensing $\mathrm{AW}$, Prins $\mathrm{MH}$, et al. Below-knee elastic compression stockings to prevent the post-thrombotic syndrome: a randomized, controlled trial. Ann Intern Med 2004; 141: 249-56.

$9 \quad$ Kahn SR, Shapiro S, Wells PS, et al. Compression stockings to prevent post-thrombotic syndrome: a randomised placebo-controlled trial. Lancet 2014; 383: 880-88.

10 Kearon C, Akl EA, Ornelas J, et al. Antithrombotic therapy for VTE disease: CHEST Guideline and Expert Panel Report. Chest 2016; 149: 315-52.

11 NICE. Venous Thromboembolism in adults: diagnosis and management, 2015. www.nice.org.uk/guidance/cg144 (accessed Nov 27, 2017).

12 Cardiovascular Disease Educational and Research Trust, European Venous Forum, North American Thrombosis Forum, International Union of Angiology, Union Internationale du Phlebologie. Prevention and treatment of venous thromboembolism: international consensus statement (guidelines according to scientific evidence). Clin Appl Thromb Hemost 2013; 19: 116-18.

13 CBO Richtlijn Diagnostiek. Preventie en behandeling van veneuze trombo-embolie en secundaire preventie van arteriele trombose. Kwaliteitsinstituut voor de Gezondheidszorg CBO. 2008. https://www.nvr.nl/cbo-richtlijnen (accessed Nov 27, 2017).

14 ten Cate-Hoek AJ. Elastic compression stockings-is there any benefit? Lancet 2014; 383: 851-53.

15 Labropoulos N, Gasparis AP, Caprini JA, Partsch H. Compression stockings to prevent postthrombotic syndrome. Lancet 2014; 384: 129-30.

16 Mol GC, van de Ree MA, Klok FA, et al. One versus two years of elastic compression stockings for prevention of post-thrombotic syndrome (OCTAVIA study): randomised controlled trial. BMJ 2016; 353: i2691.

17 ten Cate-Hoek AJ, ten Cate H, Tordoir J, Hamulyak K, Prins $\mathrm{MH}$. Individually tailored duration of elastic compression therapy in relation to incidence of the postthrombotic syndrome. J Vasc Surg 2010; 52: 132-38. 

prolonged treatment with compression stockings to prevent post-thrombotic sequelae: a randomized controlled trial. J Vasc Surg 2008; 47: 1015-21.

19 ten Cate-Hoek AJ, Bouman AC, Joore MA, Prins M, ten Cate H. The IDEAL DVT study, individualised duration elastic compression therapy against long-term duration of therapy for the prevention of post-thrombotic syndrome: protocol of a randomised controlled trial. BMJ Open 2014; 4: e005265.

Eklof B, Rutherford RB, Bergan JJ, et al. Revision of the CEAP classification for chronic venous disorders: consensus statement. J Vasc Surg 2004; 40: 1248-52.

Villalta S, Bagatella P, Piccioli A, Lensing A, Prins M, Prandoni P. Assessment of validity and reproducibility of a clinical scale for the post-thrombotic syndrome Haemostasis 1994; 24: 158a.

22 Aschwanden M, Jeanneret C, Koller MT, Thalhammer C, Bucher HC, Jaeger KA. Effect of prolonged treatment with compression stockings to prevent post-thrombotic sequelae: a randomized controlled trial. J Vasc Surg 2008; 47: 1015-21.

Partsch $\mathrm{H}$, Blättler W. Compression and walking versus bed rest in the treatment of proximal deep venous thrombosis with low molecular weight heparin. J Vasc Surg 2000; 32: 861-69.

Ginsberg JS, Hirsh J, Julian J, et al. Prevention and treatment of postphlebitic syndrome: results of a 3-part study. Arch Intern Med 2001; 161: 2105-09.

25 Prandoni $P$, Lensing AW, Bernardi E, Villalta S, Bagatella P, Girolami A. The diagnostic value of compression ultrasonography in patients with suspected recurrent deep vein thrombosis. Thromb Haemost 2002; 88: 402-06.

Kahn SR, Partsch H, Vedantham S, Prandoni P, Kearon C. Definition of post-thrombotic syndrome of the leg for use in clinical investigations: a recommendation for standardization. J Thromb Haemost 2009; 7: 879-83.

Aaronson NK, Muller M, Cohen PD, et al. Translation, validation, and norming of the Dutch language version of the SF-36 Health Survey in community and chronic disease populations. J Clin Epidemiol 1998; 51: 1055-68.

28 Brooks R. EuroQol: the current state of play. Health Policy 1996; 37: 53-72.

29 Kahn SR, Lamping DL, Ducruet T, et al. VEINES-QOL/Sym questionnaire was a reliable and valid disease-specific quality of life measure for deep venous thrombosis. J Clin Epidemiol 2006; 59: 1049-56.

30 van der Velden SK, Biemans AA, Nijsten T, Sommer A. Translation and validation of the Dutch VEINES-QOL/Sym in varicose vein patients. Phlebology 2014; 29: 227-35.

Bouman AC, Ten Cate-Hoek AJ, Dirksen CD, Joore MA. Eliciting patients' preferences for elastic compression stocking therapy after deep vein thrombosis: potential for improving compliance. J Thromb Haemost 2016; 14: 510-17.

Rothmann MD, Tsou HH. On non-inferiority analysis based on delta-method confidence intervals. J Biopharm Stat 2003; 13: 565-83.

33 Bouman AC, ten Cate-Hoek AJ, Ramaekers BL, Joore MA. Sample size estimation for noninferiority trials: frequentist approach versus decision theory approach. PLoS One 2015; 10: e0130531.

Lamping DL, Schroter S, Kurz X, Kahn SR, Abenhaim L. Evaluation of outcomes in chronic venous disorders of the leg: development of a scientifically rigorous, patient-reported measure of symptoms and quality of life. J Vasc Surg 2003; 37: 410-19. 
35 Walters SJ, Brazier JE. Comparison of the minimally important difference for two health state utility measures: EQ-5D and SF-6D. Qual Life Res 2005; 14: 1523-32.

36 Norman GR, Sloan JA, Wyrwich KW. The truly remarkable universality of half a standard deviation: confirmation through another look. Expert Rev Pharmacoecon Outcomes Res 2004; 4: 581-85.

37 GitHub contributors. Compression stockings to prevent postphlebitic syndrome, 2017. https://github.com/openMetaAnalysis/ Compression-stockings-to-prevent-postphlebitic-syndrome/blob/ master/README.md (accessed Nov 27, 2017).

Appelen D, van Loo E, Prins MH, Neumann MH, Kolbach DN. Compression therapy for prevention of post-thrombotic syndrome. Cochrane Database Syst Rev 2017; 9: Cd004174.

39 Meissner $\mathrm{MH}$, Wakefield TW, Ascher E, et al. Acute venous disease: venous thrombosis and venous trauma. J Vasc Surg 2007; 46 (suppl S): 25s-53s.

40 Perrin M, Ramelet AA. Pharmacological treatment of primary chronic venous disease: rationale, results and unanswered questions. Eur J Vasc Endovasc Surg 2011; 41: 117-25.

41 Cooley BC, Chen CY, Hess R, Schmeling G. Incomplete resolution of deep vein thrombosis under reduced flow conditions. Thromb Res 2013; 131: 55-58.

42 Mosti G, labichella ML, Partsch $\mathrm{H}$. Compression therapy in mixed ulcers increases venous output and arterial perfusion. J Vasc Surg 2012; 55: 122-28.

43 Flour M, Clark M, Partsch $\mathrm{H}$, et al. Dogmas and controversies in compression therapy: report of an International Compression Club (ICC) meeting, Brussels, May 2011. Int Wound J 2013; 10: 516-26.

44 Kearon C, Kahn SR, Agnelli G, Goldhaber S, Raskob GE, Comerota AJ. Antithrombotic therapy for venous thromboembolic disease: American College of Chest Physicians evidence-based clinical practice guidelines (8th edn). Chest 2008; 133 (suppl 6): 454S545 s. 


\section{Supplementary appendix}

\section{Supplement to the method section}

\section{$\underline{\text { Treatment protocols for the initial phase }}$}

\section{Prespecified treatment protocols}

Before study start the use of three different management strategies for the initial phase was agreed upon. The initial phase is defined as the acute phase after DVT until the acute edema has disappeared.

For each participating center only one of three strategies was applied throughout the study.

1. The leg was bandaged with short stretch bandages to a compression of 30-40 mm Hg, worn day and night and redressed twice per week.

2. Compression hosiery with $35 \mathrm{~mm} \mathrm{Hg}$ compression was prescribed (Mediven Struva 35, Medi, Breda, the Netherlands), and worn day and night.

3. No initial compression therapy was applied.

After the initial phase, a custom-fitted, flat-knitted, knee length graduated compression stocking Mediven $550^{\circledR}$ class III (ankle pressure $40 \mathrm{~mm} \mathrm{Hg}$ ) was prescribed for all patients. Compression therapy with the elastic compression stockings was started immediately after the initial phase, so there was no period without compression in between, with exception of the patients who did not receive compression in the initial phase. Patients received two new stockings every year. Patients were advised to wear the stockings during the daytime. 


\section{Quality of life questionnaires}

\section{EQ5D}

EQ5D questionnaire consists of items covering five dimensions of generic health related quality of life (mobility, self-care, usual activity, pain and anxiety (1). Health state preferences, expressed as utility scores) that are calculated with a scoring function based on preferences of a general public (2997 respondents from United Kingdom) and scores on each item(2). The range of the score is 0.59 to 1 whereby -0.59 suggests health state worse than death, 0 refers to death and 1 indicates perfect health (3).

\section{Short Form Health Survey (SF36)}

SF36 version 2 was used in this study. This questionnaire was developed by a multi-year, multi-site study to explain variations in patient outcomes. It consists of 36 questions covering several health domains: physical functioning, physical role functioning, emotional role functioning, social role functioning, mental health, bodily pain, vitality and general health perceptions(4). Score calculations was based on standard methods as proposed by Brazier \& Roberts (5) and van der Zee(6). Recoding of the items is done in a way that higher scores suggest better quality of life.

\section{Venous Insufficiency Epidemiological and Economic Study (VEINES-QoL)}

VEINES-QoL contains 26 items on the following topics: DVT-related symptoms, limitations in daily activities, time of day that the leg complaint is of greatest intensity, changes in the problems in the last year and the psychological impact (7). Calculation of the sum score was done, by standardizing the scores on each item and calculating the T-score whereby the mean is 50 and the standard deviation is 10 . We also computing the sum score based on the intrinsic method as recommended by Bland et al.(8), whereby each item score (i) is recoded to (i1)/(k-1) with $k$ referring to the number of categories. Based on the formula each 
items score has a value between 0 and 1 and the average is the final score. Also in this case higher scores suggest better quality of life. The language of the overall questionnaire that included the described sub-questionnaires was Dutch for the Dutch centres and Italian for the Italian centres.

Table S-1 Villalta scores at each visit, mean (SD)

\begin{tabular}{|c|c|c|c|c|c|c|}
\hline \multirow[b]{2}{*}{$\begin{array}{l}\text { Visit } \\
\text { (N) }\end{array}$} & \multicolumn{3}{|c|}{$\begin{array}{l}\text { Individualised duration stockings } \\
\qquad(\mathrm{n}=432)\end{array}$} & \multicolumn{3}{|c|}{$\begin{array}{l}\text { Standard duration stockings } \\
\qquad(\mathrm{n}=424)\end{array}$} \\
\hline & $\begin{array}{l}\text { Villalta } \\
\text { total } \\
\text { score }\end{array}$ & $\begin{array}{l}\text { Symptoms } \\
\text { score }\end{array}$ & $\begin{array}{l}\text { Signs } \\
\text { score }\end{array}$ & $\begin{array}{l}\text { Villalta } \\
\text { total } \\
\text { score }\end{array}$ & $\begin{array}{l}\text { Symptoms } \\
\text { score }\end{array}$ & $\begin{array}{l}\text { Signs } \\
\text { score }\end{array}$ \\
\hline $\begin{array}{l}3 \text { months } \\
(399,400)\end{array}$ & $4 \cdot 06(3 \cdot 58)$ & $2 \cdot 38(2 \cdot 62)$ & $1.58(1.69)$ & $4 \cdot 37(3.82)$ & $2 \cdot 55(2 \cdot 75)$ & $1 \cdot 76(1 \cdot 81)$ \\
\hline $\begin{array}{l}6 \text { months } \\
(400,396)\end{array}$ & $3.50(3.59)$ & $1 \cdot 86(2 \cdot 18)$ & $1.51(1.73)$ & $3.84(3.66)$ & $2 \cdot 12(2 \cdot 47)$ & $1.67(1.80)$ \\
\hline $\begin{array}{l}12 \text { months } \\
(377,383)\end{array}$ & $3 \cdot 81(3 \cdot 70)$ & $2 \cdot 14(2 \cdot 50)$ & $1 \cdot 54(1 \cdot 64)$ & $4.03(3.93)$ & $2 \cdot 33(2 \cdot 72)$ & $1 \cdot 63(1 \cdot 81)$ \\
\hline $\begin{array}{l}24 \text { months } \\
(355,359)\end{array}$ & $4 \cdot 17(3 \cdot 83)$ & $2 \cdot 43(2 \cdot 65)$ & $1.59(1.67)$ & $3.56(3.66)$ & $2 \cdot 03(2 \cdot 52)$ & $1 \cdot 50(1.81)$ \\
\hline
\end{tabular}

Table S-2 Villalta severity category, $\mathrm{n}(\%)$

\begin{tabular}{|c|c|c|c|c|c|c|c|c|}
\hline \multirow[b]{3}{*}{$\begin{array}{l}\text { Visit } \\
\text { (N) }\end{array}$} & \multirow{2}{*}{\multicolumn{4}{|c|}{$\begin{array}{l}\text { Individualised duration stockings }(n=432) \\
\text { Villalta severity category }\end{array}$}} & \multirow{2}{*}{\multicolumn{4}{|c|}{$\begin{array}{c}\text { Standard duration stockings }(n=424) \\
\text { Villalta severity category }\end{array}$}} \\
\hline & & & & & & & & \\
\hline & $\begin{array}{l}\text { None } \\
(0-4)\end{array}$ & $\begin{array}{l}\text { Mild } \\
(5-9)\end{array}$ & $\begin{array}{l}\text { Moderate } \\
(10-14)\end{array}$ & $\begin{array}{l}\text { Severe } \\
(\geq 15)^{*}\end{array}$ & $\begin{array}{l}\text { None } \\
(0-4)\end{array}$ & $\begin{array}{l}\text { Mild } \\
(5-9)\end{array}$ & $\begin{array}{l}\text { Moderate } \\
(10-14)\end{array}$ & $\begin{array}{l}\text { Severe } \\
(\geq 15)^{*}\end{array}$ \\
\hline $\begin{array}{l}3 \text { months } \\
(399,400)\end{array}$ & $248(62 \cdot 3)$ & $108(27 \cdot 1)$ & $38(9 \cdot 5)$ & $5(1 \cdot 2)$ & $250(62 \cdot 5)$ & $96(24 \cdot 0)$ & $46(11 \cdot 5)$ & $8(1 \cdot 9)$ \\
\hline $\begin{array}{l}6 \text { months } \\
(400,396)\end{array}$ & $286(71 \cdot 5)$ & $86(21 \cdot 5)$ & $25(6 \cdot 3)$ & $3(0 \cdot 8)$ & $275(69 \cdot 4)$ & $82(20 \cdot 7)$ & $32(8 \cdot 1)$ & $7(1 \cdot 7)$ \\
\hline $\begin{array}{l}12 \\
\text { months } \\
(377,383)\end{array}$ & $263(69 \cdot 8)$ & $88(23 \cdot 3)$ & $20(5 \cdot 3)$ & $6(1 \cdot 4)$ & $254(66 \cdot 3)$ & $82(21 \cdot 4)$ & $40(10 \cdot 4)$ & $7(1 \cdot 8)$ \\
\hline
\end{tabular}




\begin{tabular}{lllllllll}
\hline 24 & $218(61 \cdot 4)$ & $96(27 \cdot 0)$ & $37(10 \cdot 4)$ & $4(1 \cdot 1)$ & $259(72 \cdot 1)$ & $70(19 \cdot 5)$ & $25(7 \cdot 0)$ & $5(1 \cdot 4)$ \\
$\begin{array}{l}\text { months } \\
(355,359)\end{array}$ & & & & & & & \\
\hline
\end{tabular}

* Post thrombotic syndrome severity is rated as severe when the sum score is 15 or higher, or when a venous ulcer is present.

\section{Table S-3 Individual causes of mortality}

\section{Individualised duration stockings}

Non-small cell lung cancer

Non-small cell lung cancer

Metastatic lung cancer

Adenocarcinoma, primary origin not established

Cerebrovascular accident

Metastatic rectum cancer

Metastatic caecum cancer

Patient found dead in chair, cause of death not established

Brain stem infarction with haemorrhagic transformation

Patient found dead in chair, cause of death not established

Metastatic sarcoma

Acute lymphatic leukaemia

Ovarian cancer

Lung cancer

Acute lymphatic leukaemia

Diffuse metastatic malignancy of unestablished origin

Vascular dementia, Parkinson's disease

\section{Standard duration stockings}

Cause of death unknown

Metastatic oesophagus cancer

Prostate cancer 


\section{Metastatic breast cancer \\ Oesophagus cancer \\ Brain cancer \\ Pneumonia}

An independent adjudication committee adjudicated the causes of death.

\section{Table S-4 Self-reported use of stockings by study visit}

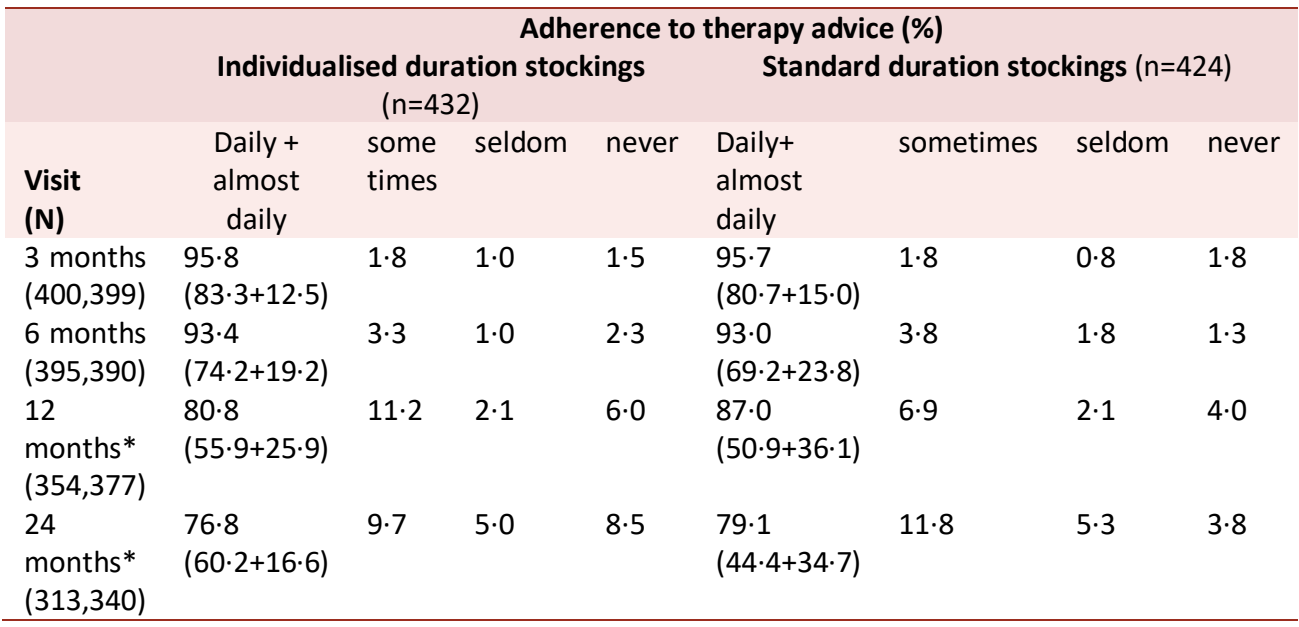

* Adherence to therapy advice differs for patients that are instructed to stop compression therapy and those that are instructed to continue compression therapy. At the 12-month visit 236 patients were instructed to stop elastic compression therapy and another 47 were given the advice to stop compression at the 24 month-visit. Daily +almost daily means that they do not wear stockings for at least $80 \%$ of the time. For those that are instructed to continue wearing elastic compression therapy 118 patients at the 12-month visit and 30 patients at the 24-month visit Daily + almost daily means that they do wear stockings for at least $80 \%$ of the time. 
Table S-5. Hazard ratio for post thrombotic syndrome (intention-to-treat and per protocol population)

\begin{tabular}{|c|c|c|c|}
\hline $\begin{array}{l}\text { Post } \\
\text { events*ף }\end{array}$ & $\begin{array}{l}\text { Individualised } \\
\text { duration } \\
\text { stockings }\end{array}$ & $\begin{array}{l}\text { Standard } \\
\text { duration } \\
\text { stockings }\end{array}$ & $\begin{array}{l}\text { Hazard ratio } \\
(95 \% \mathrm{Cl})\end{array}$ \\
\hline \multicolumn{4}{|l|}{ Primary outcome } \\
\hline Intention-to- treat analysis ${ }^{+}$ & $125 / 432(28 \cdot 9 \%)$ & $118 / 424(27 \cdot 8 \%)$ & $1 \cdot 13(0 \cdot 88-1 \cdot 46)$ \\
\hline Per protocol analysis ${ }^{\ddagger}$ & $117 / 361(32 \cdot 4 \%)$ & $117 / 397(29 \cdot 5 \%)$ & $1 \cdot 18(0 \cdot 91-1.53)$ \\
\hline
\end{tabular}

*IDEAL scoring: Villalta score of $>5$ at two consecutive visits at least 3 months apart $(9,10)$ ๆ cumulative incidence 730 days of follow up. HR adjusted for center, age, sex and BMI category (cut-off 26) ${ }^{\dagger}$ Of the 865 Patients in the intention-to-treat analysis, 856 were included in the time to event analysis. The 9 patients ( 5 for individualised duration and 4 for standard duration) were excluded due to recurrent venous thrombosis in the leg within the first six months). ${ }^{\ddagger}$ Of 865 patients 773 were included in the per protocol analysis. 61 patients were excluded in the individualised duration group (20 withdrew, 9 lost-to-follow-up, 5 late exclusions due to recurrent venous thrombosis in the leg within the first six months, 17 died and 10 crossed over to standard duration treatment). 46 patients were excluded in the standard duration group (17 withdrew, 3 lost-to-follow-up, 4 late exclusions due to recurrent venous thrombosis in the leg within the first six months, 7 died and 15 indicated not to wear stockings at two or more visits).

Table S-6. Relative efficacy of individualised versus standard duration of treatment among prespecified subgroups

\begin{tabular}{|c|c|c|c|c|}
\hline & $\begin{array}{l}\text { Individualised } \\
\text { duration } \\
\text { stockings } \\
\mathrm{N} / \mathrm{N}(\%)\end{array}$ & $\begin{array}{l}\text { Standard } \\
\text { duration } \\
\text { stockings } \\
\mathrm{N} / \mathrm{N}(\%)\end{array}$ & $\begin{array}{l}\text { HR } \\
(95 \% \mathrm{Cl})\end{array}$ & $\begin{array}{l}\text { P-value for } \\
\text { interaction }\end{array}$ \\
\hline \multicolumn{5}{|l|}{ Sex } \\
\hline Male & $73 / 249(29 \cdot 3)$ & $66 / 249(26 \cdot 5)$ & $1 \cdot 19(0 \cdot 86-1 \cdot 67)$ & $0 \cdot 30$ \\
\hline Female & $52 / 183(28 \cdot 4)$ & $52 / 175(29 \cdot 7)$ & $1 \cdot 06(0 \cdot 72-1 \cdot 56)$ & 0.76 \\
\hline
\end{tabular}




\begin{tabular}{|c|c|c|c|c|}
\hline \multicolumn{5}{|l|}{ BMI } \\
\hline$<26 \mathrm{~kg} / \mathrm{m}^{2}$ & $43 / 171(25 \cdot 1)$ & $43 / 186(23 \cdot 1)$ & $1 \cdot 23(0 \cdot 81-1 \cdot 91)$ & $0 \cdot 31$ \\
\hline$\geq 26 \mathrm{~kg} / \mathrm{m}^{2}$ & $82 / 261(31 \cdot 4)$ & $75 / 238(31 \cdot 5)$ & $1 \cdot 08(0 \cdot 79-1 \cdot 48)$ & 0.64 \\
\hline \multicolumn{5}{|l|}{ Age category (years) } \\
\hline$<40$ & $12 / 35(34 \cdot 3)$ & $9 / 53(17 \cdot 0)$ & $3 \cdot 69(1 \cdot 42-9 \cdot 63)$ & 0.008 \\
\hline $40-65$ & $76 / 253(30 \cdot 0)$ & $84 / 254(33 \cdot 1)$ & $0 \cdot 96(0 \cdot 70-1 \cdot 31)$ & $0 \cdot 78$ \\
\hline$>65$ & $37 / 144(25 \cdot 7)$ & $25 / 116(21 \cdot 6)$ & $1 \cdot 26(0 \cdot 76-2 \cdot 10)$ & $0 \cdot 37$ \\
\hline \multicolumn{5}{|c|}{ Most proximal extent of DVT } \\
\hline $\begin{array}{l}\text { Iliac or common } \\
\text { femoral vein }\end{array}$ & $29 / 96(30 \cdot 2)$ & $25 / 88(28 \cdot 4)$ & $1 \cdot 25(0 \cdot 73-2 \cdot 14)$ & $0 \cdot 42$ \\
\hline Femoral & $96 / 326(29 \cdot 4)$ & $93 / 313(28 \cdot 1)$ & $1 \cdot 11(0 \cdot 83-1 \cdot 47)$ & $0 \cdot 50$ \\
\hline Popliteal vein & & & & \\
\hline
\end{tabular}

Post thrombotic syndrome assessed by Villalta score according to IDEAL scoring (Villalta score of $>5$ at two consecutive visits at least 3 months apart (8)). Percentages are given for intentionto-treat population.

Table S-7 Quality of life scores at each study visit, mean (SD)

\begin{tabular}{|c|c|c|c|c|c|c|c|}
\hline & \multicolumn{2}{|c|}{$\begin{array}{l}\text { Individualised } \\
\text { stockings }(\mathrm{N}=432)\end{array}$} & duration & $\begin{array}{l}\text { Standard } \\
(\mathrm{N}=424)\end{array}$ & \multicolumn{2}{|c|}{ duration } & stockings \\
\hline & Generic QO & & & & & & \\
\hline \multirow[t]{3}{*}{ Visit } & SF 36 & $\mathrm{n}$ & $\Delta$ from & SF 36 & $\mathrm{n}$ & $\Delta$ from & $\Delta$ \\
\hline & & & 1 & & & 1 & groups \\
\hline & & & month & & & month & \\
\hline 1 month & $0.62(0.06)$ & 357 & - & $0.61(0.06)$ & 332 & - & $0.61(0.06)$ \\
\hline 3 months & $0.63(0.06)$ & 363 & +0.01 & $0.63(0.06)$ & 354 & +0.02 & $0.63(0.06)$ \\
\hline 6 months & $0 \cdot 80(0.13)$ & 356 & $+0 \cdot 18$ & $0.80(0.13)$ & 346 & $+0 \cdot 19$ & $0 \cdot 80(0 \cdot 13)$ \\
\hline 12 months & $0 \cdot 81(0 \cdot 13)$ & 335 & $+0 \cdot 19$ & $0.82(0.12)$ & 327 & $+0 \cdot 19$ & $0.82(0 \cdot 12)$ \\
\hline \multirow[t]{2}{*}{24 months } & $0.82(0.12)$ & 304 & $+0 \cdot 20$ & $0.82(0.13)$ & 293 & +0.21 & $0 \cdot 82(0 \cdot 13)$ \\
\hline & EQ5D & & & & & & \\
\hline 1 month & $0.82(0.21)$ & 385 & - & $0.83(0.22)$ & 351 & - & $0 \cdot 83(0 \cdot 22)$ \\
\hline 3 months & $0 \cdot 85(0 \cdot 22)$ & 399 & +0.03 & $0.86(0.22)$ & 389 & +0.03 & $0 \cdot 86(0 \cdot 22)$ \\
\hline 6 months & $0 \cdot 88(0.19)$ & 384 & +0.05 & $0.86(0.20)$ & 377 & +0.03 & $0 \cdot 86(0 \cdot 20)$ \\
\hline 12 months & $0 \cdot 88(0 \cdot 20)$ & 364 & +0.06 & $0.87(0.21)$ & 358 & +0.04 & $0 \cdot 87(0 \cdot 21)$ \\
\hline 24 months & $0.90(0 \cdot 20)$ & 326 & +0.08 & $0.88(0.19)$ & 332 & +0.05 & $0 \cdot 88(0 \cdot 19)$ \\
\hline
\end{tabular}




\begin{tabular}{|c|c|c|c|c|c|c|c|}
\hline & \multicolumn{7}{|c|}{ Disease specific QOL } \\
\hline & Veines Qol & $\mathrm{n}$ & $\Delta$ from & Veines Qol & $\mathrm{n}$ & $\Delta$ from & $\Delta$ \\
\hline & T score & & 1 & T score & & & groups \\
\hline & & & month & & & month & \\
\hline 1 month & $50 \cdot 3(9 \cdot 4)$ & 385 & - & $49 \cdot 8(10 \cdot 6)$ & 350 & - & $49 \cdot 8(10 \cdot 6)$ \\
\hline 3 months & $50 \cdot 5(9 \cdot 0)$ & 389 & $+0 \cdot 2$ & $49 \cdot 5(10 \cdot 9)$ & 374 & $-0 \cdot 3$ & $49 \cdot 5(10 \cdot 9)$ \\
\hline 6 months & $50 \cdot 7(9 \cdot 0)$ & 383 & $+0 \cdot 4$ & $49 \cdot 2(10 \cdot 9)$ & 368 & -0.6 & $49 \cdot 2(10 \cdot 9)$ \\
\hline 12 months & $50 \cdot 3(9 \cdot 5)$ & 360 & 0 & $49 \cdot 7(10 \cdot 5)$ & 349 & $-0 \cdot 1$ & $49 \cdot 7(10 \cdot 5)$ \\
\hline \multirow[t]{2}{*}{24 months } & $50 \cdot 0(10 \cdot 0)$ & 321 & $-0 \cdot 3$ & $50 \cdot 0(10 \cdot 0)$ & 314 & $+0 \cdot 2$ & $50 \cdot 0(10 \cdot 0)$ \\
\hline & \multicolumn{7}{|c|}{ Veines Qol intrinsic } \\
\hline 1 month & $0 \cdot 63(0 \cdot 17)$ & 385 & - & $0.63(0.19)$ & 350 & - & $0.63(0.19)$ \\
\hline 3 months & $0 \cdot 73(0 \cdot 15)$ & 389 & $+0 \cdot 1$ & $0 \cdot 72(0 \cdot 17)$ & 374 & $+0 \cdot 09$ & $0.72(0.17)$ \\
\hline 6 months & $0 \cdot 76(0 \cdot 14)$ & 383 & $+0 \cdot 13$ & $0 \cdot 73(0 \cdot 16)$ & 368 & $+0 \cdot 1$ & $0.73(0.16)$ \\
\hline 12 months & $0 \cdot 74(0 \cdot 15)$ & 360 & $+0 \cdot 11$ & $0 \cdot 74(0 \cdot 15)$ & 349 & $+0 \cdot 11$ & $0.74(0.15)$ \\
\hline 24 months & $0 \cdot 76(0 \cdot 14)$ & 321 & $+0 \cdot 13$ & $0 \cdot 75(0.15)$ & 314 & $+0 \cdot 12$ & $0.75(0.15)$ \\
\hline
\end{tabular}

Higher scores indicate better quality of life. Abbreviations: QoL Quality of life, SF 36 Short Form $36{ }^{(4)}$ EQ5D Euro Qol 5 Dimensions (1), Veines Qol Venous Insufficiency Epidemiological and Economic Study-Quality of Life Questionnaire $(7,11)$, T score original calculation of mean scores ${ }^{(7)}$, intrinsic alternative method for calculation of mean scores ${ }^{(8)}$ 


\section{References}

1. Brooks R. EuroQol: the current state of play. Health Policy. 1996;37(1):53-72.

2. Dolan P. Modeling valuations for EuroQol health states. Med Care. 1997;35(11):1095108.

3. EuroQol--a new facility for the measurement of health-related quality of life. Health Policy. 1990;16(3):199-208.

4. Aaronson NK, Muller M, Cohen PD, Essink-Bot ML, Fekkes $M$, Sanderman R, et al. Translation, validation, and norming of the Dutch language version of the SF-36 Health Survey in community and chronic disease populations. J Clin Epidemiol. 1998;51(11):1055-68.

5. Brazier JE, Roberts J. The estimation of a preference-based measure of health from the SF-12. Med Care. 2004;42(9):851-9.

6. van der Zee KIS, R. Het meten van de algemene gezondheidstoestand met Rand-36. 2012.

7. Kahn SR, Lamping DL, Ducruet T, Arsenault L, Miron MJ, Roussin A, et al. VEINES$\mathrm{QOL} / \mathrm{Sym}$ questionnaire was a reliable and valid disease-specific quality of life measure for deep venous thrombosis. J Clin Epidemiol. 2006;59(10):1049-56.

8. Bland JM, Dumville JC, Ashby RL, Gabe R, Stubbs N, Adderley U, et al. Validation of the VEINES-QOL quality of life instrument in venous leg ulcers: repeatability and validity study embedded in a randomised clinical trial. BMC Cardiovasc Disord. 2015;15:85.

9. Villalta S B, P, Piccioli, A., Lensing, A., Prins, M. \& Prandoni, P. Assessment of validity and reproducibility of a clinical scale for the post-thrombotic syndrome Haemostasis1994; 24:[158a p.].

10. Kahn SR, Shrier I, Julian JA, Ducruet T, Arsenault L, Miron MJ, et al. Determinants and time course of the postthrombotic syndrome after acute deep venous thrombosis. Annals of internal medicine. 2008;149(10):698-707.

11. van der Velden SK, Biemans AA, Nijsten T, Sommer A. Translation and validation of the Dutch VEINES-QOL/Sym in varicose vein patients. Phlebology. 2014;29(4):227-35. 


\section{CHAPTER 0}

\section{Individually Shortened versus Standard Duration of Elastic Compression Therapy for the Prevention of Post-Thrombotic Syndrome: a Cost- Effectiveness Analysis}

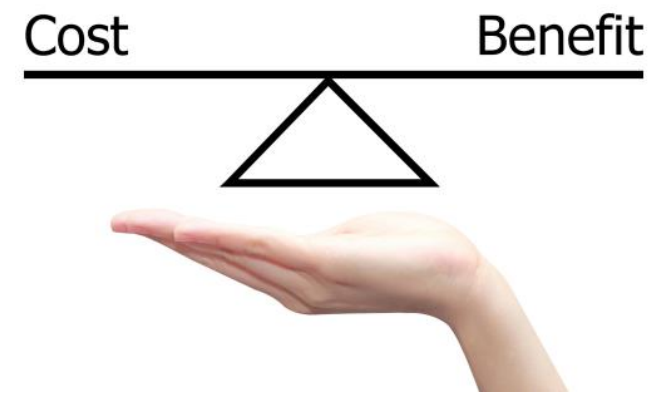

Amin EE, ten Cate-Hoek AJ, Bouman Ac, Meijer K, Tick LW, Middeldorp S, Mostard GJM, ten Wolde M, van den Heiligenberg SM, van Wissen S, van de Poel MH, Villalta S, Serné EH, Otten HM, Klappe E, Prandoni P, Prins MH, ten Cate $\mathrm{H}$, Joore MA

The Lancet Haematology. 2018 Nov; 5(11): e512- e519 


\section{Summary}

Background The IDEAL DVT study showed that it was safe to shorten the duration of elastic compression therapy on an individualised basis after deep vein thrombosis for prevention of post-thrombotic syndrome. In this study, we assessed the cost-effectiveness of this strategy.

Methods IDEAL DVT was a multicentre, randomised, non-inferiority trial that included patients with acute proximal deep vein thrombosis of the leg. After 6 months of elastic compression therapy, patients were randomly assigned (1:1) to the standard 2 years of elastic stocking compression therapy or shortened duration of compression therapy based on the patient's Villalta score. For our cost-effectiveness analysis, we assessed quality-adjusted life-years (QALYs), measured with the three-level version of EQ-5D (EQ-5D-3L; Dutch and UK tariff) and the 36-item Short Form Health Survey (SF-36), and costs in $€$ (health-care and societal perspective) according to the intention-to-treat approach. Data were collected at 3, 6, 12, and 24 months after diagnosis of thrombosis. We calculated incremental net monetary benefit using a QALY threshold of $€ 30000$, and obtained bootstrapped means and 95\% Cls. IDEAL DVT is registered with ClinicalTrials.gov, number NCT01429714.

Findings Between March 22, 2011, and July 1, 2015, 865 patients were enrolled in IDEAL DVT. 437 were assigned to individualised duration of elastic compression therapy and 428 to standard duration of elastic compression therapy. Nine patients were eventually excluded because of recurrent venous thromboembolism within 6 months after the first event. From a societal perspective, for every QALY lost measured with the EQ-5D Dutch tariff, cost savings were $€ 305.992$ (incremental net monetary benefit $€ 3205$, 95\% Cl 5025741), and for every QALY lost based on the Short-Form Six Dimension (SF-6D) utility score (derived from SF-36), cost savings were $€ 6030.941$ (€3540, 95\% Cl 1174-5953). Using the UK tariff for EQ-5D, the individualised strategy was more effective and less costly (€4071, 1452-6647). The probability that the 
individualised strategy was cost-effective was $99 \%$ at a threshold of $€ 30000$ per QALY (EQ-5D Dutch tariff).

Interpretation Individually shortened duration of elastic compression therapy was cost-effective compared with standard duration elastic compression therapy. Use of an individualised approach to elastic stocking compression therapy for the prevention of post-thrombotic syndrome after deep vein thrombosis could lead to substantial costs savings without loss in health-related quality of life.

\section{Introduction}

Post-thrombotic syndrome is a long-term consequence of deep vein thrombosis. 20-50\% of patients diagnosed with deep vein thrombosis develop postthrombotic syndrome within 2 years after diagnosis of a deep vein thrombus in the leg. ${ }^{1}$ The syndrome is irreversible and characterised by oedema, skin changes-which can range from mild skin signs to venous ulcers-and leg complaints. 2,3 Postthrombotic syndrome is associated with disability and decreased quality of life. As severity increases, quality of life worsens. ${ }^{4}$ Furthermore, post-thrombotic syndrome is associated with substantial economic costs. ${ }^{5,6}$ To prevent post-thrombotic syndrome, all patients with thrombosis of the leg are advised to wear elastic compression stockings for 2 years. ${ }^{7-9}$ A Cochrane metaanalysis ${ }^{10}$ found that compression therapy caused a $30 \%$ reduction in the occurrence of post-thrombotic syndrome. However, costs of the use of elastic compression stockings are not negligible. In the Netherlands alone, the cost of stockings for prevention of post-thrombotic syndrome was estimated to be $€ 2 \cdot 5$ million per year. ${ }^{11}$ Not all patients can apply and remove the stockings independently; in the Netherlands, €21 million is needed for home care to assist patients with the application of stockings. ${ }^{12-14}$ Hence, if the duration of elastic compression stocking treatment could be shortened in 
patients for whom it is safe to do so, a substantial burden to patients and society could be saved.

The IDEAL DVT study ${ }^{15}$ investigated individualised versus standard duration of elastic compression therapy for prevention of post-thrombotic syndrome. Most patients in the individualised group were able to stop treatment early; 236 (55\%) of 432 patients wore the stockings for only 6 months. No significant difference between groups was reported in the proportion of patients with postthrombotic syndrome at 24 months (odds ratio 1.06, 95\% Cl 0.78-1.44). However, a post-hoc analysis of 420 patients without symptoms at 1 year after diagnosis of thrombosis and with excellent adherence to therapy showed increased incidence of mild postthrombotic syndrome in patients who stopped stocking treatment early on the basis of the International Society on Thrombosis scoring method for the Villalta score (risk ratio $1 \cdot 6,95 \% \mathrm{Cl} 1 \cdot 2-2 \cdot 3$ ). To our knowledge, only two other studies have assessed variable duration of elastic compression therapy to prevent post-thrombotic syndrome, ${ }^{16,17}$ but neither assessed the cost-effectiveness of such strategies. We report a health economic evaluation of the IDEAL DVT study. We assessed the cost-effectiveness of individualised duration of elastic compression therapy compared with standard duration, both from a health-care perspective and from a societal perspective. Additionally, we assessed whether it was cost-effective to provide patients with mild post-thrombotic syndrome-as identified by a post-hoc analysis-with prolonged compression therapy.

\section{Methods}

Study design and participants in IDEAL DVT The IDEAL DVT study, a multicentre, randomised, single-blind, allocation-concealed, non-inferiority trial, was done at 12 hospitals in the Netherlands and two hospitals in Italy. ${ }^{15}$ Patients with acute proximal deep vein thrombosis of the leg, without pre-existing venous insufficiency (Clinical Etiological Anatomical and Pathophysiologic [CEAP] score 
with the Villalta score. Patients who were assigned to standard duration of stocking therapy were instructed to wear elastic Compression stockings for the entire 2-year duration of the study. Follow-up visits in the study were at 3, 6, 12, and 24 months after diagnosis of deep vein thrombosis. 865 patients were enrolled between March 22, 2011, and July 1, 2015; 437 were assigned to individualised duration and 428 to standard duration of treatment.15 The primary endpoint of IDEAL DVT was post-thrombotic syndrome at 24 months. IDEAL DVT is registered with ClinicalTrials.gov, number NCT01429714. Data inputs For our cost-effectiveness analysis, we used data on utilities (healthrelated quality of life weights), resource use, and productivity from the IDEAL DVT trial. ${ }^{11}$ In the trial, ${ }^{11}$ at a one-sided significance level of $5 \%$ and a power of $80 \%$, a sample size of 848 was required to test the hypothesis on the basis of an expected incidence of postthrombotic syndrome of $20-30 \%$. Loss to follow-up was expected to be less than $2 \%$, thus a sample of 864 was needed. Costs and utilities were collected prospectively for every patient at 3, 6, 12, and 24 months after diagnosis of acute deep vein thrombosis. In cases of recurrent ipsilateral thrombosis within the first 6 months after diagnosis, patients were excluded from further assessment. Utilities were measured with the three-level version of EQ-5D (EQ-5D-3L) and the 36-item Short Form Health Survey (SF-36) version 2. ${ }^{18-}$ 20 Patients received a link by email to an online questionnaire. Patients that did not have internet received a paper version via mail. The questionnaires were completed the day before the clinic visit. EQ-5D-3L is made up of five questions with three options (no, moderate, or severe problems) regarding five dimensions of general health status (mobility, selfcare, usual activity, pain, and anxiety). For calculation of utilities from EQ-5D-3L scores, we used both the Dutch tariff and the UK tariff. ${ }^{21,22}$ SF-36 consists of 36 questions regarding the health domains of physical functioning, physical role functioning, emotional role functioning, social role functioning, mental health, bodily pain, vitality, and general health perceptions. From SF-36 scores, we derived the Short-Form Six-Dimension (SF$6 D)$ utility score. ${ }^{23}$ For the purposes of this study we developed a cost 
questionnaire containing items to assess use of healthcare resources (general practitioner, medical specialist, anticoagulation clinic, physiotherapist, need for home care, use of elastic compression stockings, and medication use), patient costs (travel costs to medical facilities), and indirect costs (work productivity loss) related to leg complaints. For work productivity loss, we applied the prospective modular Productivity and Disease Questionnaire. ${ }^{24}$ This questionnaire used a recall period of 3 months. The guideline on health economic evaluation drafted by the Netherlands Health Care Institute was used for the standard unit price for the items in each cost category. ${ }^{25}$ We calculated the costs related to work productivity loss using the friction cost method as recommended in the Netherlands. ${ }^{26}$ The friction cost method takes the employer's perspective and only counts the costs of work productivity lost until another employee takes over the patient's work, assuming that long-term absentees are replaced. ${ }^{26}$ The current friction period is set to 12 weeks in the Dutch health economic guideline. ${ }^{25}$ All reported costs were in $€$ at 2015 price levels.

\section{Economic evaluation}

The outcome for the economic evaluation was quality adjusted life-years (QALYS). A QALY combines mortality and quality of life into a single index, multiplying time by utility. 1 QALY represents 1 life-year in perfect health. Hence, in this analysis a patient could experience a maximum of 2 QALYs. We derived QALYs from utilities on the basis of EQ-5D-3L (Dutch and UK tariffs) and SF-6D scores. Because the intervention only started at 6 months after enrolment of each patient, we used the group average (ie, mean) for the calculation of QALY in the first 6 months. After 6 months, we assumed for each patient that the utility between two consecutive measurements would equal the mean of those two measurements. Because the cost questionnaire had a 3-month recall period, we interpolated the costs. Similar to the analysis of QALYs, we also used the group mean for the costs in the first 6 months for each patient. Subsequently, for each 
patient, we multiplied the costs reported at 12 months by 2 and the mean of the costs reported at 12 and 24 months by 4 . We calculated health-care costs and societal costs. Societal costs consist of health-care and patient and family costs, and costs associated with lost productivity. We determined cost-effectiveness by relating the incremental costs to the incremental QALYs over the 2-year time horizon. Additionally, we calculated incremental net monetary benefits by multiplying incremental QALYs by the customary threshold of $€ 30000$ and subtracting the incremental costs. A positive incremental net monetary benefit indicates cost-effectiveness.

\section{Ethics approval}

Ethics approval was obtained from the institutional review board of Maastricht University Medical Centre (Maastricht, Netherlands; number 32073.068.10) and was ratified by the ethical review board of the participating centres. All participants gave written informed consent before any study-related activity was done.

\section{Statistical analysis}

We used the intention-to-treat approach for data analysis. We imputed missing data with single stochastic regression imputation, using chained equations to prevent loss of statistical power and to decrease the probability of obtaining biased estimates. We assumed data were missing at random (ie, missing conditional on other covariates). We used predictive mean matching to draw the imputed values, because this method is more robust to misspecification of the imputation model and non-normality of continuous variables compared with standard regression imputation. ${ }^{27}$ We assessed group comparability for differences in demographic and clinical characteristics, both for differences in QALYs and for costs. We assessed differences in demographic and clinical characteristics with an independent sample t test or Mann-Whitney $U$ test depending on the normality of data distribution, and for categorical variables we 
used $\chi^{2}$. We tested differences in quality of life over time with split plot ANOVA analysis. We used bootstrapping to obtain $95 \%$ Cls for QALYs, costs, and incremental net monetary benefits. In this method, cost and effectiveness (QALYS) pairs are randomly drawn from the original data with replacement until the size of the original sample is achieved. We drew 5000 bootstrap samples to obtain a stable result. We presented the results of the bootstrap simulation in a cost-effectiveness plane in which the incremental costs were plotted against incremental QALYs. We obtained Cls based on the 2.5th and 97.5th percentiles. We obtained cost-effectiveness acceptability curves to determine the probability of costeffectiveness for individualised duration of elastic compression stockings versus standard duration of stockings for different thresholds for a QALY. Because the study predominantly investigated Dutch patients, we considered analysis with the QALY based on the EQ-5D-3L Dutch tariff as the base case. We did sensitivity analyses with QALYs based on the more widely used EQ-5D-3L UK tariff (to increase generalisability of our results and hence usefulness for other countries) and the SF-6D. We did two additional analyses: a sensitivity analysis with complete cases (ie, without missing data), and a subgroup analysis in a subset of patients with low Villalta scores who stopped treatment at 6 months compared with patients with similar Villalta scores within the standard treatment group who continued stocking therapy until the end of study. Analyses were done in SPSS version 23 and Excel version 10.

\section{Results}

Between March 22, 2011, and July 1, 2015, 865 patients were enrolled in the study. 437 were randomly assigned to individualised duration of elastic compression therapy and 428 to standard duration of elastic compression therapy. Nine patients were eventually excluded because of recurrent venous thromboembolism within 6 months after the first event. Before imputation, the 
proportion of missing EQ-5D questionnaires was 68 (8\%) of 856 at 3 months, 95 (11\%) of 856 at 6 months, 134 (16\%) of 856 at 12 months, and 198 (23\%) of 856 at 24 months. For the SF-6D and cost questionnaires, these proportions were $139(16 \%)$ of 856 at 3 months, 154 (18\%) of 856 at 6 months, 194 (23\%) of 856 at 12 months, and 259 (30\%) of 856 at 24 months. We found no statistically significant differences between the group utilities at any timepoint (table 1).

\begin{tabular}{|c|c|c|c|}
\hline & $\begin{array}{l}\text { Individualised duration of } \\
\text { compression stocking use } \\
(n=432)\end{array}$ & $\begin{array}{l}\text { Standard 2-year duration } \\
\text { of compression stocking } \\
\text { use }(n=424)\end{array}$ & p value \\
\hline EQ-5D Dutch tariff & .. & .. & 0.26 \\
\hline 3 months & $0.8717(0.2063)$ & $0.8739(0.1986)$ & .. \\
\hline 6 months & $0.8903(0.1932)$ & $0.8852(0.1774)$ & .. \\
\hline 12 months & $0.8720(0.2319)$ & $0.8752(0.2069)$ & . \\
\hline 24 months & $0.8640(0.2691)$ & $0.8848(0.1974)$ & .. \\
\hline EQ-5D UK tariff & .. & .. & 0.36 \\
\hline 3 months & $0.8524(0.2220)$ & $0.8541(0.2235)$ &. \\
\hline 6 months & $0.8873(0.1839)$ & $0.8658(0.1995)$ & .. \\
\hline 12 months & $0.8748(0.2060)$ & $0.8639(0.2182)$ & . \\
\hline 24 months & $0.8877(0.2191)$ & $0.8809(0.1936)$ & $\cdot$ \\
\hline$S F-6 D$ & $\cdot$. & .. & 0.38 \\
\hline 3 months & $0.6258(0.0560)$ & $0.6295(0.0552)$ &.. \\
\hline 6 months & $0.7963(0.1252)$ & $0.7887(0.1279)$ & .. \\
\hline 12 months & $0.8055(0.1268)$ & $0.8093(0.1266)$ & .. \\
\hline 24 months & $0.8093(0.1326)$ & $0.8082(0.1355)$ & .. \\
\hline \multicolumn{4}{|l|}{ QALYs over 2 years' time horizon } \\
\hline Based on EQ-5D Dutch tariff & $1.7487(0.3223)$ & $1.7602(0.2509)$ & 0.38 \\
\hline Based on EQ-5D UK tariff & $1.7543(0.2746)$ & $1.7373(0.2651)$ & $0 \cdot 51$ \\
\hline Based on SF-6D & $1.5628(0.1747)$ & $1.5633(0.1773)$ & 0.22 \\
\hline
\end{tabular}

QALYs based on the EQ-5D-3L Dutch tariff were 1.7487 (SD 0.3223, 95\% Cl 1.7177-1.7778) for individualised duration of therapy and 1.7602 (0.2509, 1.7355-1.7831) for standard duration of therapy. With the SF-6D, QALYs were $1.5628(0.1747,1.5458-1.5788)$ for individualised duration of therapy and 
$1.5633(0.1773,1.5462-1.5801)$ for standard duration of therapy. QALYs based on the EQ-5D-3L UK tariff were $1.7543(0.2746,1.7273-1.7790)$ for individualised duration of therapy and $1.7373(0.2651,1.7110-1.7619)$ for standard duration of therapy. The mean societal costs were lower for individualised duration of compression therapy ( $€ 8251,95 \% \mathrm{Cl} 6690$ to 9690 ) compared with standard duration of therapy ( $€ 11803,10020$ to 13651; table 2). The incremental societal costs amounted to $-€ 3552(95 \% \mathrm{Cl}-5793$ to -1241 ; table 2). In both the individualised duration of therapy and the standard duration of therapy groups, the mean societal costs mainly consisted of health-care costs (€6022 [95\% Cl 5003 to 7061] for individualised duration, and €9740 [8054 to 11561] for standard duration; table 3). Health-care costs were mostly for home care ( $€ 4417.01$ for individualised duration and $€ 7438.60$ for standard duration; table 3). Patient and family and productivity costs were slightly lower for individualised duration of stockings as compared with standard duration ( $€ 563$ [95\% $\mathrm{Cl} 426$ to 779] vs $€ 601$ [ 485 to 749 ]; table 3). The mean incremental costeffectiveness ratio in the base case equalled €305.992 saved per QALY lost with the EQ-5D-3L Dutch tariff (table 4). When QALYs were based on the SF-6D, the mean incremental costeffectiveness ratio was €6030.941 saved per QALY lost (table 4). With the EQ-5D-3L UK tariff, the intervention was found to be more effective and cost saving (table 4). The incremental net monetary benefit in the base case was $€ 3205$ (95\% Cl 502-5741) with the EQ-5D-3L Dutch tariff, €4071 (1452-6647) with the EQ-5D-3L UK tariff, and $€ 3540$ (1174-5953) with SF-6D. The uncertainty surrounding the incremental costs and QALYs is shown in figure 1. The probability for the individualised strategy to be cost-effective was $99 \%$ at a threshold of $€ 30000$ per QALY (on the basis of the EQ-5D-3L Dutch tariff; figure 2). The probability that the study was cost-effective at thresholds between $€ 7000$ and $€ 82000$ was $90 \%$ at the lowest (figure 2). Complete case analysis showed that individualised shortened duration of compression therapy was more effective and cost saving compared with standard duration of compression therapy, irrespective of the instrument used to assess utilities for QALYs. We 
compared the cost-effectiveness of shortened duration of therapy in the individualised intervention group for a subgroup patients who did not wear elastic compression stockings after 6 months compared with patients in the standard duration group who had similar Villalta scores and continued wearing the stockings until the end of the study. Although there was a slightly larger difference in post-thrombotic syndrome between these subgroups than between the entire individualised treatment group compared with the entire standard treatment group, we found slightly more cost savings for the individualised treatment subgroup ( $€ 3850$ compared with $€ 3536$ for the entire population) and a gain in QALYs as compared with the overall population of patients in the IDEAL DVT trial. 


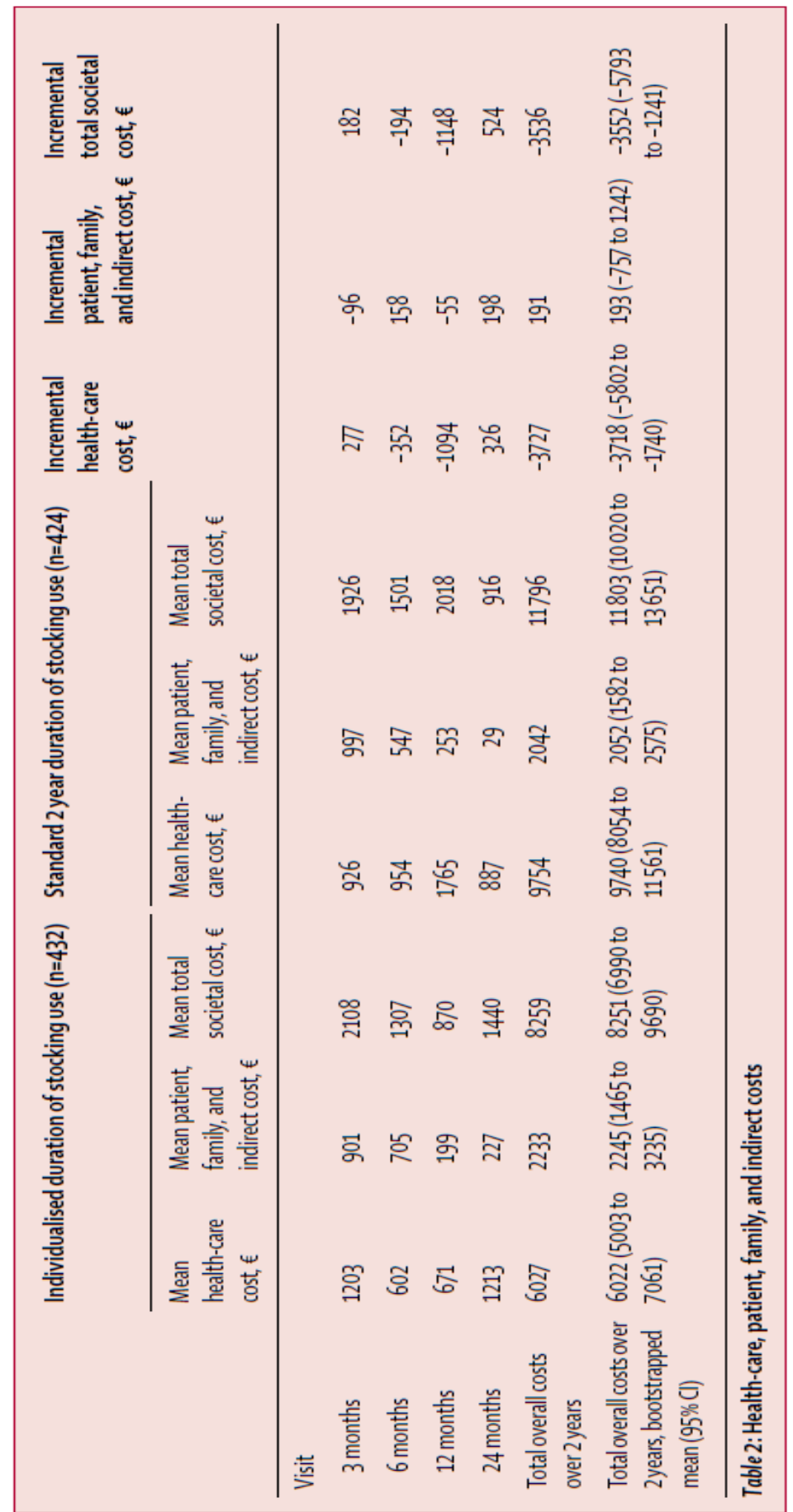




\begin{tabular}{|c|c|c|c|c|c|}
\hline & \multirow[t]{2}{*}{ Unit cost, $€$} & \multicolumn{2}{|c|}{$\begin{array}{l}\text { Individualised duration of } \\
\text { stocking use }(n=432)\end{array}$} & \multicolumn{2}{|c|}{$\begin{array}{l}\text { Standard 2-year duration } \\
\text { of stocking use }(n=424)\end{array}$} \\
\hline & & $\begin{array}{l}\text { Number } \\
\text { of users }\end{array}$ & Mean cost, $€$ & $\begin{array}{l}\text { Number } \\
\text { of users }\end{array}$ & Mean cost, $€$ \\
\hline \multicolumn{6}{|l|}{ Health-care costs } \\
\hline General practitioner & $33-50$ & 94 & $188 \cdot 27$ & 107 & $200 \cdot 66$ \\
\hline $\begin{array}{l}\text { General practitioner out of } \\
\text { hours care }\end{array}$ & $33-50$ & 13 & 36.87 & 13 & 76.03 \\
\hline Medical specialist & 91 & 139 & 494.85 & 145 & $537 \cdot 70$ \\
\hline Medication use & $1.07-74.78$ & 432 & $92 \cdot 55$ & 424 & $150 \cdot 12$ \\
\hline Anticoagulation clinic & 9 & 316 & $178 \cdot 93$ & 299 & $227 \cdot 60$ \\
\hline Elastic compression stockings* & 50 & $432^{*}$ & $127 \cdot 30$ & 424 & $339 \cdot 28$ \\
\hline Physiotherapy & $33-50$ & 50 & $491 \cdot 30$ & 48 & 783.87 \\
\hline Home care & $23-73$ & 76 & $4417 \cdot 01$ & 62 & 7438.60 \\
\hline $\begin{array}{l}\text { Total health-care costs } \\
\text { bootstrapped mean }(95 \% \mathrm{Cl})\end{array}$ & .. &. & $\begin{array}{l}6022 \\
(5003-7061)\end{array}$ & .. & $\begin{array}{l}9740 \\
(8054-11561)\end{array}$ \\
\hline \multicolumn{6}{|l|}{ Patient and family costs } \\
\hline Travel costs & $2 \cdot 66-43 \cdot 14$ & 55 & 88.03 & 55 & $80 \cdot 53$ \\
\hline Family care & 14 & 74 & $476 \cdot 94$ & 68 & 518.82 \\
\hline $\begin{array}{l}\text { Total patient and family costs, } \\
\text { bootstrapped mean }(95 \% \mathrm{Cl})\end{array}$ & .. &. & $\begin{array}{l}563 \\
(426-779)\end{array}$ & .. & $\begin{array}{c}601 \\
(485-749)\end{array}$ \\
\hline \multicolumn{6}{|l|}{ Indirect costs } \\
\hline Productivity loss & $34 \cdot 75$ & 34 & $1667 \cdot 65$ & 35 & $1442 \cdot 90$ \\
\hline \multicolumn{6}{|l|}{ Total societal costs } \\
\hline $\begin{array}{l}\text { Total societal costs, } \\
\text { bootstrapped mean }(95 \% \mathrm{Cl})\end{array}$ & .. & .. & $\begin{array}{l}8251 \\
(6990-9690)\end{array}$ & .. & $\begin{array}{l}11803 \\
(10020-13651)\end{array}$ \\
\hline
\end{tabular}




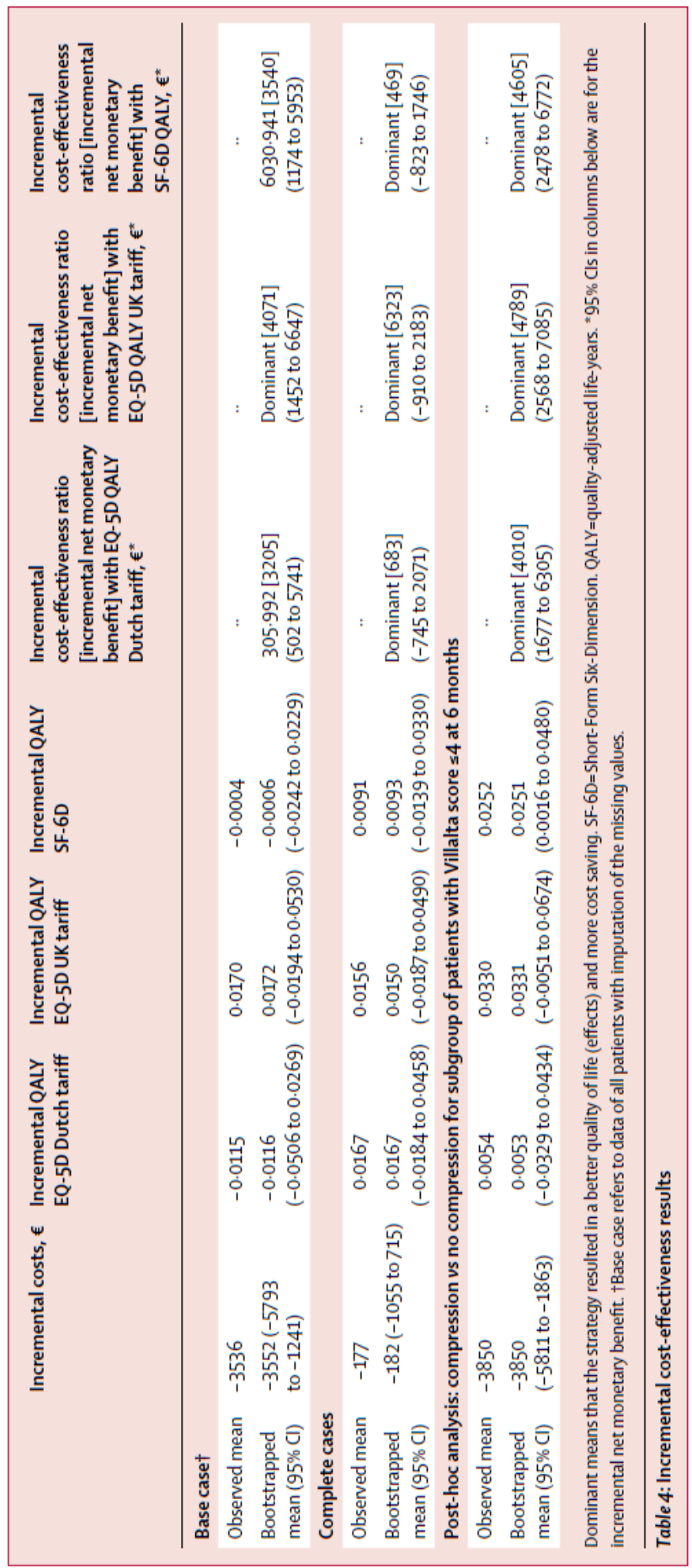




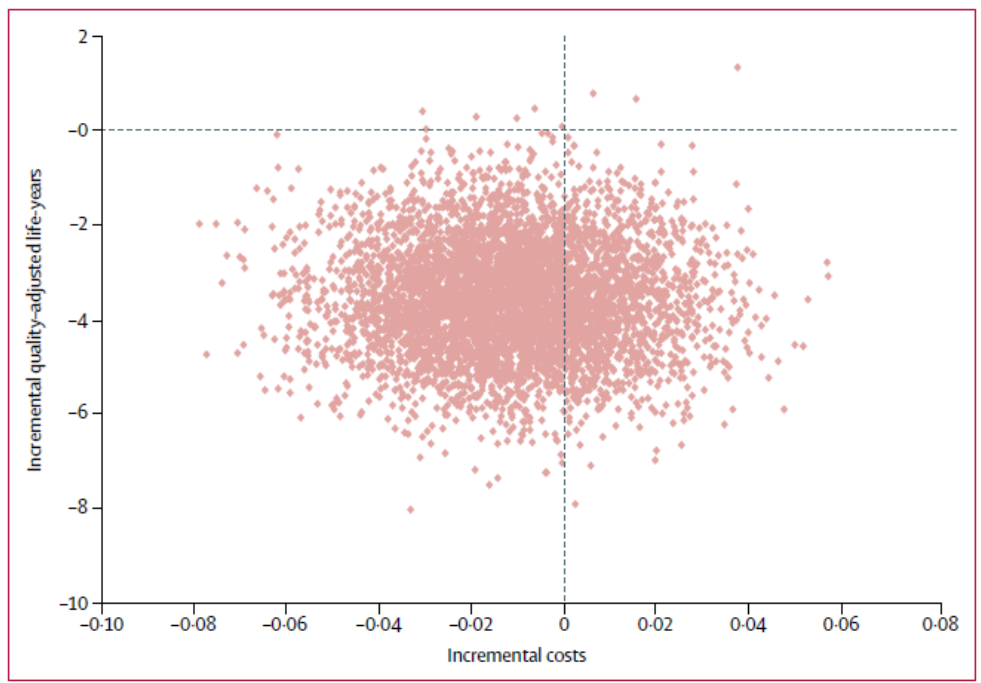

Figure 1: Bootstrapped incremental cost-effectiveness results (based on EQ-5D Dutch tariff) of individualized duration of elastic compression stocking treatment

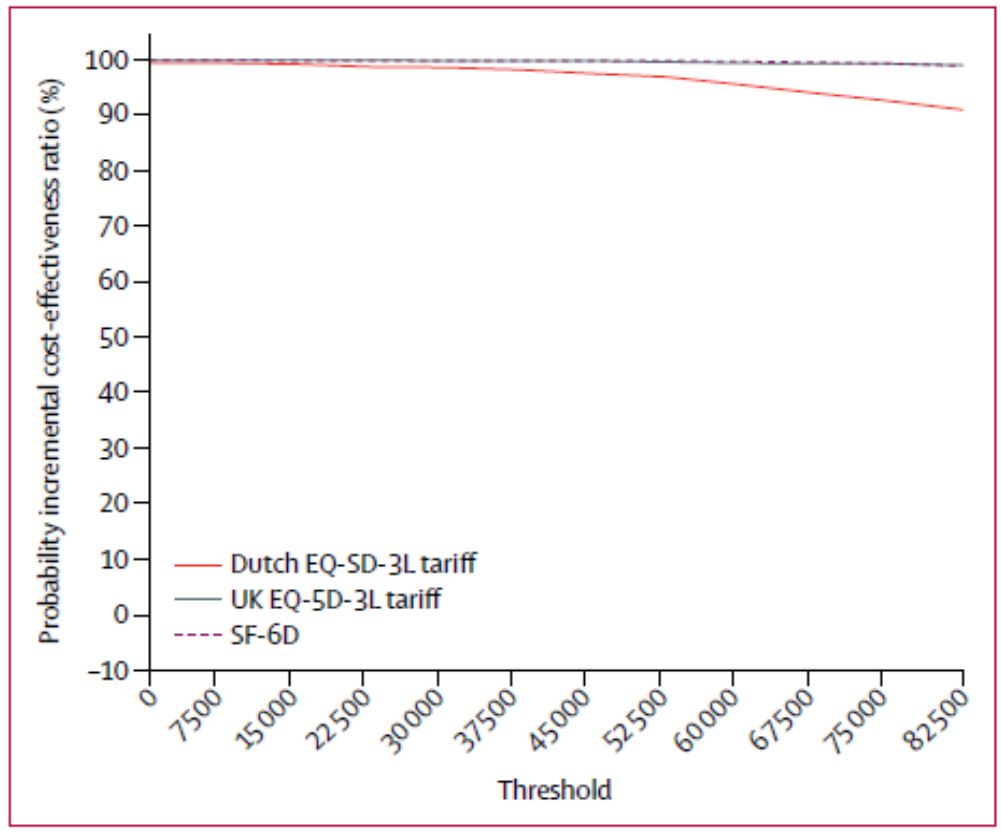

Figure 2: Cost-effectiveness acceptability curves of use of individualised duration of elastic compression stocking treatment versus standard duration of stocking treatment. SF-6D=Short-Form Six-Dimension. 


\section{Discussion}

To our knowledge, this is the first health economic evaluation of the use of elastic compression therapy for prevention of post-thrombotic syndrome. We specifically directed our analysis at the cost-effectiveness of individualised shortened duration of therapy compared with standard duration of therapy, which is 2 years. $^{7-9}$ Two previous studies have assessed variable duration of elastic compression therapy to prevent post-thrombotic syndrome, ${ }^{16,17}$ but neither assessed the cost-effectiveness of such strategies. Aschwanden and colleagues compared 6 months of treatment with elastic compression therapy versus a prolonged duration of 24 months in patients with newly-diagnosed deep vein thrombosis. ${ }^{16}$ They found that the occurrence of post-thrombotic skin changes, assessed according to the CEAP score, in the group allocated to 6 months of elastic compression therapy did not differ significantly from the group assigned to longterm duration of therapy (hazard ratio $0 \cdot 60,95 \% \mathrm{Cl} 0 \cdot 28-1 \cdot 28$ ). In the OCTAVIA study, ${ }^{17}$ selected patients with Villalta scores of less than 5 and excellent adherence to compression therapy were randomly assigned to standard 24 months of elastic compression therapy versus 1 year of compression therapy. This trial failed to show non-inferiority for the shortened duration of therapy: the absolute difference in occurrence of post-thrombotic syndrome was $6.9 \%$, with the $95 \% \mathrm{Cl}$ upper limit of $12 \cdot 3 \%$ exceeding the predefined noninferiority margin of $10 \%$. In December, 2017, we reported the primary outcome of the IDEAL DVT study, ${ }^{15}$ which showed that individualised shortened duration of elastic compression therapy for prevention of post-thrombotic syndrome was feasible. We showed that 283 (66\%) of 432 patients in the intervention group could stop treatment early, guided by a low Villalta score. We found no significant difference in the proportion of post-thrombotic syndrome after 2 years for those assigned to individualised shortened duration as compared with standard duration of therapy (odds ratio $1.06,95 \% \mathrm{Cl}-0.78$ to 1.44 ). We concluded that individualised duration of elastic compression therapy was safe 
and effective and anticipated that this treatment strategy was likely to reduce health-care costs. Our results from this analysis show that quality of life as measured by EQ-5D-3L and SF-36 version 2 started increasing 3 months after the thrombotic event, and quality of life did not differ between patients assigned to individualised duration or standard 2-year duration of elastic compression therapy throughout the study. The costs for both treatment groups consisted mainly of healthcare costs due to the high costs of home care. We found individualised duration of elastic compression therapy to be the most costeffective option, irrespective of the instrument used to obtain utilities to calculate QALYs. In the Netherlands, for 25000 incident cases of deep vein thrombosis per annum, ${ }^{28}$ savings (measured over 2 years) from implementing the individualised strategy would amount to $€ 88$ million $(95 \% \mathrm{Cl} 31$ million to 144 million). Sensitivity analysis with the complete cases showed individualised duration of elastic compression therapy was more effective and less costly than was treatment with standard duration of compression therapy. In the complete case analysis the cost savings were lower, but overall the individualised strategy was still cost-effective. On the basis of results from OCTAVIA, ${ }^{17}$ which showed that the incidence of post-thrombotic syndrome was increased in patients with a low Villalta score who stopped elastic compression therapy early, we did a posthoc analysis in a subgroup of patients from the IDEAL DVT trial with a Villalta score of 4 or less until 6 months. This analysis suggested that shorter duration of compression stocking use is also cost-effective in this subpopulation. Therefore, in these patients prolonged treatment might also be forgone. The data for our economic study had some limitations. First, the number of patients who used some of the categories of care was small. Despite the large number of patients in the IDEAL DVT study population, the trial might therefore have been underpowered for some specific data categories. Nevertheless, the $95 \% \mathrm{Cl}$ of the incremental costs ranged from $€ 5793$ saved to $€ 1241$ saved, and the probability that individualised therapy duration was cost-effective was calculated to be $99 \%$. Second, the time window for the economic analysis was limited to the 2-year 
duration of the study, so long-term consequences for cost-effectiveness are unknown. However, most patients who develop postthrombotic syndrome are diagnosed with this syndrome within the first 2 years after deep vein thrombosis. ${ }^{29}$ Although the consequences of post-thrombotic syndrome will extend beyond the time limit of our trial, the small difference in incidence of post-thrombotic syndrome at 2 years and the similarities in quality of life between groups shown in this analysis suggest that the likelihood of long-term negative effects on health is small. Third, the IDEAL DVT study design only allowed for shortened duration of compression therapy on the basis of Villalta score results after 6 months of therapy. Whether the duration of compression therapy can be reduced even further, with potential further implications for costeffectiveness, could be the objective of further studies. Finally, because of the amount of missing data, we had to impute data to prevent a loss of statistical power and to decrease the probability of obtaining biased estimates. We used predictive mean matching (the only method that yields plausible imputations and preserves the original data distributions $)^{27}$ and the conclusions that we drew from analysis of complete data and imputed data were the same, so we are confident that the outcomes we present are robust. Some of the main strengths of this economic analysis are the large sample size, the low risk of bias because of the randomised nature of the IDEAL DVT trial from which the data were extracted, and the use of three instruments to obtain utilities to calculate QALYs, with consistent results between these calculations. In conclusion, we showed that individualised duration of elastic compression therapy for prevention of postthrombotic syndrome is a cost-effective strategy compared with the standard 2-year duration of compression stocking use. By using an individualised approach, substantial cost savings can be made, both from a health-care perspective and a societal perspective, without significant loss in health-related quality of life. 


\section{References}

1. Prandoni P, Kahn SR. Post-thrombotic syndrome: prevalence, prognostication and need for progress. Br J Haematol 2009;145: 286-95.

2. Kahn SR, Shrier I, Julian JA, et al. Determinants and time course of the postthrombotic syndrome after acute deep venous thrombosis. Ann Intern Med 2008; 149: 698-707.

3. Pesavento R, Villalta S, Prandoni P. The postthrombotic syndrome. Intern Emerg Med 2010; 5: 185-92.

4. Kahn SR, Ducruet T, Lamping DL, et al. Prospective evaluation of health-related quality of life in patients with deep venous thrombosis. Arch Intern Med 2005; 165: 1173-78.

5. Bergqvist $D$, Jendteg $S$, Johansen L, Persson U, Odegaard K. Cost of long-term complications of deep venous thrombosis of the lower extremities: an analysis of a defined patient population in Sweden. Ann Intern Med 1997; 126: 454-57.

6. Caprini JA, Botteman MF, Stephens JM, et al. Economic burden of long-term complications of deep vein thrombosis after total hip replacement surgery in the United States. Value Health 2003;6: 59-74.

7. Brandjes DP, Buller HR, Heijboer $\mathrm{H}$, et al. Randomised trial of effect of compression stockings in patients with symptomatic proximal-vein thrombosis. Lancet 1997; 349: 75962.

8. Prandoni $\mathrm{P}$, Lensing $\mathrm{AW}$, Prins $\mathrm{MH}$, et al. Below-knee elastic compression stockings to prevent the post-thrombotic syndrome:a randomized, controlled trial. Ann Intern Med 2004; 141: 249-56.

9. Guyatt GH, Akl EA, Crowther M, et al. Executive summary: Antithrombotic therapy and prevention of thrombosis, 9th ed: American College of Chest Physicians Evidence-Based Clinical Practice Guidelines. Chest 2012; 141 (2 suppl): 7S-47S.

10. Appelen D, van Loo E, Prins MH, Neumann MH, Kolbach DN. Compression therapy for prevention of post-thrombotic syndrome. Cochrane Database Syst Rev 2017; 9: CD004174.

11. Ten Cate-Hoek AJ, Bouman AC, Joore MA, Prins M, Ten Cate H. The IDEAL DVT study, individualised duration elastic compression therapy against long-term duration of therapy for the prevention of post-thrombotic syndrome: protocol of a randomised controlled trial. BMJ Open 2014; 4: e005265.

12. Blattler W. Aspects of cost effectiveness in therapy of acute leg/pelvic vein thrombosis. Wien Med Wochenschr 1999; 149: 61-65

13. Raju S, Hollis K, Neglen P. Use of compression stockings in chronic venous disease: patient compliance and efficacy. Ann Vasc Surg 2007; 21: 790-95.

14. Gelderblom G, Hagedoorn-Meuwissen EAV. Kousen uittrekhulpmiddel Easy-Lever. Een onderzoek naar bruikbaarheid, effecten en belemmeringen. in opdracht van ZonMw. 2005.

15. ten Cate-Hoek AJ, Amin EE, Bouman AC, et al. Individualised versus standard duration of elastic compression therapy for prevention of post-thrombotic syndrome (IDEAL DVT): a multicentre, randomised, single-blind, allocation-concealed,non-inferiority trial. Lancet Haematol 2018; 5: e25-33.

16. Aschwanden M, Jeanneret C, Koller MT, Thalhammer C, Bucher HC, Jaeger KA. Effect of prolonged treatment with compression stockings to prevent post-thrombotic sequelae:a randomized controlled trial. J Vasc Surg 2008; 47: 1015-21. 
17. Mol GC, van de Ree MA, Klok FA, et al. One versus two years of elastic compression stockings for prevention of post-thrombotic syndrome (OCTAVIA study): randomised controlled trial. BMJ 2016; 353: i2691.

18. Brooks R. EuroQol: the current state of play. Health Policy 1996; 37: 53-72.

19. Ware JE, Snoww K, Kosinski MA, Gandek BG. SF-36R Health Survey Manual and Interpretation Guide. Lincoln, RI: Quality Metric Inc, 1993.

20. Zee van der KL SR. Het meten van de algemene gezondheidstoestand met de RAND-36, een handleiding2012; Tweede herziene druk. https://www.umcg.nl/ SiteCollectionDocuments/research/institutes/SHARE/assessment\%20tools/handleiding_r and36_2e_druk.pdf (accessed Sept 28, 2018).

21. Dolan P. Modeling valuations for EuroQol health states. Med Care 1997; 35: 1095-108.

22. Lamers LM, Stalmeier PF, McDonnell J, Krabbe PFM, van Busschbach JJ. Measuring the quality of life in economic evaluations: the Dutch EQ-5D tariff. Ned Tijdschr Geneeskd 2005;149: 1574-78.

23. Brazier JE, Roberts J. The estimation of a preference-based measure of health from the SF12. Med Care 2004; 42: 851-59.

24. Koopmanschap MA. PRODISQ: a modular questionnaire on productivity and disease for economic evaluation studies. Expert Rev Pharmacoecon Outcomes Res 2005; 5: 23-28.

25. Hakkaart-van Roijen L, van der Linden N, Bouwmans C, Kanters T, Tan SS. Kostenhandleiding. Methodologie van kostenonderzoek en referentieprijzen voor economische evaluaties in de gezondheidszorg. Institute for Medical Technology Assessment Erasmus Universiteit 2016. Https://www.zorginstituutnederland.nl/publicaties/publicatie/2016/02/29/richtlijnvoor-het-uitvoeren-van-economische-evaluaties-in-degezondheidszorg (accessed Sept 9, 2018).

26. Brouwer WB, Koopmanschap MA. The friction-cost method: replacement for nothing and leisure for free? Pharmacoeconomics 2005; 23: 105-11

27. Vink G, Frank LE, Pannekoek J, van Buuren S. Predictive mean matching imputation of semicontinuous variables. Stat Neerl 2014; 68: 61-90.

28. Naess IA, Christiansen SC, Romundstad P, Cannegieter SC, Rosendaal FR, Hammerstrom J. Incidence and mortality of venous thrombosis: a population-based study. J Thromb Haemost 2007; 5: 692-99.

29. Prandoni $P$, Lensing AW, Cogo A, et al. The long-term clinical course of acute deep venous thrombosis. Ann Intern Med 1996; 125: 1-7. 


\section{CHAPTER 6}

\section{Clinical and Economic Impact of Compression in the Acute Phase of Deep Vein Thrombosis}

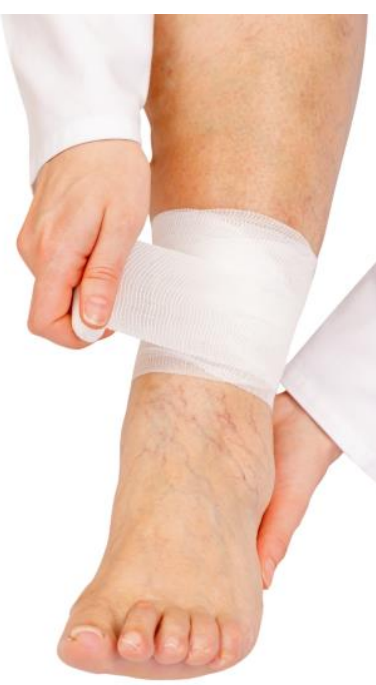

Amin EE, Joore MA, Ten Cate H, Meijer K, Tick LW, Middeldorp S, Mostard GJM, Ten Wolde M, van den Heiligenberg SM, van Wissen S, van de Poel MHW, Villalta S, Serné EH, Otten HM, Klappe EH, Prandoni P, Ten Cate-Hoek AJ

Journal of Thrombosis and Haemostasis: JTH. 2018 Jun; 16: 1555-1563 


\section{Summary}

Background The effectiveness of compression therapy in the acute phase of deep vein thrombosis (DVT) is yet undetermined.

Objectives To investigate the impact of compression therapy in the acute phase of DVT on determinants of the Villalta score, health related quality of life (HRQOL) and costs.

Patients/Methods 865 patients with proximal DVT (sub-study to the IDEAL DVT study), received immediately after DVT diagnosis no compression, multilayer bandaging or hosiery. In the acute phase and three months after diagnosis, HRQOL was determined by using the EQ-5D, SF6D and VEINES-QoL. At three months, signs and symptoms were assessed for the total and separate items of the Villalta score and health care costs were calculated.

Results Compression groups had lower overall objective Villalta scores than the no compression group $(1.47 \pm 1.57$ and $1.59 \pm 1.64$ vs. $2.21 \pm 2.15) \quad p<0.001$. Differences were mainly due to irreversible skin signs (induration, hyperpigmentation, venectasia) and pain on calf compression. Subjective and total Villalta scores were similar across groups. Differences in HRQOL were only observed at one month; HRQOL was better for hosiery (EQ-5D 0.86 \pm 0.18 , VEINES-QoL int $0.66 \pm 0.18$ ) compared to multilayer compression bandaging (EQ$5 \mathrm{D} 0.81 \pm 0.23, \mathrm{p} 0.028$, VEINES-QoL $0.62 \pm 0.19, \mathrm{p} 0.030)$. Mean health care costs per patient were for bandaging €417.08 (€354.10-€489.30), hosiery €114.25 (€92.50-€198.43), and no compression €105.86 (€34.63-€199.30).

Conclusions Initial compression reduces irreversible skin signs, edema and pain at calf compression. Multilayer bandaging is slightly more effective than hosiery at substantially higher costs, without gain in HRQOL. From patients' and economical perspective compression hosiery would be preferred when initial compression is applied. 


\section{Introduction}

Deep vein thrombosis (DVT) is a potential debilitating and life-threatening disease, with an annual incidence of 1-2 per 1000 people. ${ }^{[1]}$ Complaints related to DVT can vary from mild to severe, with DVT recurrence and pulmonary embolism being the most severe consequences ${ }^{[2]}$. The long-term complication is known as post-thrombotic syndrome (PTS), and develops in $20-50 \%$ of patients within 2 years after DVT diagnosis ${ }^{[3,4]}$. PTS is an irreversible condition that comprises a combination of patient-reported symptoms such as pain and cramps, and objective signs such as edema and venous ulcers. The severity of each of the signs and symptoms is assessed with the Villalta score. According to the current consensus ISTH scoring method, a sum score of $\geq 5$ at least 6 months after DVT is considered to show that PTS is present ${ }^{[5]}$. It has been shown that quality of life is reduced in patients with DVT in general ${ }^{[6,7]}$, and in PTS patients in particular ${ }^{[8]}$. Moreover, DVT complicated by PTS is associated with higher costs than DVT without PTS ${ }^{[9,10]}$. The main, although disputed, form of preventive therapy for PTS is the use of elastic compression stockings (ECS) (class III, ankle pressure of $40 \mathrm{mmHg}$ ) for a period of up to 2 years following DVT ${ }^{[3,4,11]}$. Generally, ECS are applied as soon as leg edema is resolved, which usually takes 2-6 weeks. Currently, there is no consensus regarding what the preferred mode of treatment is in the time frame between DVT diagnosis and ECS application. There are three possible approaches to bridge the acute phase: no compression, the application of multilayer compression bandages, or the use of thigh-high compression hosiery (Mediven Struva $35 \mathrm{mmHg}$ ). Up to now, only a limited number of, mainly smaller, studies have explored the general effects of compression therapy in the acute phase of DVT. A randomized controlled trial with 69 patients compared the effect of multilayer bandaging with no compression, and found an improvement in clinical symptoms and a decrease in leg circumference 7 days after intervention, but no effect was found after 1 month and 3 months, or in relation to PTS after 1 year ${ }^{[12]}$. Beneficial effects of 
compression therapy immediately after thrombosis were observed by others ${ }^{[13]}$. A study in 53 patients that compared compression with inelastic bandaging or ECS in addition to daily walking exercise vsersus no compression combined with bed rest showed that, at 9 days, quality of life was significantly better in the compression group. Patients who received compression reported significantly less pain and swelling ${ }^{[14]}$. On the basis of the outcomes of these few studies, compression in the acute phase of DVT seems to have beneficial effects in terms of diminished signs and symptoms; however, conclusive answers are lacking, as the studies were relatively small. Therefore, the current study was aimed at comparing the effects of no compression, multilayer bandaging and compression hosiery in the acute phase of DVT on the separate items as well as the overall Villalta score. In addition, the present study aimed to assess the impact of acute compression therapy on quality of life, and to estimate the initial healthcare costs related to acute compression therapy following DVT diagnosis.

\section{Methods}

\section{Study design and population center}

This study was an a priori-planned substudy of the IDEAL DVT study, which has been described in detail previously ${ }^{[15]}$. In short, the IDEAL DVT study was a multicenter randomized controlled trial that started in April 2011 and was concluded in July 2017. The study involved 865 patients with objectively confirmed proximal DVT without venous insufficiency or previous DVT from 12 medical centers across the Netherlands and two in Italy.

The study compared individualized duration of ECS use with standard long-term (24 months) duration. Three prespecified treatment protocols that were agreed upon before study start described which form of compression therapy was applied in the acute phase of DVT in each individual center in the time frame between DVT diagnosis and the start of ECS use ${ }^{[16]}$. All included patients received thigh-high short stretch multilayer compression bandaging applied by trained 
healthcare professionals, thigh-high elastic compression hosiery (Mediven Struva $35 \mathrm{mmHg}$ ), or no compression; this initial treatment was not randomized, but was allocated according to the centers' prespecified treatment protocols. The randomization for the IDEAL DVT study was stratified by center in order to ensure an equal distribution of initial treatments. If compression was initiated, this was performed within $24 \mathrm{~h}$ of DVT diagnosis. A week prior to the outpatient clinic visits, the patients filled out a questionnaire on quality of life and costs. The first (baseline) questionnaire was filled out within a week after the inclusion. The language of the overall questionnaire was Dutch for the Dutch centers and Italian for the Italian centers.

\section{Outcomes}

Determinants of the Villalta score at three months after DVT were assessed. These included five patient-rated symptoms (pain, cramps, heaviness, paresthesia, and itching) and six physical signs (pretibial edema, skin induration, hyperpigmentation, pain during calf compression, venous ectasia and redness). All items were graded for intensity on a 4-point scale: 0 points when there were no deviations from normal, 1 point if the signs or symptoms were mild, 2 points if they were moderate, and 3 points if they were severe. Symptoms of the subjective Villalta score were rated and filled out by patients in the questionnaire. The objective items were assessed and filled out at each study visit by a medical doctor or a research nurse in the case report form. Healthrelated quality of life (HRQOL) was assessed in the acute phase of DVT (1 week after inclusion) and 3 months after DVT diagnosis. HRQOL was determined with two generic questionnaires and one disease-specific questionnaire: the EQ-5D, the Short Form Health Survey version 2 (SF36), and the disease-specific Venous Insufficiency Epidemiological and Economic Study (VEINESQoL). The EQ-5D covers five dimensions of generic HRQOL (mobility, self-care, usual activity, pain, and anxiety). Health state preferences, expressed as utility scores, are calculated with a scoring function based on the preferences of a general public (2997 
respondents from the UK) and scores on each item ${ }^{[17]}$. The range of the score is -0.59 to 1 , where -0.59 suggests a health state worse than death, 0 refers to death, and 1 indicates perfect health. The SF36 consists of 36 questions covering several health domains: physical functioning, physical role functioning, emotional role functioning, social role functioning, mental health, bodily pain, vitality, and general health perceptions. A utility score derived from the SF36, the SF6D, was calculated ${ }^{[18]}$. On the basis of the literature, a difference of 0.076 in EQ-5D scores and a difference of 0.041 in SF6D scores were considered to be clinically relevant differences ${ }^{[19]}$.

The VEINES-QoL contains 26 items on the following topics: DVT-related symptoms, limitations in daily activities, time of day when the leg complaint is of greatest intensity, changes in leg complaints over the last year, and the psychological impact of the leg complaints ${ }^{[20]}$. The VEINES-Qol average score was calculated on the basis of the intrinsic method (VEINES-QoLint) as recommended by Bland et al. $\left.{ }^{[21}\right]$, whereby each item score (i) is recoded to (i$1) /(k-1)$, with $k$ referring to the number of categories. Based on this formula, each item's score has a value between 0 and 1 , and the average is the final score. This intrinsic method makes it possible to compare average quality of life scores with other quality of life scores. For all quality of life instruments, a higher score suggests better quality of life.

The following cost domains were estimated: visits (including transportation costs) to the general practitioner, general practice center out of hours care, or medical specialist, the use of painkillers, home care nursing demands, and costs of compression material use. Unit costs were multiplied by the patient-reported frequency of resource use, with recall periods of 4 weeks for nursing and 8 weeks for other items (reported at 3 months after DVT diagnosis), and divided by the total number of patients per group. Unit costs were based on the guidelines on healthcare costs drafted by the Dutch Health Authority ${ }^{[22]}$. The costs of the compression bandages were based on amounts as indicated in the Dutch G- 
standard March $2017^{[23]}$. The costs of the compression hosiery were $€ 25$ to $€ 55$ per item ${ }^{[24]}$.

\section{Statistical analysis}

All statistical analyses were performed with SPSS version 23, with a P-value of $\leq 0.05$ being considered to be statistically significant. The association between different compression strategies and separate signs and symptoms forming the Villalta score were analyzed, as were the total objective, total subjective and the complete Villalta scores, by the use of ANCOVA for comparison of multiple groups and regression analysis for two-group comparisons. Split plot analysis of variance for repeated measures was performed for assessment of the time effect on quality of life scores. Analyses were adjusted for center and baseline variables that differed significantly among groups. Costs were bootstrapped to obtain $95 \%$ credibility intervals. Sensitivity analyses were performed with complete data. Subanalysis with regard to assessment of signs and symptoms was performed in patients with iliofemoral DVT. All analyses were also performed with the bandaging group and hosiery group taken together as one compression group.

\section{Results}

The percentages of missing data attributable to withdrawals, loss to follow-up, disease and late exclusion were $4.3 \%, 1.4 \%, 2.8 \%$, and $1.0 \%$, respectively. Analyses with complete cases and cases with some missing data on the items showed no statistically significant difference. Therefore, imputation of missing data was not performed.

\section{Subjects' characteristics}

The study population consisted of 865 patients. The average inclusion date was 18.4 _ 12 days after DVT diagnosis. A total of 668 patients (78.0\%) received initial compression, of whom 415 (48.5\%) were in the multilayer bandaging group, and $253(29.6 \%)$ were in the compression hosiery group. However, 16 of 253 (6.3\%) 
patients in the hosiery group required multilayer bandaging because of leg complaints. One hundred and eighty-eight patients $(21.9 \%)$ received no initial compression. Table 1 shows the baseline characteristics for the study population. Overall, the mean age was $57.2 \pm 15.1$ years. The percentage of male patients was $58.2 \%$. The average body mass index was $27.9 \pm 5.2 \mathrm{~kg} / \mathrm{m}^{2}$. DVT located in the left leg was seen in 451 (52.7\%) of patients. Previous contralateral DVT was seen in 81 (9.5\%) patients. The baseline characteristics across groups were mostly similar; a statistically significant difference among the groups was found only with regard to the nature and location of DVT. In the no-compression group, 108 (57.4\%) patients had unprovoked DVT, in comparison with 296 $(71.3 \%)$ in the multilayer bandaging group and $175(69.2 \%)$ in the hosiery group $(P=0.017)$. DVT was located in the common femoral vein in $33.5 \%$ of patients in the no-compression group, as compared with $19.0 \%$ in the multilayer bandaging group and $16.6 \%$ in the hosiery group $(P<0.001)$. 


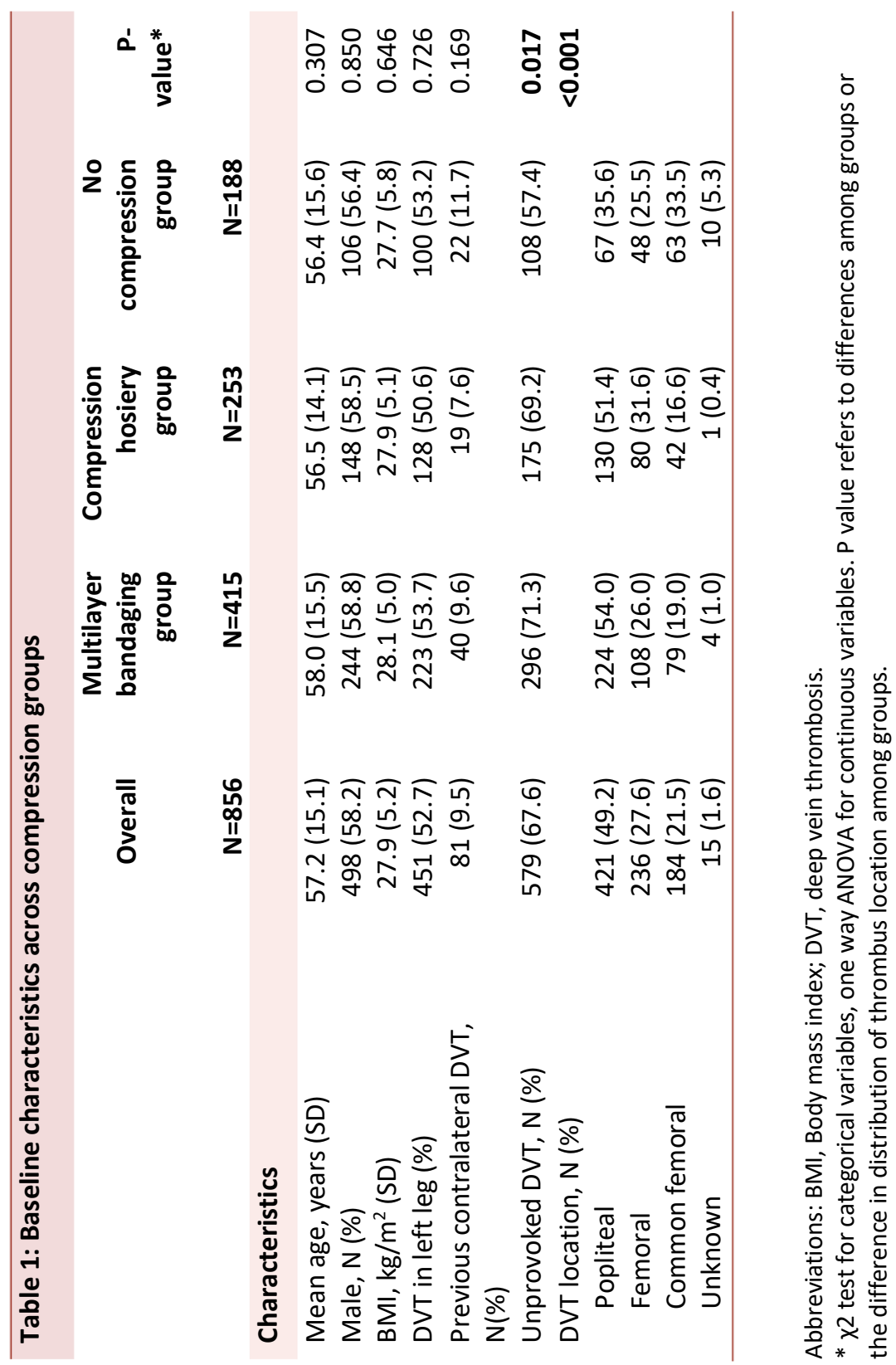


Figure 1 and Table 2 show the Villalta scores at 3 months after DVT diagnosis. The total Villalta score, the total subjective Villalta score and all individual items constituting the subjective part were not significantly different among groups. Significant differences were observed for the objective part of the Villalta score; the total objective score in the compression groups combined $(1.52 \pm 1.59$, $\mathrm{P}<0.001)$ was lower than that in the no-compression group $(2.21 \pm 2.15)$ The scores for the separate compression groups were also lower than that in the nocompression group: $1.47 \pm 1.57$ in the multilayer bandaging group $(P<0.001)$, and $1.59 \pm 1.64$ in the hosiery group $(P<0.001)$. Additionally, statistically significant differences between the compression group and the no-compression group were seen for mainly irreversible signs, i.e. skin induration, hyperpigmentation, and venectasia, and for pain upon calf compression. Those with bandaging had statistically significant lower scores on the objective items skin induration and hyperpigmentation than those with hosiery (respectively: $0.04 \pm 0.27$ versus $0.15 \pm 0.44, P=0.002$; and $0.11 \pm 0.37$ versus $0.20 \pm 0.46$, $P=0.028)$.

The results of the subgroup analysis using only data of patients with iliofemoral thrombosis were in line with the results for the entire population. There were no differences in the total Villalta score or the subjective part of the Villalta score. The total objective part was significantly lower in the compression groups than in the no compression group $(1.78 \pm 2.17$ versus $2.20 \pm 2.17, \mathrm{P}=0.025)$. The efficacy of compression was entirely based on multilayer compression bandaging. In this group, a significantly lower total objective Villalta score with fewer irreversible skin signs, i.e. indurations, hyperpigmentation, and venectasia, was observed than in the no-compression group $(1.52 \pm 160$ versus $2.2 \pm 2.17, \mathrm{P}=0.017)$ and the hosiery group $(2.25 \pm 1.72, \mathrm{P}=0.158)$. 


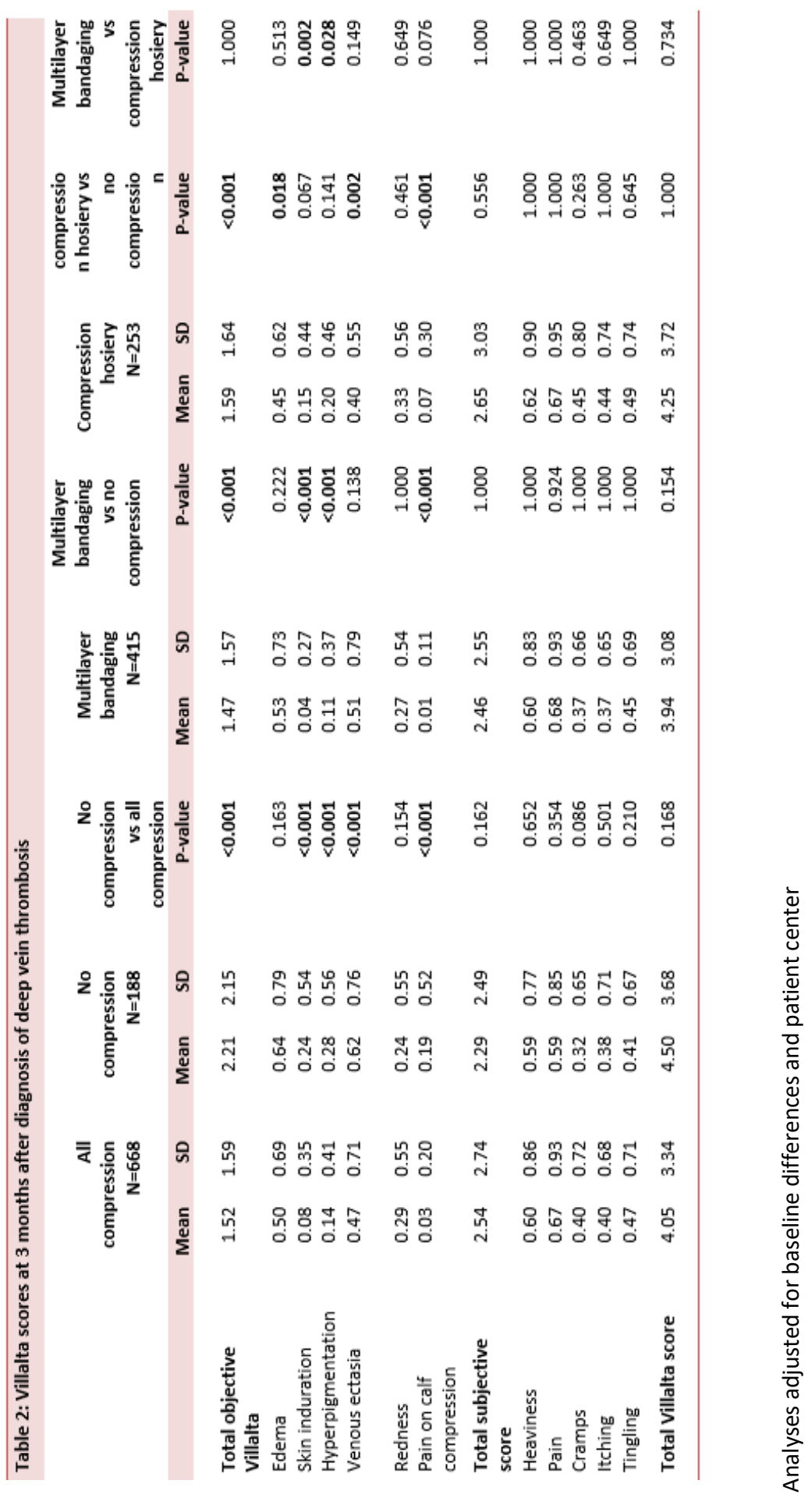




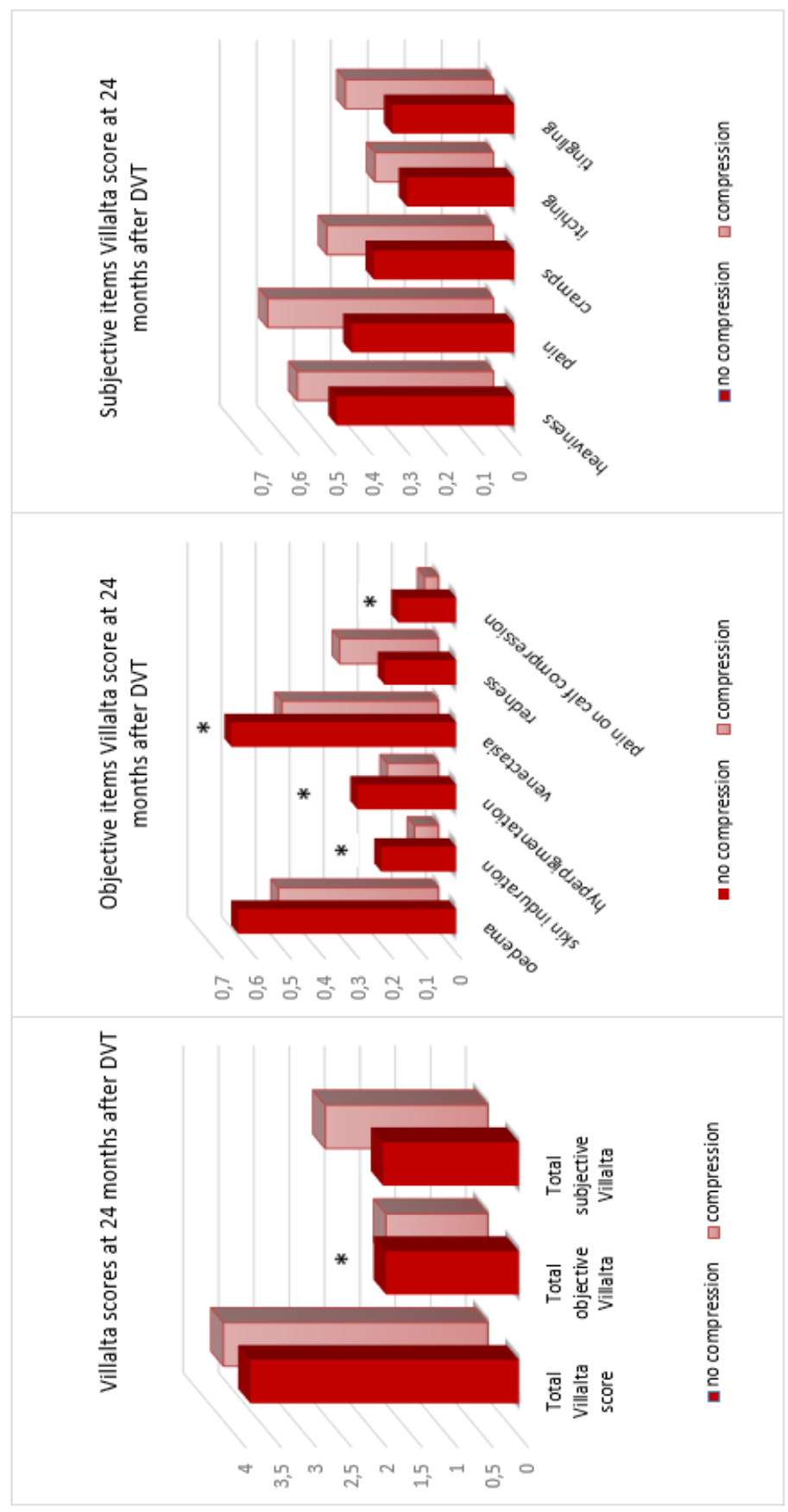


Results for the subgroup analysis using only data of patients with iliofemoral thrombosis were in line with results observed for the entire population. There was no difference in the total Villalta score or the subjective part of the Villalta score. The total objective part was significantly lower in the compression groups versus no compression group $(1.78 \pm 2.17$ versus $2.20 \pm 2.17 p=0.025)$. The efficacy of compression was entirely based on multilayer compression bandaging. In this group significantly lower total objective Villalta score with less irreversible skin signs; indurations, hyperpigmentation and venectasia was observed in comparison to the no compression group $(1.52 \pm 160$ versus $2.2 \pm 2.17 p=0.017)$, and the hosiery group $(2.25 \pm 1.72 \mathrm{p}=0.158)$.

\section{Quality of life}

Table 3 shows the quality of life scores in the acute phase and at 3 months after DVT. There were no statistically significant differences in HRQOL for all compression versus no compression. In the acute phase, however, the hosiery group had statistically significantly higher scores than the bandaging group on the EQ- $5 \mathrm{D}(0.86 \pm 0.18$ versus $0.81 \pm 0.23, P=0.015)$ and the VEINES-QoLint $(0.66$ \pm 0.18 versus $0.62 \pm 0.19, P=0.030$ ). Three months after DVT, no statistically significant differences were observed. Split plot analysis of variance for repeated measures showed no statistically significant difference over time (SF6D, $P=0.470$; EQ-5D, $P=0.263$; and VEINES-QoLint, $P=0.136$ ). This means that, if the two time points are combined, no differences in the compression groups exist. 


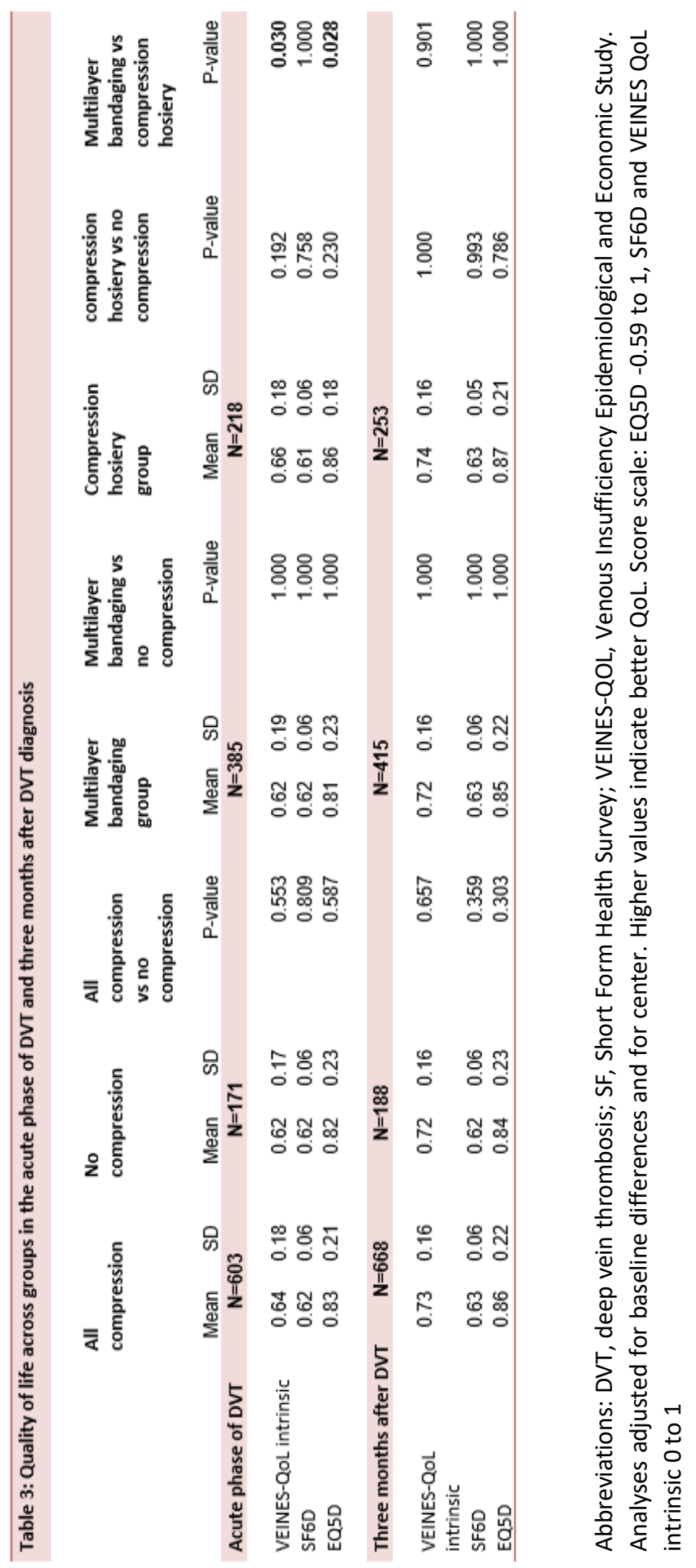


Costs

Healthcare costs in the compression groups are shown in Table 4. The mean total costs per patient were highest for the bandaging group (€417.08, 95\% confidence interval $[\mathrm{Cl}] € 354.10$ to $€ 489.30$ ), followed by the hosiery group ( $€ 114.25,95 \% \mathrm{Cl} € 92.50$ to $€ 198.43$ ); the costs were lowest for the nocompression group (€105.86, 95-\% Cl €34.63 to €199.30). The differences in costs across groups were mainly attributable to costs related to compression material use and home care nursing demands, which were both highest in the bandaging group and lowest in the no-compression group.

\section{Discussion}

Compression in the acute phase of DVT reduces the occurrence of pain on calf compression, and the incidence of hyperpigmentation, venectasia, and skin induration, which are irreversible skin signs that are associated with PTS. Consequently, the objective part of the Villalta score was significantly decreased in patients who received initial compression therapy. These effects, although small in absolute terms, were significantly more pronounced in the group of patients who received multilayer bandaging. No differences among groups were seen with regard to the subjective items of the Villalta score and the sum total Villalta score. The exact pathophysiology of PTS is not yet known; however, it is assumed that, in the acute phase, venous hypertension caused by thrombus obstruction and subsequent inflammation and edema are central features. External compression reduces the vein diameter and improves venous flow velocity, thereby improving venous outflow and reducing edema and inflammation. Therefore, compression in the acute phase may reduce inflammation and secondary skin changes associated with PTS ${ }^{[25-27]}$, as is also suggested by our results. It might be argued whether these small differences are clinically relevant. In absolute terms, the majority of patients had low Villalta scores, with no or minimal signs and symptoms. 


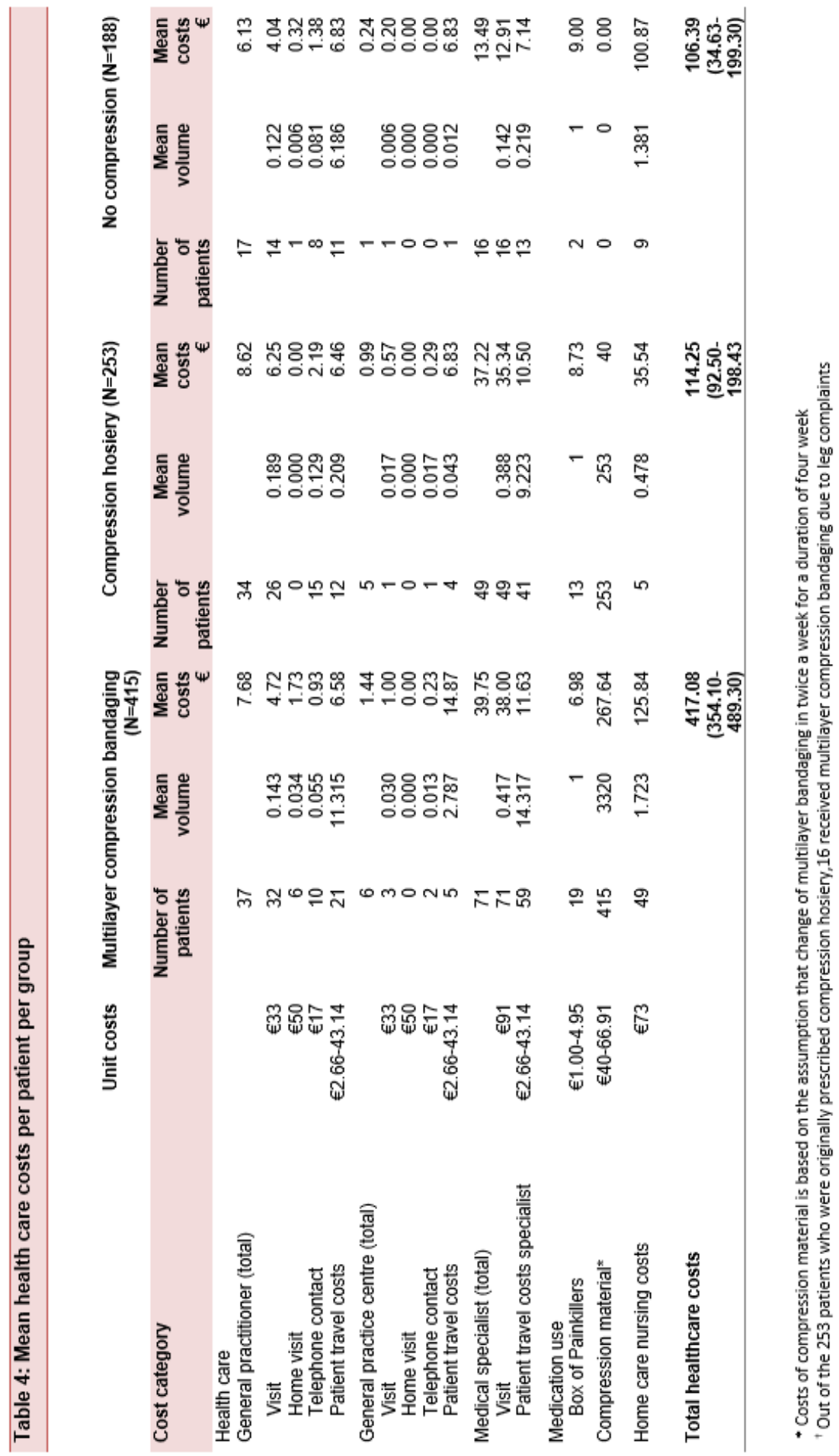


However, if the percentages of moderate and severe signs between groups are compared, then the differences become prominent. As these differences involve irreversible skin signs, they may be considered to be clinically relevant. Overall, patients experienced relatively few complaints. This lack of contrast between treatment groups for the subjective part of the Villalta score was reflected in the similar outcomes for quality of life assessments. In the initial phase, however, HRQOL was significantly better for hosiery than for bandaging. The costs and burdens related to multilayer bandaging are higher than those related to no compression and hosiery. The question is, what amount of expenditure and discomfort is justified in relation to the outcome? Therefore, it is of the utmost importance to be able to identify patients at the highest risk, as patients at risk for PTS constitute a heterogeneous group. So far, only a few studies have assessed the merits of compression in the acute phase. The numbers of participants were rather small, i.e. 69, 53 and 73 patients [12] [14,28]. Moreover, those studies did not assess the signs and symptoms of PTS individually. Despite the mentioned limitations, they too found some beneficial effects of compression in the acute phase of DVT.

The strengths of our study are its size and its multicenter nature, as it involved both academic and non-academic centers, and the fact that quality of life and cost aspects were also assessed. A limitation of our study design is the lack of randomization of patients for the three preventive options. However, each center offered the same therapy to all patients from that center, so the choice of intervention could be considered to be quasirandomized. Furthermore, analyses were adjusted for center and baseline differences between treatment groups. It is important to determine which of the three mentioned options (multilayer bandaging, compression hosiery, or no initial compression) should be chosen, not only because their effects on clinical symptoms might differ, but also because the costs related to each option can vary substantially. Multilayer bandaging requires the help of 
(para)medical professionals and more medical materials, owing to regular redressing, than compression hosiery, which patients need to purchase only once and can apply by themselves. We found that, for the subgroup of patients with iliofemoral DVT, that compression hosiery was not effective, but that multilayer bandaging provided a significant reduction in irreversible skin signs. For the specific subgroup of patients with iliofemoral DVT, the costs and burdens of multilayer bandaging might therefore be weighted differently and favour multilayer bandaging.

In conclusion, there are significant reductions in irreversible signs, edema and pain on calf compression associated with initial compression therapy in any form, and there is clinically significantly better HRQOL for initial compression with compression hosiery than for multilayer bandaging. Multilayer bandaging is, overall, slightly more effective than compression hosiery, but without the gain in HRQOL, and at a significantly higher cost. Compression hosiery is a relatively cheap, easy to use and safe alternative to multilayer bandaging in all patients. Therefore, both from both a patient perspective and an economic perspective, compression hosiery would be the preferred choice when initial compression is applied in unselected patients. 


\section{References}

1. Naess, I.A., et al., Incidence and mortality of venous thrombosis: a population-based study. J Thromb Haemost, 2007. 5(4): p. 692-9.

2. Leizorovicz, A., Long-term consequences of deep vein thrombosis. Haemostasis, 1998. 28 Suppl 3: p. 1-7.

3. Brandjes, D.P., et al., Randomised trial of effect of compression stockings in patients with symptomatic proximal-vein thrombosis. Lancet, 1997. 349(9054): p. 759-62.

4. Prandoni, P., et al., The long-term clinical course of acute deep venous thrombosis. Ann Intern Med, 1996. 125(1): p. 1-7.

5. Kahn, S.R., et al., Definition of post-thrombotic syndrome of the leg for use in clinical investigations: a recommendation for standardization. J Thromb Haemost, 2009. 7(5): p. 879-83.

6. Utne, K.K., et al., Health-related quality of life after deep vein thrombosis. Springerplus, 2016. 5(1): p. 1278.

7. Kahn, S.R., et al., Prospective evaluation of health-related quality of life in patients with deep venous thrombosis. Arch Intern Med, 2005. 165(10): p. 1173-8.

8. Kahn, S.R., et al., Determinants of health-related quality of life during the 2 years following deep vein thrombosis. J Thromb Haemost, 2008. 6(7): p. 1105-12.

9. Bergqvist, D., et al., Cost of long-term complications of deep venous thrombosis of the lower extremities: an analysis of a defined patient population in Sweden. Ann Intern Med, 1997. 126(6): p. 454-7.

10. Caprini, J.A., et al., Economic burden of long-term complications of deep vein thrombosis after total hip replacement surgery in the United States. Value Health, 2003. 6(1): p. 5974.

11. Appelen, D., et al., Compression therapy for prevention of post-thrombotic syndrome. Cochrane Database Syst Rev, 2017. 9: p. Cd004174.

12. Roumen-Klappe, E.M., et al., Multilayer compression bandaging in the acute phase of deep-vein thrombosis has no effect on the development of the post-thrombotic syndrome. J Thromb Thrombolysis, 2009. 27(4): p. 400-5.

13. Blattler, W. and H. Partsch, Leg compression and ambulation is better than bed rest for the treatment of acute deep venous thrombosis. Int Angiol, 2003. 22(4): p. 393-400.

14. Arpaia, G., et al., Efficacy of elastic compression stockings used early or after resolution of the edema on recanalization after deep venous thrombosis: the COM.PRE Trial. Blood Coagul Fibrinolysis, 2007. 18(2): p. 131-7.

15. Ten Cate-Hoek, A.J., et al., Individualised versus standard duration of elastic compression therapy for prevention of post-thrombotic syndrome (IDEAL DVT): a multicentre, randomised, single-blind, allocation-concealed, non-inferiority trial. Lancet Haematol, 2017.

16. Ten Cate-Hoek, A.J., et al., The IDEAL DVT study, individualised duration elastic compression therapy against long-term duration of therapy for the prevention of postthrombotic syndrome: protocol of a randomised controlled trial. BMJ Open, 2014. 4(9): p. e005265.

17. Dolan, P., Modeling valuations for EuroQol health states. Med Care, 1997. 35(11): p. 1095108.

18. van der Zee, K.I.S., R., Het meten van de algemene gezondheidstoestand met Rand-36. 2012. 
19. Walters, S.J. and J.E. Brazier, Comparison of the minimally important difference for two health state utility measures: EQ-5D and SF-6D. Qual Life Res, 2005. 14(6): p. 1523-32.

20. Kahn, S.R., et al., VEINES-QOL/Sym questionnaire was a reliable and valid disease-specific quality of life measure for deep venous thrombosis. J Clin Epidemiol, 2006. 59(10): p. 104956.

21. Bland, J.M., et al., Validation of the VEINES-QOL quality of life instrument in venous leg ulcers: repeatability and validity study embedded in a randomised clinical trial. BMC Cardiovasc Disord, 2015. 15: p. 85.

22. Hakkaart-van Roijen, L., Linden van der, N., Boumans, C., Kanters. T. \& Tan, S.S., Kostenhandleiding: Methodologie van kostenonderzoek en referentieprijzen voor economische evaluaties in de gezondheidszorg. Institute for Medical Technology Assessment Erasmus Universiteit Rotterdam, 2016.

23. Z-index. G-Standaard. 2017 [cited 2017 March ]; Available from: http://www.z-index.nl/.

24. steunkousen.nl. Steunkousen.nl. [cited 2017 August 2017]; Available from: https://www.steunkousen.nl/steunkousen-kopen-steunpanty/verbandkousenthrombexin-18-mediven-struva.

25. Ten Cate-Hoek, A.J., P.K. Henke, and T.W. Wakefield, The post thrombotic syndrome: Ignore it and it will come back to bite you. Blood Rev, 2015.

26. Mosti, G., M.L. labichella, and H. Partsch, Compression therapy in mixed ulcers increases venous output and arterial perfusion. J Vasc Surg, 2012. 55(1): p. 122-8.

27. Flour, M., et al., Dogmas and controversies in compression therapy: report of an International Compression Club (ICC) meeting, Brussels, May 2011. Int Wound J, 2013. 10(5): p. 516-26.

28. Partsch, H., M. Kaulich, and W. Mayer, Immediate mobilisation in acute vein thrombosis reduces post-thrombotic syndrome. Int Angiol, 2004. 23(3): p. 206-12. 


\section{CHAPTER}

\section{Residual Vein Occlusion in Relation to Immediate Compression and Post-Thrombotic Syndrome in Deep Vein Thrombosis}

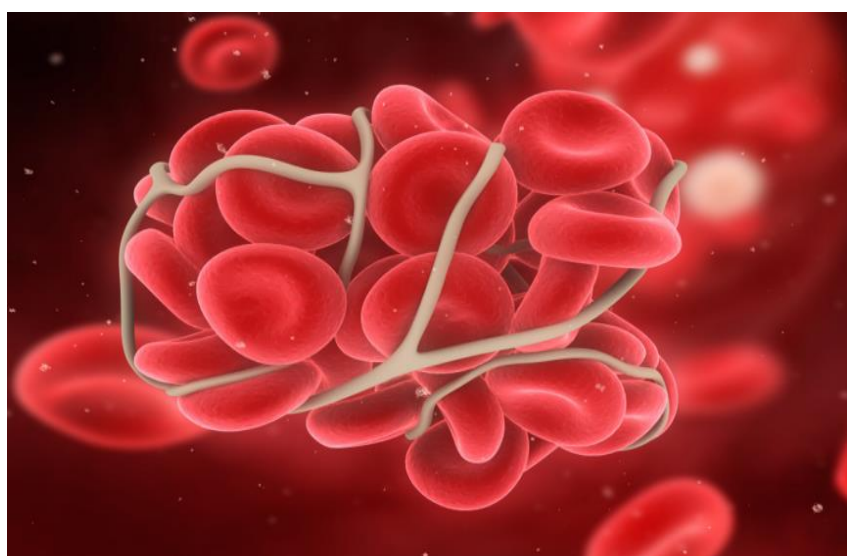

Amin EE, Bistervels IM, Meijer K, Tick LW, Middeldorp S, Mostard G, van de Poel M, Serné EH, Otten HM, Klappe EM, Joore MA, ten Cate $H$, ten Wolde $\mathrm{M}$ and ten Cate-Hoek AJ

Blood. 2018 Nov 22;132(21):2298-2304. 


\section{Abstract}

Thus far the association between residual vein occlusion and immediate compression therapy and post thrombotic syndrome is undetermined. Therefore, we investigated whether compression therapy immediately after diagnosis of deep vein thrombosis affects the occurrence of residual vein obstruction, (RVO) and whether the presence of RVO is associated with post thrombotic syndrome and recurrent venous thromboembolism.

In a pre-specified sub study within the IDEAL DVT trial, 592 adult patients from 10 academic and non-academic centers across the Netherlands, with objectively confirmed proximal deep vein thrombosis of the leg, received no compression or acute compression within 24 hours of diagnosis of deep vein thrombosis with either multi-layer bandaging or compression hosiery (pressure $35 \mathrm{mmHg}$ ). Presence of RVO and recurrent venous thromboembolism was confirmed with compression ultrasonography, incidence of post thrombotic syndrome as a Villalta score of $>5$ at 6 and 24 months. The average time from diagnosis until assessment of RVO was 5.3 (SD 1.9) months. A significantly lower percentage of patients who did receive compression therapy immediately after deep vein thrombosis had RVO, (46.3\% versus $66.7 \%$; OR $0.4695 \% \mathrm{Cl} 0.27$ to 0.80 ; $p=0.005)$. Post thrombotic syndrome was less prevalent in patients without RVO (46.0\% versus. $54.0 \%$; OR $0.6595 \% \mathrm{Cl} 0.46$ to $0.92 ; \mathrm{p}=0.013$ ). Recurrent venous thrombosis showed no significant association with RVO.

Immediate compression should therefore be offered to all patients with acute deep venous thrombosis of the leg irrespective of severity of complaints. This study was registered at ClinicalTrials.gov (NCT01429714) and the Dutch Trial registry in November 2010 (NTR2597). 


\section{Introduction}

While most guidelines for the management of deep vein thrombosis (DVT) emphasize the pharmacological treatment with anticoagulants and mainly focus on prevention of recurrent events, little attention is directed towards the prevention of long-term outcomes such as post thrombotic syndrome. ${ }^{(1-3)}$ Post thrombotic syndrome is the most frequent complication of DVT, affecting 20$50 \%$ of patients $1-2$ years after DVT. (4-7) It is a chronic condition that is characterized by mild to severe symptoms and signs of venous insufficiency ranging from pain, sensation of leg heaviness, discomfort, pretibial edema, skin induration, hyperpigmentation, to venous ulceration in the most severe cases. The Villalta scale is a tool to diagnose and define the severity of post thrombotic syndrome using the above-mentioned signs and symptoms. ${ }^{(8)}$ Due to its frequency, possible severity and chronicity, post thrombotic syndrome is not only costly but is also associated with a decrease in quality of life. ${ }^{(9-11)}$ Currently, there is no cure for the condition; therefore acute treatment of DVT should include prompt prevention of post thrombotic syndrome. Post thrombotic syndrome is thought to be a result of venous hypertension, caused by a combination of vein-wall remodeling, residual vein obstruction (RVO) and valvular reflux. $\left({ }^{12,13)(14-16)}\right.$ The role of RVO as an independent risk factor for the onset of post thrombotic syndrome remains controversial. Known risk factors for post thrombotic syndrome are amongst others older age (RR 1.3-3; $\left.{ }^{5}, 17-19\right)$, obesity (RR >2), (5, 17, 19, 20) history of ipsilateral DVT (RR 6-7),(18-22) proximal DVT (RR 2-3), (22, 23) pre-existing primary venous insufficiency (RR 1.2-1.8) ${ }^{(22)}$ and inadequate international normalized ratio (INR) control during first 3 months of warfarin treatment (RR 2.7). ${ }^{(21)}$ The role of compression for the prevention of post thrombotic syndrome is undecided. A recent guidance for prevention of post thrombotic syndrome solely recommends optimal anticoagulant treatment of DVT with the use of pharmacologic agents or mechanical thromboprophylaxis in high-risk patients. ${ }^{24,25)}$ Once venous thrombosis has occurred, there is weak 
recommendation (class IIB) against routine use of elastic compression stockings to prevent post thrombotic syndrome. Nevertheless, a recent Cochrane metaanalysis showed that a $30 \%$ reduction in occurrence of post thrombotic syndrome could be achieved by application of compression stockings. (24-26) Elastic compression stockings are usually prescribed and fitted once the acute edema has resolved. Until then, it is customary in the Netherlands to offer early compression therapy in the form of multilayer compression bandaging or compression hosiery starting within 24 hours after DVT. The immediate compression phase typically comprises 4 weeks after the acute event of thrombosis and ends as soon as the edema is resorbed and compression stockings are fitted. To date, little is known about the effect of immediate compression in this early stage of the thrombosis; only three small, randomized controlled trials ( $n=45, n=69, n=73$ ) have been published. ${ }^{(27-29)}$ All these studies found an effect of direct compression therapy on occurrence of post thrombotic syndrome and recanalization on the short term. Moreover two of them reported faster reduction of pain and swelling with compression. However long-term effects were negative, (28) not assessed ${ }^{(29)}$ or uncertain. ${ }^{(27)}$ Furthermore, the effect of compression on occurrence of RVO, and the role of RVO in relation to risk of recurrence is not unequivocally clear. ${ }^{(30)}$ The aim of the current study is to investigate the effect of immediate compression therapy on the presence of $\mathrm{RVO}$, and to assess the association of RVO with the incidence of post thrombotic syndrome 6 and 24 months after venous thrombosis as well as the association between RVO and recurrent venous thromboembolism within 24 months.

\section{Methods}

For this study, no separate ethical was needed or acquired, but data from the IDEAL study were used. For the IDEAL study, ethical approval was obtained by the institutional review board of Maastricht University Medical Centre and acknowledged by the ethical review boards of participating centers (NL 
32073.068.10). The trial was funded by a grant by ZonMw the Netherlands (grant number 171102007). The trial was registered at ClinicalTrials.gov number, NCT01429714. All participants gave written informed consent before any study related activity was performed.

\section{Study design and population}

The present study is pre-specified a sub study of the IDEAL DVT trial.

Briefly, the IDEAL DVT study was a randomized controlled non-inferiority trial that included 865 adult patients with objectively confirmed proximal DVT, without any history of previous ipsilateral venous thrombosis and without signs of venous insufficiency in 12 centers in the Netherlands and two centers in Italy. The study compared fixed duration of elastic compression therapy to tailored duration based on clinical signs and symptoms (the Villalta score). The study has been described in detail previously. ${ }^{(31)}$ The current sub study assessed the presence of RVO at one week before cessation of anticoagulant treatment. Ten of the 12 Dutch centers that participated in the IDEAL DVT trial also participated in present study; the two Italian centers did not participate.

In the acute phase compression was initiated and executed according to three pre-specified protocols, one per participating center. One center followed the protocol of no initial compression, seven centers applied short stretch multilayer compression bandaging (thigh high with $30-40 \mathrm{mmHg}$ pressures applied) and two centers used compression hosiery (Mediven ${ }^{\circledR}$ Struva35mmHg) initially until edema was resorbed and compression stockings were fitted. After this initial phase, all patients wore fitted compression stockings for 6 months. All patients participating in the RVO sub study were anticoagulated for a period of at least three months. The mean time within therapeutic range for the first 3 months of treatment for the patients anticoagulated with vitamin $\mathrm{K}$ antagonists within the ten study sites that participated in the sub study was provided by the anticoagulation clinics and calculated according to the Rosendaal method. (32) The current study assessed the presence of RVO at one week before cessation 
of anticoagulant treatment. Ten of the 12 Dutch centers participated in the present sub study, the two Italian centers did not participate.

\section{The outcomes}

When discontinuation of anticoagulation was considered, independent radiologists in the participating centers performed compression ultrasonography to determine the presence of RVO, guided by a pre-specified protocol based on literature. ${ }^{(33)}$ The patients were in a supine position, and the examined vein was imaged in a transverse plane. RVO was defined as the persistence of thrombotic material resulting in a diameter of at least $2 \mathrm{~mm}$ during full compression in either the common femoral vein at the groin or the popliteal vein in the popliteal fossa. The radiologists were required to describe the findings systematically according to one standard, provided by the study. Technical devices were dependent on hospital's preferences and availability. Post thrombotic syndrome was assessed using the ISTH consensus scoring method: a total Villalta score of $\geq 5$ at least 6 months after the diagnosis of DVT. An independent radiologist objectively confirmed the occurrence of recurrent venous thromboembolism.

\section{Statistical analysis}

Baseline differences between the groups with and without compression in the acute phase were assessed based on $\mathrm{Chi}^{2}$ test for categorical variables, and oneway ANOVA for continuous variables. The presence of RVO was analyzed as a binominal outcome. For the associations between RVO, compression in the acute phase of DVT and recurrent venous thromboembolism, multivariate logistic regression analyses was performed. Analyses were adjusted for statistically significant baseline differences: extent and type of thrombosis (provoked, unprovoked). Analyses were also adjusted for treatment effect after 6 months (individualized or standard duration of elastic compression stockings, the IDEAL intervention effect). Sensitivity analysis was performed with complete cases and by performing the analyses restricted to the group of patients with 
DVT in the common femoral vein. The level of statistical significance was set at a $p$ value of $\leq 0.05$. The software program SPSS version 23.0 was used for all analyses.

\section{Results}

In total 592 patients with a mean age of 57.0 years (SD 15.0) participated in this study. The majority (57.8\%) was male. The average body mass index was 28.2 $\mathrm{km} / \mathrm{m}^{2}$ (SD 5.3). A history of contralateral DVT was seen in $10.1 \%$. In $52.2 \%$ of patients the DVT was located in the popliteal vein, followed by the femoral vein in $27.5 \%$ and the common femoral vein in $20.1 \%$. The left leg was involved in $52.7 \%$, the right leg in $46.5 \%$ and $0.8 \%$ of patients had bilateral DVT. The majority of patients (80.6\%) were prescribed vitamin $\mathrm{K}$ antagonists, 3.0\% received direct oral anticoagulants, $11.1 \%$ used investigational anticoagulants (either warfarin or rivaroxaban) and $4.4 \%$ used low molecular weight heparin monotherapy. The mean duration of anticoagulant therapy was 258 (SD 178) days. The meantime within therapeutic range for short-term anticoagulation therapy (first 3 months of treatment) was $74.03 \%$ (SD 3.7) for the sites with immediate compression (both multilayer bandaging and compression hosiery) and 76.07(SD 4.6) for the site without initial compression. The average time from diagnosis to the assessment of RVO was 5.3 (SD 1.9) months. Table 1 provides the baseline characteristics of the study population for clinical characteristics.

Overall, in the acute phase 72 patients (12.2\%) received no compression, multilayer compression bandaging was applied in 369 patients (62.3\%) and compression hosiery was applied in 151 patients (25.5\%). Statistically significant differences in the compression groups were observed in regard to thrombus location and type of DVT. In the non-compression group thrombus location was at the level of the popliteal vein in $39.4 \%$, in $28.2 \%$ femoral and $32.4 \%$ common femoral. For the compression group, this was $54.0 \%$ (range across centers $43.9 \%$ to $65.0 \%$ ), $27.5 \%$ (range across centers $0 \%$ to $43.9 \%$ ) and $18.5 \%$ (range across 
centers $5.9 \%$ to $45.5 \%$ ) respectively, $p=0.014$. Provoked DVT was observed in $42.3 \%$ of the patients without compression and $29.3 \%$ (range across groups $13.3 \%$ to $48.5 \%)$ of the patients with compression therapy $(p=0.046)$.

Compression in the acute phase and residual vein obstruction

In total 289 out of 592 patients (48.8\%) had RVO on ultrasound (Table 2). Of the patients in the non-compression group, $66.7 \%$ had RVO compared to $46.3 \%$ of the patient that received compression therapy $(47.4 \%$ for compression bandaging, $43.7 \%$ hosiery). This corresponds to an absolute reduction of $20.4 \%$ (OR 0.46 (95\% Cl 0.27 to 0.80) p=0.005 of RVO when compression therapy is applied in the acute phase. 


\section{Table 1: Baseline demographic and clinical characteristics $\mathrm{N}=592$}

Mean age, years (SD)

57.0 (15.0)

Male, N (\%)

$342(57.8)$

Mean body mass index, $\mathrm{kg} / \mathrm{m}^{2}(\mathrm{SD})$

$28.2(5.3)$

Previous DVT contralateral N (\%)

Provoked thrombosis N (\%)

$182(30.7)$

DVT location N (\%)

Popliteal vein

309 (52.2)

Femoral vein

Common femoral vein

Left leg

Right leg

275 (46.5)

Bilateral

DVT treatment (\%)

Vitamin $\mathrm{K}$ antagonist (VKA) ${ }^{\dagger}$

477 (80.6)

Non vitamin $\mathrm{K}$ anticoagulants (DOAC) ${ }^{\ddagger}$

Investigational anticoagulants ${ }^{\S}$

Low molecular weight heparin

Duration anticoagulant therapy (days)

Average time from diagnosis to second ultrasound, months (SD)

Compression therapy in the acute phase of DVT (\%)

No initial compression

Initial compression therapy

Multilayer compression bandaging

Compression hosiery

Deep vein thrombosis (DVT). ${ }^{\dagger}$ All patients with VKA had initially 5-10 days Low molecular

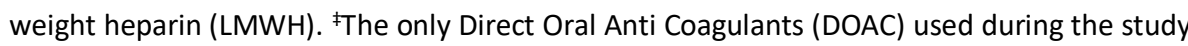
was rivaroxaban. \$Some patients participated in studies comparing investigational anticoagulants (warfarin versus edoxaban), LMWH in patients with malignancy. 


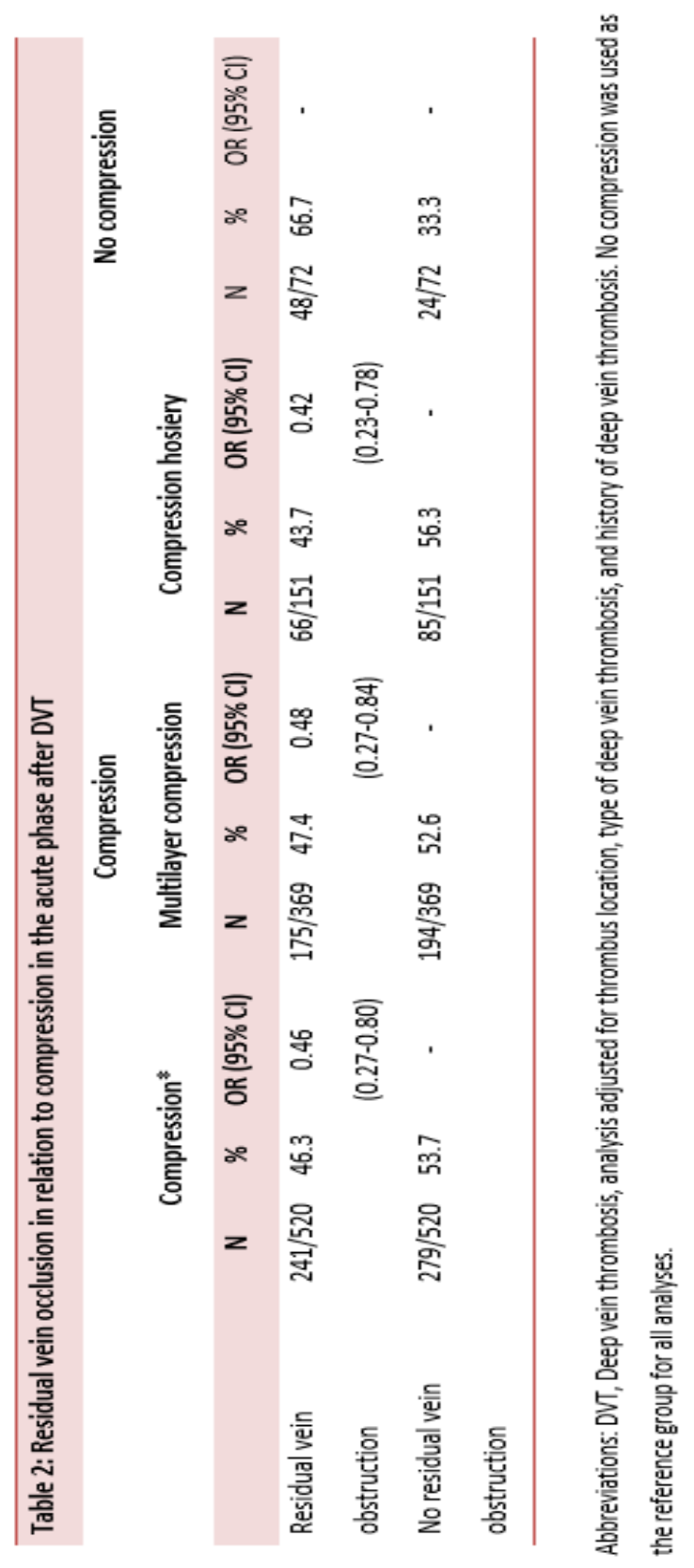




\section{Residual vein obstruction and post thrombotic syndrome}

Table 3 illustrates the occurrence of RVO in relation to post thrombotic syndrome at 6 and 24 months after DVT, and recurrent venous thromboembolism at 24 months after DVT. At 6 months $55.7 \%$ of patients with post thrombotic syndrome had RVO compared to $44.3 \%$ without post thrombotic syndrome (OR $0.6695 \% \mathrm{Cl} 0.46-0.96, p=0.029$ ). The same trend was observed at 24 months: patients without post thrombotic syndrome had less often RVO (46.0\%) than patients with post thrombotic syndrome (54.0\%); OR $0.65 ; 95 \% \mathrm{Cl} 0.46-0.92, \mathrm{p}=0.013)$. Sub group analyses with only patients who were diagnosed with DVT in the common femoral vein showed no significant effect of immediate compression in the acute phase on presence of RVO. RVO was observed in $65.2 \%$ of the patients with common femoral vein thrombosis in the no compression group, and in $64.6 \%$ of the patients with compression (OR $0,9395 \% \mathrm{Cl} 0.35-2.43 \mathrm{p}=0.579$ ). RVO was also not significantly associated with post thrombotic syndrome at 24 months (OR $0.7795 \% \mathrm{Cl} 0.54$ to $1.12, p=0.186$ ) in this subgroup of patients.

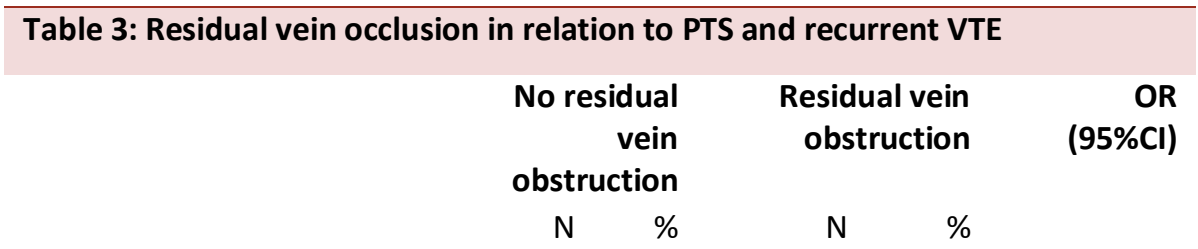

Post thrombotic syndrome at $\mathbf{6}$ and 24 months after DVT*

$\begin{array}{lllllr}\text { Villalta score } \geq 5 \text { at } 6 \text { months } & 77 / 174 & 44.3 & 97 / 174 & 55.7 & 0.66(0.46- \\ & & & & & 0.96) \\ \text { Villalta score } \geq 5 \text { between at } & 142 / 309 & 46.0 & 167 / 309 & 54.0 & 0.65(0.46- \\ 24 \text { months } & & & & & 0.92)\end{array}$

Recurrent venous thromboembolism between 6 to 24 months*

$\begin{array}{llllll}\text { Deep vein thrombosis } & 12 / 30 & 40.0 & 18 / 30 & 60.0 & 0.82(0.61-\end{array}$ 
\begin{tabular}{llllll}
\hline Pulmonary embolism & $9 / 19$ & 47.7 & $10 / 19$ & 52.6 & $0.95(0.61-$
\end{tabular}

Abbreviations: PTS, post thrombotic syndrome; OR; Odds ratio; $\mathrm{Cl}$; confidence interval; DVT, deep vein thrombosis; VTE, venous thromboembolism *Analyses adjusted for the intervention effect in IDEAL DVT study

Residual vein obstruction and recurrent thromboembolism

No significant association between RVO and recurrent venous thromboembolism was observed (Table 3). A total of 30 recurrent events of DVT was observed during the study of which 60 percent had RVO compared to $40 \%$ without RVO; OR 0.82 (0.61 to 1.12), p=0.263. Recurrent pulmonary embolism occurred in 19 patients in total of whom $52.6 \%$ had RVO, and $47.7 \%$ not; OR 0.95 (0.61 to 1.46$) p=0.805)$.

\section{Discussion}

This study shows that starting compression treatment in the acute phase, as soon as 24 hours after the diagnosis of DVT, significantly reduces the absolute incidence of RVO with $20.4 \%$. Moreover, the incidence of post thrombotic syndrome both at 6 and at 24 months was significantly lower in patients without RVO compared to patients with RVO with an absolute difference of $11.4 \%$ at 6 months and $8 \%$ at 24 months. This suggests that RVO does contribute to the development of post thrombotic syndrome and that compression therapy may prevent post thrombotic syndrome from the very early start of thrombosis treatment. The efficacy of both multilayer bandaging compression and compression hosiery was similar. Our data do not show a significant association of RVO with the occurrence of recurrent venous thromboembolism; the number of recurrences was however too low to allow for a definitive conclusion. 
Our study has some weaknesses, first this is a sub analysis of data from a large randomized trial, and the study sample as such is not randomized. However, adjustments for differences in distribution of patient characteristics between the groups compared were made in the analyses. Furthermore, a small proportion of patients were anticoagulated with a direct oral anticoagulant or low molecular weight monotherapy. It has been suggested that these types of anticoagulation may influence the risk of post thrombotic syndrome. Another potential weakness is the fact that only assumptions can be made on the mode of action of compression; therefore the data do not allow inference for causality. There are however several strengths. First, this is the first study with a long term follow up of patients and with a sufficiently large sample size to provide reliable information on the clinical importance of early compression therapy following acute DVT. Second, the assessor-blinded design that included frequent assessments of the leg provided sufficient and dependable data for analysis. Only three studies have been performed on the efficacy of early compression therapy in the acute phase so far. One trial $(n=45)$ randomized between inelastic bandages plus walking exercises, elastic compression stockings plus walking exercises, and no compression with bed rest. ${ }^{(27)}$ After 2 years, less post thrombotic syndrome was seen in patients randomized to compression therapy and ambulation (34), it is uncertain whether this was the effect of early compression or walking exercises. Roumen et al randomized between immediate multilayer compression bandages and no compression before application of elastic compression stockings. ${ }^{(28)}$ This study $(n=69)$ found a reduction of symptoms and edema in the first week, but no difference in PTS after 1 year. The third trial $(n=73)$ compared acute initiation of compression hosiery with hosiery starting after 14 days. ${ }^{(29)}$ Better recanalization of the thrombus was detected at 14 and 90 days in patients in which acute initiation of hosiery was applied, but long-term effects on post thrombotic syndrome were not assessed. Hence, our study fills both the need for a larger sample size and the evaluation of long-term effects. 
In the past decade, improvements have been achieved mainly in the pharmacological treatment of DVT in terms of reducing the risk of recurrence against a lower risk of bleeding. However, to date, no effective therapy in the acute phase is available to help restore venous patency and reduce the risk of long-term sequelae such as post thrombotic syndrome.

Our conclusion suggests that early compression treatment results in a lower incidence of residual vein thrombosis and consequently in less post thrombotic syndrome, and is in line with expectations based on the open vein hypothesis: "early thrombus resolution results in less post thrombotic syndrome because there is less vein wall damage due to the shorter duration that the thrombus is adjacent to the vessel wall".

The use of early catheter directed thrombolysis to restore venous patency was expected to effectively reduce the risk of post thrombotic syndrome in selected patients with more proximal extended thrombosis. However, so far thrombolysis has been consistently associated with an increased risk of bleeding, but its effectiveness has not been unequivocally proven. ${ }^{(34,35)}$

Compression therapy has virtually no contraindications and harbors no risk of bleeding. In our population, 119 patients (20.1\%) were diagnosed with a proximal DVT in the common femoral vein. We found that especially in this subset of patients, early compression therapy might not be effective, highlighting the importance of correct identification of patients eligible for treatment strategies in the acute phase and the need for additional treatment options.

How precisely immediate compression therapy affects the recovery of venous patency cannot be answered by the current study. We may only hypothesize that mechanical compression reduces the vein diameter and thereby increases the venous return and as a result promotes thrombus resolution. ${ }^{(36,37)}$ Better venous return reduces edema and improves calf muscle function. (38) Moreover, compression therapy restores the microcirculation thereby promoting the inflammatory response necessary for thrombus resolution. Current guidelines 
suggest application of compression only in case patients experience complaints. (1) In alignment with this some clinicians only tend to apply immediate compression therapy if the patient presents with more severe symptoms of the DVT. The results of our study indicate however that immediate compression therapy should not only be applied in patients with increased symptomatology merely to reduce symptoms, but more importantly suggests that immediate compression should be applied in all patients even in those that are asymptomatic in order to prevent post thrombotic syndrome. That impaired thrombus resolution is an important driver in the onset of post thrombotic syndrome is also known from earlier studies showing that sub therapeutic anticoagulant therapy, and thereby insufficient inhibition of the formation of thrombin and activation of TAFI, is a risk factor for post thrombotic syndrome. (21) (39) Sub therapeutic INR was found to increase the risk of post thrombotic syndrome almost two-fold, while adequate anticoagulation therapy reduced the risk of post thrombotic syndrome by $11.9 \%$ (40) A risk reduction of the same order was found among patients using direct oral anticoagulants compared to warfarin, but this was not statistically significant and needs further corroboration. ${ }^{(41)}$ Also long-term treatment with low-molecular weight heparin in comparison to warfarin treatment has been shown to result in lower incidences of PTS. ${ }^{(42)}$ The effect of immediate compression therapy is similar to the effect of improvement of anticoagulant therapy. In our sample the time within therapeutic range was found to be adequate and highly comparable between centers with and without immediate compression therapy.

We would like to suggest therefore that compression therapy should be added to new pharmacological strategies in order to achieve optimal prevention of post thrombotic syndrome. The application of immediate compression therapy within 24 hours of the diagnosis of DVT is common clinical practice in most Dutch hospitals. It is therefore shown that it is feasible to provide such care. 
The cost-effectiveness for the application of immediate compression for all patients with acute DVT should be investigated. It may be anticipated that the application of multi-layer bandaging will be less cost-effective compared to compression hosiery. Furthermore, patients with iliofemoral DVT did not profit from immediate compression to the same extend as patients with less extensive DVT. Future research should be directed at better understanding of the underlying pathophysiology, and should be tailored to the individual patient's needs. The use of prediction models might assist doctors in the allocation of adjunctive treatment modalities to those who are likely to profit most.

In conclusion, we suggest that in addition to adequate anticoagulation therapy, immediate compression therapy - either with multilayer bandaging or with compression hosiery - should be implemented in daily clinical practice and that the application of early compression therapy in patients with acute DVT should be irrespective of symptomatology in order to optimize the prevention of post thrombotic syndrome. Furthermore, identification of patients at increased risk of post thrombotic syndrome should be performed in the acute phase in order to be able to provide these patients with adjunctive treatment. 


\section{References}

1. Kearon C, Akl EA, Ornelas J, et al. Antithrombotic Therapy for VTE Disease: CHEST Guideline and Expert Panel Report. Chest. 2016;149(2):315-52.

2. Howard LS, Hughes RJ. NICE guideline: management of venous thromboembolic diseases and role of thrombophilia testing. Thorax. 2013;68(4):391-3.

3. National Clinical Guideline C. National Institute for Health and Clinical Excellence: Guidance. Venous Thromboembolic Diseases: The Management of Venous Thromboembolic Diseases and the Role of Thrombophilia Testing. London: Royal College of Physicians (UK)National Clinical Guideline Centre; 2012.

4. Prandoni $P$, Lensing $A W, \operatorname{Cogo} A$, et al. The long-term clinical course of acute deep venous thrombosis. Ann Intern Med. 1996;125(1):1-7.

5. Kahn SR, Shrier I, Julian JA, et al. Determinants and time course of the postthrombotic syndrome after acute deep venous thrombosis. Ann Intern Med. 2008;149(10):698-707.

6. Prandoni P, Kahn SR. Post-thrombotic syndrome: prevalence, prognostication and need for progress. Br J Haematol. 2009;145(3):286-95.

7. Saarinen J, Kallio T, Lehto M, Hiltunen $S$, Sisto $T$. The occurrence of the post-thrombotic changes after an acute deep venous thrombosis. A prospective two-year follow-up study. J Cardiovasc Surg (Torino). 2000;41(3):441-6.

8. Villalta S BP, Picolli A, Lensing A, Prins M, Prandoni P. Assessment of validity and reproducibility of a clinical scale for the post thrombotic syndrome. Haemostasis. 1994;24((158a))

9. Kahn SR, Hirsch A, Shrier I. Effect of postthrombotic syndrome on health-related quality of life after deep venous thrombosis. Arch Intern Med. 2002;162(10):1144-8.

10. Bergqvist D, Jendteg $S$, Johansen L, Persson U, Odegaard K. Cost of long-term complications of deep venous thrombosis of the lower extremities: an analysis of a defined patient population in Sweden. Ann Intern Med. 1997;126(6):454-7.

11. Lubberts B, Paulino Pereira NR, Kabrhel C, Kuter DJ, DiGiovanni CW. What is the effect of venous thromboembolism and related complications on patient reported health-related quality of life? A meta-analysis. Thromb Haemost. 2016;116(3):417-31.

12. Amin E, Joore MA, Ten Cate-Hoek AJ. Compression to prevent PTS: a controversy? Phlebology. 2016;31(1 Suppl):41-7.

13. ten Cate-Hoek AJ, Henke PK, Wakefield TW. The post thrombotic syndrome: Ignore it and it will come back to bite you. Blood Rev. 2016;30(2):131-7. Kurstjens RL, de Wolf MA, Konijn HW, et al. Intravenous pressure changes in patients with postthrombotic deep venous obstruction: results using a treadmill stress test. J Thromb Haemost. 2016;14(6):1163-70.

14. Strandness DE, Jr., Langlois $Y$, Cramer M, Randlett A, Thiele BL. Long-term sequelae of acute venous thrombosis. JAMA. 1983;250(10):1289-92.

15. Prandoni $\mathrm{P}$, Lensing $\mathrm{AW}$, Prins $\mathrm{MH}$, et al. The impact of residual thrombosis on the longterm outcome of patients with deep venous thrombosis treated with conventional anticoagulation. Semin thromb hemost. 2015;41(2):133-40.

16. Galanaud JP, Holcroft CA, Rodger MA, et al. Predictors of post-thrombotic syndrome in a population with a first deep vein thrombosis and no primary venous insufficiency. $J$ Thromb Haemost. 2013;11(3):474-80.

17. Schulman $S$, Lindmarker $P$, Holmstrom $M$, et al. Post-thrombotic syndrome, recurrence, and death 10 years after the first episode of venous thromboembolism treated with warfarin for 6 weeks or 6 months. J Thromb Haemost. 2006;4(4):734-42. 
18. Tick LW, Kramer MH, Rosendaal FR, Faber WR, Doggen CJ. Risk factors for post-thrombotic syndrome in patients with a first deep venous thrombosis. I Thromb Haemost. 2008;6(12):2075-81.

19. Stain $M$, Schonauer V, Minar E, et al. The post-thrombotic syndrome: risk factors and impact on the course of thrombotic disease. J Thromb Haemost. 2005;3(12):2671-6.

20. van Dongen CJ, Prandoni P, Frulla M, Marchiori A, Prins MH, Hutten BA. Relation between quality of anticoagulant treatment and the development of the postthrombotic syndrome. J Thromb Haemost. 2005;3(5):939-42.

21. Tick LW, Doggen CJ, Rosendaal FR, et al. Predictors of the post-thrombotic syndrome with non-invasive venous examinations in patients 6 weeks after a first episode of deep vein thrombosis. J Thromb Haemost. 2010;8(12):2685-92.

22. Labropoulos N, Waggoner T, Sammis W, Samali S, Pappas PJ. The effect of venous thrombus location and extent on the development of post-thrombotic signs and symptoms. J Vasc Surg. 2008;48(2):407-12.

23. Kahn SR, Galanaud JP, Vedantham S, Ginsberg JS. Guidance for the prevention and treatment of the post-thrombotic syndrome. J Thromb Thrombolysis.2016;41(1):144-53.

24. Kahn SR, Comerota AJ, Cushman M, et al. The postthrombotic syndrome: evidence-based prevention, diagnosis, and treatment strategies: a scientific statement from the American Heart Association. Circulation. 2014;130(18):1636-61.

25. Appelen D, van Loo E, Prins MH, Neumann MH, Kolbach DN. Compression therapy for prevention of post-thrombotic syndrome. Cochrane Database Syst Rev. 2017;9:Cd004174.

26. Partsch $\mathrm{H}$, Blattler $\mathrm{W}$. Compression and walking versus bed rest in the treatment of proximal deep venous thrombosis with low molecular weight heparin. J Vasc Surg. 2000;32(5):861-9.

27. Roumen-Klappe EM, den Heijer M, van Rossum J, et al. Multilayer compression bandaging in the acute phase of deep-vein thrombosis has no effect on the development of the postthrombotic syndrome. J Thromb Thrombolysis. 2009;27(4):400-5.

28. Arpaia G, Cimminiello C, Mastrogiacomo O, de Gaudenzi E. Efficacy of elastic compression stockings used early or after resolution of the edema on recanalization after deep venous thrombosis: the COM.PRE Trial. Blood Coagul Fibrinolysis. 2007;18(2):131-7.

29. Donadini MP, Ageno W, Antonucci E, et al. Prognostic significance of residual venous obstruction in patients with treated unprovoked deep vein thrombosis: a patient-level meta-analysis. Thromb Haemost. 2014;111(1):172-9.

30. Ten Cate-Hoek AJ, Amin EE, Bouman AC, et al. Individualised versus standard duration of elastic compression therapy for prevention of post-thrombotic syndrome (IDEAL DVT): a multicentre, randomised, single-blind, allocation-concealed, non-inferiority trial. Lancet Haematol. 2018; 5(1): e25-e33.

31. Rosendaal FR, Cannegieter SC, van der Meer FJ, Briet E. A method to determine the optimal intensity of oral anticoagulant therapy. Thromb Haemost. 1993;69(3):236-9.

32. Tan $M$, Bornais $C$, Rodger $M$. Interobserver reliability of compression ultrasound for residual thrombosis after first unprovoked deep vein thrombosis. J Thromb Haemost. 2012;10(9):1775-82.

33. Partsch $\mathrm{H}$, Kaulich M, Mayer W. Immediate mobilisation in acute vein thrombosis reduces post-thrombotic syndrome. Int Angiol. 2004;23(3):206-12.

34. Haig $Y$, Enden $T$, Grotta $O$, et al. Post-thrombotic syndrome after catheter-directed thrombolysis for deep vein thrombosis (CaVenT): 5-year follow-up results of an openlabel, randomised controlled trial. Lancet Haematol. 2016;3(2):e64-71. 
35. Flour $\mathrm{M}$, Clark $\mathrm{M}$, Partsch $\mathrm{H}$, et al. Dogmas and controversies in compression therapy: report of an International Compression Club (ICC) meeting, Brussels, May 2011. Int wound j. 2013;10(5):516-26.

36. Cooley BC, Chen CY, Hess R, Schmeling G. Incomplete resolution of deep vein thrombosis under reduced flow conditions. Thromb Res. 2013;131(1):55-8.

37. Mosti G, labichella ML, Partsch H. Compression therapy in mixed ulcers increases venous output and arterial perfusion. J Vasc Surg. 2012;55(1):122-8.

38. Ziegler S, Schillinger M, Maca TH, Minar E. Post-thrombotic syndrome after primary event of deep venous thrombosis 10 to 20 years ago. Thromb Res. 2001;101(2):23-33.

39. Chitsike RS, Rodger MA, Kovacs MJ, et al. Risk of post-thrombotic syndrome after subtherapeutic warfarin anticoagulation for a first unprovoked deep vein thrombosis: results from the REVERSE study. J Thromb Haemost. 2012;10(10):2039-44.

40. Cheung YW, Middeldorp S, Prins MH, et al. Post-thrombotic syndrome in patients treated with rivaroxaban or enoxaparin/vitamin $\mathrm{K}$ antagonists for acute deep-vein thrombosis. A post-hoc analysis. Thromb Haemost. 2016;116(4):733-8.

41. Hull RD, Liang J, Townshend G. Long-term low-molecular-weight heparin and the postthrombotic syndrome: a systematic review. Am J Med. 2011;124(8):756-65. 
PART III

SUMMARY \& GENERAL DISCUSSION 


\section{Chapter 8}

Summary \& General Discussion 
The objective of this thesis was to make a contribution to the field and to develop a tool to enable clinicians to personalize management for the prevention of postthrombotic syndrome (PTS). Focus is placed on the non-invasive management approach with compression therapy as the main factor. This chapter provides a summary of the principle findings and elaborates on the results in light of current clinical practice.

\section{Part I Prevention and Prediction}

After a general introductory chapter, in part I of the thesis strategies to improve prevention and prediction in PTS management were studied. Chapter $\mathbf{2}$ is a literature review summarizing current challenges in PTS management. It was concluded that in order to advance PTS management it is necessary to start piecing the puzzle together, aggregating current knowledge on pathophysiology, risk factors, available preventive measures and the impact PTS may have on quality of life and societal costs. Previously, it has been shown that the quality of life becomes worse as PTS becomes more severe ${ }^{(1)}$. Moreover, deep vein thrombosis (DVT) with PTS occurrence is significantly more expensive than DVT without PTS ${ }^{(2,3)}$. Hence, PTS may have serious consequences for the individual patient as well as the society at large.

The main hypothesis with respect to the pathophysiology of PTS is that it results from a combination of venous valve damage, flow obstruction and an inflammatory response to acute thrombus formation that contributes to occurrence of venous hypertension ${ }^{(4-7)}$. As a consequence, there is a capillary overload resulting in impaired microcirculation, which induces the skin changes that are associated with PTS ${ }^{(8)}$. In order to prevent PTS, this chain of events needs to be stopped. It is assumed that venous hypertension can be counteracted with application of compression therapy, and consequently compression therapy has been the most widely prescribed preventive measure for PTS. Apart from compression therapy, some other preventive options are 
being proposed e.g. optimal anticoagulant treatment in order to reduce ongoing thrombus formation $(9,10)$, the use of anti-inflammatory medication to attenuate the inflammatory response(11), the use of veno-active drugs to attenuate oedema $(12,13)$, and life style interventions to reduce weight and promote calf muscle action ${ }^{(14,15)}$. These options could be applied in addition to or as a substitute to compression therapy. The effect of most of these interventions still needs to be established.

In chapter 3 we described the development and validation of a prediction model for PTS. We used a cohort of 479 consecutive patients with DVT to develop a practical two-step prediction model. We subsequently derived two simplified clinical risk scores. Selection of the candidate predictors was based on what in the literature is known as established or presumed risk factor of PTS, and variables that were present in the derivation cohort. With use of multivariate logistic regression backwards elimination techniques, the candidate predictors were chosen. We developed two models; a baseline model with only baseline clinical and demographic characteristics to be used at time of DVT diagnosis for predicting the risk of PTS occurrence at 6 months after DVT, and a secondary model with additional variables for PTS prediction at 24 months in patients who did not develop PTS until 6 months after DVT. These risk scores were externally validated in an Italian cohort of 1107 consecutive patients with DVT in which one predictor (smoking) was missing. Despite the missing predictor, the validation of the risk scores was successful. This validated practical clinical risk score can therefore be used in clinical practice to further personalize preventive treatment.

In the developmental phase of the model we have explored the influence of alternative PTS definitions on the model's performance and found that

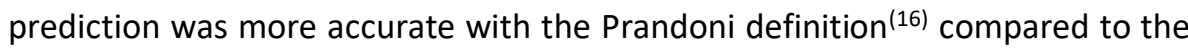
ISTH definition, for the secondary model (AUCs baseline and secondary model after internal validation 0.69 , versus 0.71 and 0.60 for ISTH definition baseline and secondary model respectively). Moreover, prediction was more efficient 
with the Prandoni definition i.e. if the Prandoni definition is chosen less patients with no or mild symptoms are identified as being at risk for PTS compared to the models based on the ISTH definition. Hence, the choice of PTS definition affects the prediction accuracy and efficiency to a large extent. This is presumably due to the fact that the diagnosis is made more conservatively and thereby more accurately in the subacute phase when the Prandoni definition to diagnose PTS is used. Further analysis showed that the main difference in ability of both definitions to distinguish between PTS and no PTS was for diagnosis of mild cases of PTS. In diagnosis of moderate and severe cases both definitions performed similarly.

\section{Part II Comparative effectiveness and cost effectiveness}

Part II of the thesis enclosed studies on comparative effectiveness of several strategies for PTS prevention and the cost-effectiveness of the main strategy. Chapter 4 describes the results of the IDEAL DVT study. The individualized duration of elastic compression stockings (ECS) for prevention of PTS was compared to the standard duration of 24 months. The aim was to investigate whether a shorter duration of ECS was feasible and safe. The main outcome measure was PTS defined as two consecutive Villalta scores of $\geq 5$ (original definition of PTS, according to Prandoni); $55 \%$ of the patients allocated to the individualized treatment wore ECS for 6 months and another $11 \%$ wore ECS until 12 months. In total, $66 \%$ of the patients had ECS therapy less than the standard duration of 24 months. Compliance, indicating adherence to therapy advice daily or almost daily, ranged from $96 \%$ at 3 months to $78 \%$ at 24 months. This high rate of compliance strengthens the observations in this non-inferiority trial. The IDEAL trial also showed that at 24 months the cumulative incidence of PTS was $28.9 \%(95 \% \mathrm{Cl} 24.7$ to 33.5 ) in the individualized group and $27.8 \%$ (95\% Cl 23.6 to 32.4 ) in the standard ECS duration group, hazard ratio adjusted for centre $1.13,95 \% \mathrm{Cl} 0.88$ to $1.46 ; \mathrm{p}=0.77$. The absolute difference was $1.1 \%$ with $95 \% \mathrm{Cl}$ 
upper limit 7.3\%, meaning that the trial met its predefined non-inferiority margin of $7.5 \%$. No statistically significant difference in quality of life was observed between the groups. The quality of life was high in both groups and showed an increase 3 months after diagnosis of thrombosis. The main outcome of the trial indicates that it is safe to individually shorten the duration of ECS based on patients' signs and symptoms.

In analogy of the OCTAVIA study ${ }^{(17)}$ we compared subgroups of patients without complaints and with excellent adherence to ECS therapy from the individualized strategy who were instructed to stop treatment with similar patients from the standard treatment strategy that continued treatment. This sub analysis showed a significant benefit for the standard treatment group, with a number needed to treat of seven for the prevention of PTS for the continuation of 18 months therapy when using the ISTH scoring method. This finding emphasizes that, in general, compression therapy prevents PTS, but given the IDEAL study data, not for all patients prolonged application of stockings is required. The use of a prediction rule, as indicated above, may help to better select those patients that particularly benefit from (prolonged) elastic compression.

In chapter $\mathbf{5}$ we performed an economic evaluation of the investigated strategy in the IDEAL DVT trial as well as for the sub group analysis. The use of ECS induces substantial costs. In the Netherlands alone, the costs of ECS material were estimated to be $€ 2.5$ million per year ${ }^{(18)}$. However, the significant costs are due to homecare associated with ECS use since not all patients are capable of applying and removing the stockings independently. It was calculated that in the Netherlands $€ 21$ million per year is required for home care to assist patients with the application of ECS ${ }^{(18)}$. In order to enhance generalizability, the economic evaluation was carried out with the use of three instruments for effect assessment; EQ-5D-3L Dutch tariff, EQ-5D-3L UK tariff and SF6D. All three instruments demonstrated that quality adjusted life years (QALY) were not different whether patients had shortened duration of ECS or not. In summary, cost-effectiveness analysis showed that individualized duration of ECS was cost- 
effective compared to standard duration with incremental cost effect ratios (ICER) ranging from €305.992 per QALY lost using the EQ-5D-3L Dutch tariff to $€ 6.030 .941$ per QALY lost. Complete case analysis as well as the sub group analysis showed that the strategy was dominant with all instruments. The results indicate that in the Netherlands, for 25.000 incident cases of DVT per annum, the savings (measured over two years) from implementing the individualized strategy would amount to 88 million euros (95\% Cl 31 to 144 million). Uncertainty analysis showed that the probability that the investigated strategy is cost-effective is nearly $100 \%$ with all three instruments. Hence, from an economic perspective, duration of ECS should be individualized.

In Chapter 6 the scope was directed at the clinical and economic impact of compression therapy in the acute phase of DVT. ECS are only applied as soon as the initial oedema is stabilized. Until then, patients with DVT are usually offered some kind of initial compression. This may consist of multilayer compression bandaging, or, more recently, of compression hosiery (pressure $35 \mathrm{mmHg}$ ). In some cases patients do not receive initial compression therapy. The choice is dependent on hospital's protocols and patient's signs and symptoms. Only three small studies have so far assessed the effect of immediate compression on signs and symptoms $(6,19,20)$. The results seemed to suggest beneficial effect of compression, however conclusive answers remained absent. Within the IDEAL trial we compared the effect of three different initial strategies. We studied the influence of compression therapy on the clinical signs and symptoms, assessed with the Villalta score, on quality of life and on healthcare costs measured 3 months after DVT. In accordance with the postulated pathophysiology of PTS, we assumed that external compression would increase (microvascular) flow, allowing better thrombus resolution and improved calf muscle function and thus have better clinical outcomes. We found that compression in any form resulted in a $15 \%$ lower mean Villalta score compared to no initial compression. Compression affected the objective items of the Villalta score that involved irreversible skin signs, and showed no influence on the subjective elements. This 
was reflected in quality of life scores that showed no difference across groups. The costs connected to these different forms of compression were, as could be expected, lowest for the no compression ( $€ 106.39,95 \% \mathrm{Cl} 34.63$ to 199.30 ) and highest for the multilayer bandaging (€417.08, 95\% Cl 354.10 to 489.30 ). When a comparison was made between the two compression groups, it was found that multilayer compression bandaging was more effective in terms of lowering some items of the objective Villalta score, although it was associated with a significantly lower quality of life and substantially higher costs than elastic compression hosiery. Therefore, we concluded that all patients with DVT should be offered compression therapy in the acute phase, as irreversible skin signs develop soon after DVT diagnosis. The acute phase seems crucial for PTS development. Hence, therapy to minimize the risk of PTS development should be offered to the patients with compression hosiery as the preferred choice of therapy.

In Chapter 7 we performed a pre-specified sub study within the IDEAL DVT trial including 592 patients to further elucidate the value of compression in the acute phase and to assess long-term effects of initial compression therapy. For that purpose we investigated the impact of immediate compression in the acute phase of DVT on the presence of residual vein occlusion (RVO) and subsequently the relation between RVO and PTS. In addition, we assessed the impact of residual thrombosis on recurrent venous thrombosis. It was observed that immediate compression was associated with less RVO; $46.3 \%$ of patients who received immediate compression had RVO compared to $66.7 \%$ of patients who did not receive immediate compression (OR $0.4695 \% \mathrm{Cl} 0.27$ to $0.80, \mathrm{p}=0.005$ ). Patients without RVO had significantly less PTS than patients in whom RVO was present ( $46.0 \%$ versus. $54.0 \%$; OR $0.6595 \% \mathrm{Cl} 0.46$ to $0.92 ; \mathrm{p}=0.013$ ). Recurrent venous thrombosis showed no significant association with RVO. These results are in line with the open vein hypothesis, which stipulates that early thrombus resolution results in less PTS because there is less vein wall damage due to the shorter duration that the thrombus is adjacent to the vessel wall. Because 
compression therapy has virtually no contraindications and harbours no risk of bleeding, we concluded that immediate compression should be offered to all patients with acute DVT of the leg irrespective of severity of complaints.

\section{Conclusions and implications of the principle findings}

The value of compression therapy for the prevention of PTS

At the time the IDEAL study was initiated the evidence for the efficacy of compression therapy to prevent PTS was undisputed. Thus, the IDEAL trial was not designed to prove the efficacy of ECS, merely to assess whether individualized ECS treatment would be feasible and would result in similar outcomes for PTS incidence. Upon publication of the SOX trial in $2014^{(21)}$, the ACCP guideline evidence level of compression therapy in PTS prevention was

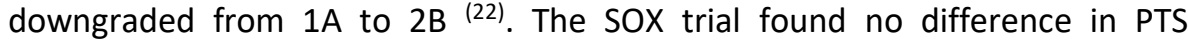
incidences between the ECS group and the placebo stockings group for the outcome PTS ${ }^{(21)}$, challenging the effectiveness of compression therapy. In spite of this negative study, a very recent meta-analysis showed that even incorporating the results of the SOX trial, compression therapy following DVT is anticipated to result in a $30 \%$ reduction in the onset of PTS ${ }^{(23)}$. The results of the comparison of three different strategies for the management of the initial phase of DVT within the IDEAL study, further strengthens the efficacy of compression therapy, also in the initial phase of DVT; immediate compression was associated with less irreversible skin signs, and less RVO which in its turn was associated with less PTS. Moreover, a post hoc analysis for a subgroup of patients in the IDEAL DVT trial showed that the PTS percentage was higher in patients who stopped ECS therapy early. In summary, our data and those of other studies favour the use of compression therapy in all patients with DVT for a variable duration of time, with a minimum of 6 months. 


\section{Implications for clinical practice}

Combining the results presented in this thesis, future clinical management of patients with PTS would implicate a stepwise approach. First, at time of DVT diagnosis all patients without exception should be offered immediate compression therapy in form of compression hosiery. Second, with the use of the externally validated prediction model and its clinical risk score, the risk of PTS development can be calculated and preventive therapy can be adjusted accordingly. Third, immediately following the initial compression phase when acute oedema is stabilized, patients should be prescribed ECS and be instructed on their daily use for at least 6 months. During this period assessment of clinical signs and symptoms by Villalta score should be performed at least two times. This stepwise predictive, preventive and personalized strategy results in a more cost-effective therapy with substantial costs savings, as treatment is tailored to patients' needs with substantial costs savings. Next to costs savings, the stepwise individualized treatment regimen may also result in better therapy compliance on the patients' part. However, whether the ability to provide better individualized advice on both need for and duration of ECS, translates into more optimal adherence to therapy, remains to be established.

\section{External validity and possible implication challenges}

The results from this thesis can be generalized to other PTS populations. Our studies involved a large number of adult patients from academic and nonacademic centres across the Netherlands and Italy. We measured quality of life with generic and disease specific instruments and all outcomes were comparable.

The diagnosis of PTS remains a challenging problem because no gold standard is available. Although it is very much desirable to have one consensus mode of diagnosis, the question whether this method is an accurate one is still disputable. The PTS population is a heterogeneous group of patients ranging from those who experience severe objective signs and subjective complaints to patients with 
hardly any objective signs and mild subjective complaints. Moreover, it has been observed that the Villalta scores fluctuate over time ${ }^{(24)}$ suggesting that one-time assessment of the score may not be ideal. Consequently, the Prandoni definition may serve as a more accurate method. As we found in our analyses, both definitions were equally able to distinguish between moderate and severe cases of PTS and the non-PTS cases. For distinguishing the mild cases from non-cases, the Prandoni definition showed to be more accurate, leading to less overdiagnoses. In practice however, the current ISTH consensus method is more feasible as it requires less frequent assessment of the Villalta score. For better comparison to other studies on PTS, we used the ISTH consensus definition in all our studies. Only for the IDEAL DVT study we used the original Prandoni definition of PTS as the main outcome because the ISTH consensus method was established after the start of preparations for the study. However, we also used the ISTH definition as a secondary outcome. Regardless of the definition, the conclusion that compression therapy is a major contributor to PTS prevention remained the same.

\section{Directions for future research}

The next step in PTS management would be the implementation of the proposed stepwise strategy in order to achieve a cost-effective personalized therapy. This implementation process is not expected to encounter considerable difficulties. The prediction model uses easily available baseline clinical and demographic characteristics at no expenses. For risk prediction in the subacute phase performing ultrasonography is needed and although this does bring costs, these costs are relatively low and the nature of the investigation is non-invasive. Use of compression hosiery in the acute phase showed no negative impact on patients 'quality of life as the patients with compression hosiery had comparable scores for quality of life as patients without any compression. 
Nonetheless, applying the stepwise approach does not conclude PTS management. The principle findings in this thesis raise some new questions and the optimal preventive therapy still needs more fine-tuning. First, an important aspect raised by this thesis is the diagnostic method of PTS. We have argued that the current recommended PTS definition might not accurately distinguish between PTS and non-PTS cases due to a relatively low cut off value for the diagnosis. In addition, the items comprising the subjective part of the score are not specific for PTS and therefore may obscure the outcome. A solution however, is not easily obtained in absence of a gold standard for diagnosis. Imaging techniques could be used to investigate whether alternative clinical scores or cut off values of the Villalta score might be a solution.

Second, theoretically, the presented prediction model might become more accurate if predictive biomarkers in the acute phase of DVT are added. Previous studies have suggested CRP, FVIII, D-dimers, IL6, IL8 and ICAM-1 as biomarkers of value for PTS prediction ${ }^{(25-27)}$.

Third, we have shown that ECS use can be shortened to 6 months if Villalta scores are low. The choice for a 6 months period was based on a previously published management study ${ }^{(24)}$. The question arises whether duration less than 6 months is also feasible, and if so, what would be the minimum duration? We have also shown that immediate compression therapy has attenuating effects on objective signs of PTS, and is associated with less residual vein occlusion. The results from this sub study suggest that compression therapy as short as two to four weeks could be sufficient to prevent PTS development. This further reduction in ECS therapy duration should be studied. Shorter therapy duration may need to be accompanied by additional preventive measures, including life style intervention (weight loss programs, exercise), or the addition of anti-inflammatory drugs or, veno-active drugs, to further attenuate the development in PTS in conjunction with compression therapy. Several drugs including statins and vaso-active agents like hydroxyethylrutoside, merit additional study in patients having suffered a DVT. Whether such pharmacological interventions should be specifically studied 
in highest risk for PTS patients also needs to be investigated. Ideally, future research would be directed at investigating the before mentioned unanswered questions.

Finally, the scope of this thesis was limited to non-invasive treatment strategies. The jury is still out on more invasive methods such as catheter directed thrombolysis of proximal venous thrombosis, to reduce the risk of PTS. While the CAVENT trial showed a $15 \%$ reduction in PTS after CDT ${ }^{(28)}$, the recently published and larger (but also more heterogeneous) ATTRACT study showed no overall benefit of CDT ${ }^{(29)}$. The ongoing CAVA study will add additional data to support or refute $\mathrm{CDT}$ as an intervention aimed at reducing PTS. 


\section{References}

1. Kahn SR, Ducruet T, Lamping DL, Arsenault L, Miron MJ, Roussin A, et al. Prospective evaluation of health-related quality of life in patients with deep venous thrombosis. Archives of internal medicine. 2005;165(10):1173-8.

2. Bergqvist $D$, Jendteg $S$, Johansen $L$, Persson $U$, Odegaard K. Cost of long-term complications of deep venous thrombosis of the lower extremities: an analysis of a defined patient population in Sweden. Annals of internal medicine. 1997;126(6):454-7.

3. Ramacciotti E, Gomes M, de Aguiar ET, Caiafa JS, de Moura LK, Araujo GR, et al. A cost analysis of the treatment of patients with post-thrombotic syndrome in Brazil. Thrombosis research. 2006;118(6):699-704.

4. Phillips $L, 2$ nd, Sarkar R. Molecular characterization of post-thrombotic syndrome. Journal of vascular surgery. 2007;45 Suppl A:A116-22.

5. Stewart GJ. Neutrophils and deep venous thrombosis. Haemostasis. 1993;23 Suppl 1:12740.

6. Arpaia G, Cimminiello C, Mastrogiacomo O, de Gaudenzi E. Efficacy of elastic compression stockings used early or after resolution of the edema on recanalization after deep venous thrombosis: the COM.PRE Trial. Blood coagulation \& fibrinolysis : an international journal in haemostasis and thrombosis. 2007;18(2):131-7.

7. Varma MR, Varga AJ, Knipp BS, Sukheepod P, Upchurch GR, Kunkel SL, et al. Neutropenia impairs venous thrombosis resolution in the rat. Journal of vascular surgery. 2003;38(5):1090-8.

8. ten Cate-Hoek AJ, Henke PK, Wakefield TW. The post thrombotic syndrome: Ignore it and it will come back to bite you. Blood reviews. 2016;30(2):131-7.

9. van Dongen $\mathrm{CJ}$, Prandoni $\mathrm{P}$, Frulla M, Marchiori A, Prins MH, Hutten BA. Relation between quality of anticoagulant treatment and the development of the postthrombotic syndrome. Journal of thrombosis and haemostasis : JTH. 2005;3(5):939-42.

10. Chitsike RS, Rodger MA, Kovacs MJ, Betancourt MT, Wells PS, Anderson DR, et al. Risk of post-thrombotic syndrome after subtherapeutic warfarin anticoagulation for a first unprovoked deep vein thrombosis: results from the REVERSE study. Journal of thrombosis and haemostasis : JTH. 2012;10(10):2039-44.

11. Rodriguez AL, Wojcik BM, Wrobleski SK, Myers DD, Jr., Wakefield TW, Diaz JA. Statins, inflammation and deep vein thrombosis: a systematic review. Journal of thrombosis and thrombolysis. 2012;33(4):371-82.

12. Ippolito E, Belcaro G, Dugall M, Cesarone MR, Feragalli B, Errichi BM, et al. Venoruton(R): post thrombotic syndrome. Clinical improvement in venous insufficiency (signs and symptoms) with Venoruton(R). A five-year, open-registry, efficacy study. Panminerva medica. 2011;53(3 Suppl 1):13-9.

13. Katsenis K. Micronized purified flavonoid fraction (MPFF): a review of its pharmacological effects, therapeutic efficacy and benefits in the management of chronic venous insufficiency. Current vascular pharmacology. 2005;3(1):1-9.

14. Shrier I, Kahn SR, Steele RJ. Effect of early physical activity on long-term outcome after venous thrombosis. Clinical journal of sport medicine : official journal of the Canadian Academy of Sport Medicine. 2009;19(6):487-93.

15. Padberg FT, Jr., Johnston MV, Sisto SA. Structured exercise improves calf muscle pump function in chronic venous insufficiency: a randomized trial. Journal of vascular surgery. 2004;39(1):79-87. 
16. Villalta S BP, Picolli A, Lensing A, Prins M, Prandoni P. . Assessment of validity and reproducibility of a clinical scale for post thrombotic syndrome (abstract)1994; 24:[158a p.].

17. Mol GC, van de Ree MA, Klok FA, Tegelberg MJ, Sanders FB, Koppen S, et al. One versus two years of elastic compression stockings for prevention of post-thrombotic syndrome (OCTAVIA study): randomised controlled trial. BMJ (Clinical research ed). 2016;353:i2691.

18. Ten Cate-Hoek AJ, Bouman AC, Joore MA, Prins M, Ten Cate H. The IDEAL DVT study, individualised duration elastic compression therapy against long-term duration of therapy for the prevention of post-thrombotic syndrome: protocol of a randomised controlled trial. BMJ open. 2014;4(9):e005265.

19. Roumen-Klappe EM, den Heijer M, van Rossum J, Wollersheim $H$, van der Vleuten $C$, Thien $\mathrm{T}$, et al. Multilayer compression bandaging in the acute phase of deep-vein thrombosis has no effect on the development of the post-thrombotic syndrome. Journal of thrombosis and thrombolysis. 2009;27(4):400-5.

20. Blattler W, Partsch H. Leg compression and ambulation is better than bed rest for the treatment of acute deep venous thrombosis. International angiology : a journal of the International Union of Angiology. 2003;22(4):393-400.

21. Kahn SR, Shapiro S, Wells PS, Rodger MA, Kovacs MJ, Anderson DR, et al. Compression stockings to prevent post-thrombotic syndrome: a randomised placebo-controlled trial. Lancet (London, England). 2014;383(9920):880-8.

22. Kearon C, Akl EA, Ornelas J, Blaivas A, Jimenez D, Bounameaux H, et al. Antithrombotic Therapy for VTE Disease: CHEST Guideline and Expert Panel Report. Chest. 2016;149(2):315-52.

23. Appelen D, van Loo E, Prins MH, Neumann MH, Kolbach DN. Compression therapy for prevention of post-thrombotic syndrome. The Cochrane database of systematic reviews. 2017;9:Cd004174.

24. Ten Cate-Hoek AJ, Ten Cate H, Tordoir J, Hamulyak K, Prins MH. Individually tailored duration of elastic compression therapy in relation to incidence of the postthrombotic syndrome. Journal of vascular surgery. 2010;52(1):132-8.

25. Latella J, Desmarais S, Miron MJ, Roussin A, Joyal F, Kassis J, et al. Relation between Ddimer level, venous valvular reflux and the development of post-thrombotic syndrome after deep vein thrombosis. Journal of thrombosis and haemostasis : JTH. 2010;8(10):2169-75.

26. Bouman AC, Smits JJ, Ten Cate H, Ten Cate-Hoek AJ. Markers of coagulation, fibrinolysis and inflammation in relation to post-thrombotic syndrome. Journal of thrombosis and haemostasis : JTH. 2012;10(8):1532-8.

27. Rabinovich A, Cohen JM, Cushman M, Wells PS, Rodger MA, Kovacs MJ, et al. Inflammation markers and their trajectories after deep vein thrombosis in relation to risk of postthrombotic syndrome. Journal of thrombosis and haemostasis: JTH. 2015;13(3):398-408.

28. Haig Y, Enden T, Grotta O, Klow NE, Slagsvold CE, Ghanima W, et al. Post-thrombotic syndrome after catheter-directed thrombolysis for deep vein thrombosis (CaVenT): 5-year follow-up results of an open-label, randomised controlled trial. The Lancet Haematology. 2016;3(2):e64-71.

29. Vedantham S, Goldhaber SZ, Julian JA, Kahn SR, Jaff MR, Cohen DJ, et al. Pharmacomechanical Catheter-Directed Thrombolysis for Deep-Vein Thrombosis. The New England journal of medicine. 2017;377(23):2240-52. 


\section{PART IV ADDENDUM}


Summary in Dutch 
Jaarlijks wordt er bij 1 tot 2 op 1000 mensen de diagnose diep veneuze trombose (DVT) vastgesteld waarbij een bloedstolsel in één of meerdere aders wordt gezien. Binnen twee jaar na deze diagnose ontwikkelt 20 tot $50 \%$ van de patiënten een chronische aandoening genaamd post trombotisch syndroom (PTS). Dit syndroom wordt gekenmerkt door een combinatie van subjectief ervaren klachten als pijn, jeuk en tintelingen, en door objectief vast te stellen symptomen aan het been zoals hyperpigmentatie, roodheid en in ernstige gevallen, veneuze ulceratie wat ook wel "open been" wordt genoemd. PTS ontstaat als gevolg van verschillende processen die optreden nadat een bloedstolsel in de ader(s) ontstaat. De aanwezigheid van PTS heeft vele consequenties. Naarmate de ernst van PTS toeneemt, daalt de kwaliteit van leven. Bovendien is aangetoond dat het optreden van PTS gepaard gaat met toename in kosten. Tot op heden bestaan er geen curatieve behandelingen voor PTS, zodat de focus wordt gelegd op de preventie ervan.

In dit proefschrift wordt een gepersonaliseerde management strategie voor de preventie van PTS onderzocht. Het proefschrift bestaat uit acht hoofdstukken onderverdeeld in drie delen; in deel 1 is ingegaan op de factoren die een (mogelijke) rol spelen in de preventie van PTS, en de mogelijkheid om het risico van het optreden van PTS te kunnen voorspellen. In deel twee worden verschillende vergelijkende onderzoeken over de rol en de duur van compressie therapie gepresenteerd. Deel drie bevat een samenvatting en discussie van de belangrijkste bevindingen.

Hoofdstuk 1 is de algemene inleiding. In hoofdstuk 2 wordt het ziektebeeld verder uitgewerkt. Daarbij wordt het ontstaansmechanisme van PTS en het werkingsmechanisme van compressie therapie als preventie methode beschreven. Het exacte ontstaansmechanisme van PTS is niet bekend. Momenteel wordt gedacht dat nadat het bloedstolsel in het vat is ontstaan, het oplossen ervan gepaard gaat met ontstekingsreacties die zowel schade aan de vaatwand als schade aan de vaatkleppen kunnen veroorzaken. Dit laatste kan ook optreden wanneer het stolsel dicht bij de kleppen aanwezig is. Als gevolg 
van beschadigde kleppen, littekenvorming en obstructie wanneer het stolsel niet (volledig) wordt opgelost, kan de vaatwand stijf worden en bloeddoorstroming belemmerd worden. Uiteindelijk leiden deze processen tot het ontstaan van hoge bloeddruk in de venen. Deze veneuze hypertensie is de oorzaak van de klachten die geassocieerd zijn met PTS. Omdat veneuze hypertensie het hart van dit proces vormt, wordt er gedacht dat het tegengaan ervan een effectieve preventiemethode zou zijn. Daarom worden patiënten met DVT geadviseerd om dagelijks elastische steunkousen te dragen zodat de druk in de vene zakt en de flow verbetert. Hierdoor zouden er minder klachten zijn waardoor het dagelijkse functioneren beter wordt. Naast elastische compressie kousen zijn er tot dusver geen andere preventiemethoden die bewezen effectief zijn. Van fysieke activiteit, manuele lymfedrainage, en bepaalde medicatie wordt gedacht dat dit mogelijk een effect zouden kunnen hebben. Dit moet echter nog worden bewezen.

Om voor elke patiënt een op maat gemaakt preventieplan te kunnen opstellen is het van belang om een goede inschatting van het individuele risico te kunnen maken. In hoofdstuk 3 wordt er ingegaan op de risicofactoren voor PTS. Er zijn momenteel meerdere beïnvloedbare en vaste risicofactoren bekend. Het was echter niet mogelijk om bij verschillende combinaties van deze factoren aan te geven wat het risico van een patiënt met die specifieke set van risicofactoren zou zijn. In dit hoofdstuk wordt de ontwikkeling en validatie van een klinisch predictiemodel voor PTS beschreven. Met behulp van het predictiemodel zijn er twee klinische risico scores opgesteld. De eerste risico score berekent met behulp van demografische en klinische karakteristieken ten tijde van de DVT diagnose de kans dat de patiënt zes maanden later PTS zal ontwikkelen. De tweede risico score berekent vervolgens wat de kans op PTS is op 24 maanden in patiënten die tot zes maanden na de DVT nog geen PTS hebben ontwikkeld. Het vermogen van deze klinische risico scores om een goede inschatting van de kansen te maken bleek voldoende. Validatie van deze scores in een nieuwe set van patiënten met DVT liet zien dat de scores ook in andere groepen patiënten 
een goed voorspellend vermogen hebben waardoor deze dus in de klinische praktijk kunnen worden toegepast. Op dit moment bestaan er naast deze predictiemodellen en klinische risico scores nog geen andere gevalideerde predictiemodellen voor PTS.

De ontwikkelingsfase van het predictiemodel hebben wij tevens uitgevoerd met een alternatieve definitie van de uitkomstmaat PTS. Er kan van PTS worden gesproken wanneer een patiënt minimaal zes maanden na de DVT diagnose, gebaseerd op de klachten en objectieve kenmerken, een totale zogenaamde Villalta score heeft van $\geq 5$. Dit is de huidige consensus methode/definitie waarmee de aanwezigheid van PTS wordt bepaald. De alternatieve versie is de zogenaamde Prandoni definitie waarbij minimaal twee opeenvolgende Villalta scores van $\geq 5$ nodig is om de diagnose PTS te stellen. Het predictiemodel met deze laatste definitie bleek beter in staat om het risico op PTS te schatten, zowel in de eerste zes maanden als na twee jaar. Dit is waarschijnlijk het gevolg van de strengere grens die bij deze definitie wordt gehanteerd. Een predictiemodel met deze definitie zou efficiënter zijn, echter omdat minstens tweemaal het been beoordeeld moet worden, kan het minder praktisch zijn.

In deel 2 van het boekje worden verschillende onderzoeken gepresenteerd die de effectiviteit en de kosteneffectiviteit van verschillende preventiemethodes met elkaar vergelijken. Het eerste onderzoek wat hoofdstuk 4 beslaat gaat over de IDEAL DVT studie. In deze studie met 865 patiënten is er gekeken of het mogelijk is om de duur van de steunkousen te bekorten. Gewoonlijk werden de patiënten met DVT geadviseerd om de steunkous gedurende twee jaar na de DVT diagnose te dragen. In dit onderzoek is gekeken of dit kon worden teruggebracht tot zes maanden op basis van subjectieve klachten en objectieve kenmerken. Patiënten werden op 3, 6, 12, en 24 maanden na de DVT gezien door een arts, waarbij de subjectieve en objectieve beenklachten en kenmerken werden gescoord. Op basis van die score kregen patiënten die in de interventiegroep waren geloot een geïndividualiseerd advies met betrekking tot de draagduur van de kousen. Er waren 4 mogelijke adviezen in de 
interventietroep; 1) kous kon na 6 maanden uit 2) op 6 maanden na DVT werd al geadviseerd om de kous gedurende 24 maanden in totaal dagelijks te dragen 3) kous kon na 12 maanden worden uitgelaten 4) op 12 maanden na DVT werd geadviseerd om de kous te blijven dragen tot 24 maanden na DVT. Patiënten in de controlegroep werd aan het begin van de studie geadviseerd om tot 24 maanden na de DVT diagnose de kous dagelijks te dragen. Uit deze studie bleek dat ongeveer $66 \%$ van de patiënten de kousen korter dan een jaar hoefde te dragen. $56 \%$ droeg de kous zelfs slechts zes maanden in totaal. Na twee jaar bleek het verschil in PTS percentage tussen de groep waarbinnen de draagduur van de kous geïndividualiseerd was en de groep de kous gedurende twee jaar droeg $1.1 \%$. Daarmee werd aangetoond dat verkorten van de draagduur een veilige methode is. Deze methode is nog niet eerder onderzocht.

In hoofdstuk $\mathbf{5}$ is er gekeken of het individualiseren van de draagduur van elastische steunkousen een kosteneffectieve methode is. Met drie verschillende instrumenten is de kwaliteit van leven gemeten in de groep patiënten die het geïndividualiseerde kousadvies hadden (interventiegroep) en in de groep die de steunkousen gedurende de vaste standaard periode (controlegroep) droegen. Met behulp van vragenlijsten zijn de gemaakte kosten als gevolg van beenklachten in beide groepen berekend. Dit waren zowel kosten gerelateerd aan zorg als indirecte kosten als productiviteitsverlies. De kosteneffectiviteitsanalyse werd uitgevoerd over een periode van twee jaar. De resultaten lieten zien dat de kwaliteit van leven in beide groepen vergelijkbaar was. De verschillen waren minimaal. De kosten in de interventiegroep waren een stuk lager dan in de controle groep en bestonden voornamelijk uit de kosten van kousmateriaal en thuiszorgkosten. Geïndividualiseerde draagduur van steunkousen zou, berekend over twee jaar, een kostenbesparing van gemiddeld 88 miljoen euro betekenen. Ongeacht welke van de drie meetinstrumenten wordt gebruikt, de interventie zal kosteneffectief zijn. Bovendien liet verdere analyse zien dat de kans dat de interventie kosteneffectief is bijna $100 \%$ was. Dat 
wil zeggen dat vanuit kosteneffectiviteitsperspectief kousadvies na DVT altijd geïndividualiseerd dient te zijn.

Hoofdstuk 6 beschrijft een onderzoek naar het effect van compressie therapie in de acute fase van DVT. Elastische steunkousen worden niet direct na de diagnose van DVT gegeven maar wanneer het initiële oedeem is gestabiliseerd, dus in de subacute fase. In de acute fase bestaan er drie andere mogelijkheden; geen compressie, compressie in de vorm van zwachtels of compressie met behulp van een compressiekous die iets verschilt in de druk van de elastische compressiekousen die in de subacute fase wordt gedragen. Welke van deze drie methoden wordt toegepast is afhankelijk van het betreffende ziekenhuisprotocol. Tot nu toe zijn er geen onderzoeken die deze drie opties met elkaar hebben vergeleken. Drie relatief kleine, kortdurende studies hebben eerder gekeken naar het effect van compressie in acute fase en vonden tegenstrijdige resultaten. In het onderzoek in dit hoofdstuk hebben we in een groep van 865 patiënten onderzocht wat de klinische en economische impact van deze drie methoden gedurende drie maanden na de DVT diagnose. Het bleek dat patiënten die binnen 24 uur na DVT diagnose een vorm van compressie therapie hadden, minder huidafwijkingen hadden aan het been na 3 maanden. Wanneer de beide compressiemethoden met elkaar werden vergeleken bleek dat zwachtelen een iets effectievere methode was. Echter de zorgkosten gerelateerd aan het zwachtelen waren substantieel hoger dan de kosten in de groep met zwachtelkous en de groep zonder compressie; dit had te maken met de hoge kosten van het zwachtelmateriaal en de kosten gerelateerd aan het wisselen van het materiaal door (para)medische zorgverleners. De kwaliteit van leven was niet verschillend tussen de groepen op één maand of drie maanden na de DVT. Gebaseerd op deze studie concluderen wij dat patiënten met DVT in de acute fase de zwachtelkous zou moeten worden voorgeschreven.

In hoofdstuk $\mathbf{7}$ is de rol van residuele vaatobstructie in relatie tot PTS, compressie in de acute fase, en recief trombose onderzocht in een groep van 592 patiënten. Een deel van deze patiënten had in de acute fase compressie 
therapie ontvangen en een deel had geen compressie. Compressie in de acute fase bleek geassocieerd met $20 \%$ absolute verlaging in residuele vaatobstructie. Diegenen bij wie er sprake was van restobstructie hadden bovendien significant meer kans op PTS. Het percentage PTS in deze groep was $54 \%$ in vergelijking met $46 \%$ in de groep zonder restafwijkingen. De bevindingen steunen de huidige hypothese over het ontstaansmechanisme van PTS, zoals beschreven in hoofdstuk 2. De resultaten suggereren dat compressie in de acute fase zou moeten worden gegeven aan alle patiënten met DVT. Het optreden van recidief trombose was niet geassocieerd met residuele vaatobstructie. Dit was mogelijk gerelateerd aan de lage aantallen trombose recidieven die gedurende de studie optraden.

In het laatste hoofdstuk van het proefschrift, hoofdstuk 8, worden de bevindingen uit eerdere hoofdstukken samengevat en bediscussieerd. Wanneer alle bevindingen worden gecombineerd zou een gepersonaliseerd management van PTS het volgende inhouden. Alle patiënten met DVT, ongeacht klachten en klinische kenmerken, zouden in de acute fase compressie therapie moeten krijgen. Met behulp van de gevalideerde risico score zou ten tijde van de DVT diagnose een schatting worden gemaakt van het individuele risico op het krijgen van PTS. Afhankelijk van het berekende risico kan het vervolgbeleid worden aangepast. $\mathrm{Na}$ de acute fase dienen alle patiënten ministens zes maanden elastische compressie kousen te dragen waarbij regelmatig het been en de klachten worden beoordeeld. Gebaseerd op die beoordelingen kan een geïndividualiseerd advies met betrekking van de draagduur worden gegeven. Dit stappenplan kan leiden tot kosteneffectieve zorg en mogelijk ook tot betere therapietrouw. Dit laatste moet echter nog worden aangetoond.

De bevindingen in dit proefschrift roepen nog enkele vragen op aangaande het management van PTS waarvoor toekomstig onderzoek nodig is. Allereerst de vraag met betrekking tot de diagnostische methode van PTS. De huidige definitie van PTS leidt mogelijk tot overdiagnostisering. De Prandoni definitie is strenger en beter in staat een onderscheid te maken tussen echte PTS gevallen en geen 
PTS. Echter, deze definitie is in de praktijk minder gemakkelijk toepasbaar. De vraag is dan ook of een andere afkappunt van de huidige definitie een oplossing zou kunnen bieden.

Een tweede vraag die voortvloeit uit de resultaten van dit proefschrift is of de minimale duur van de elastische steunkousen korter kan zijn dan zes maanden. Mogelijk hebben sommige patiënten voldoende aan minder lang dragen. Als de optimale draagduur van de steunkousen kan worden vastgesteld, kan de kostenbesparing nog hoger zijn en de zorg dus efficiënter. Ook is het de vraag of andere preventieve opties, zoals besproken in hoofdstuk 2, een rol kunnen spelen in PTS management en ter vervanging of versterking van elastische steunkousen kunnen worden toegepast. Tenslotte is de vraag wat voor een rol invasieve preventiemethoden kunnen spelen. Vooralsnog zijn de resultaten van studies met invasieve methodes als kathetergeleide trombolyse niet conclusief. 


\section{Valorization}




\section{Societal and economic relevance}

Annually 1 to 2 per 1000 persons are affected by deep vein thrombosis (DVT) ${ }^{(1)}$. For the Netherlands this means that approximately 25.000 patients each year are diagnosed with DVT of whom $20 \%$ to $50 \%$ develop the chronic condition known as post-thrombotic syndrome (PTS) ${ }^{(2,3)}$. Hence, 5000 to 12.500 patients in the Netherlands alone develop some form of post-thrombotic problems. The condition has been shown to affect the quality of life extensively and to induce significant societal costs ${ }^{(4-6)}$. Previously, the average weighted costs per person involved with PTS were estimated by our group to be $€ 3.367$ for incident PTS and $€ 3.247$ for the health state ${ }^{(7)}$. As curative therapies are absent prevention is of significant importance. Thus far however, an optimal management strategy is missing. The present thesis aimed to establish a personalized, predictive, preventive and cost-effective management approach for PTS. In order to arrive at this management strategy some important research questions needed to be answered.

First, we focused our research on the individualization of the current preventive therapy (chapter 4). This is a relevant approach for several reasons. After the initial edema is reduced, all patients with DVT are prescribed the same therapy i.e. to wear daily elastic compression stockings (ECS) for 2 years. This strategy is costly and not optimal for all patients. We hypothesized that individualized therapy would result in similar effectiveness but with the addition of better health related quality of life and positive monetary consequences (chapter 5). Second, we questioned the effect of preventive measures in the acute phase of DVT. There is no consensus as to what the best preventive therapy might be in the acute phase prior to ECS use. (Chapter 6) Based on the presumed pathophysiology of PTS, compression in the acute phase might improve venous flow and thereby possibly promote thrombus resolution and mitigate inflammatory reactions. We have investigated the effect of immediate 
compression therapy after DVT diagnosis versus no compression and found that patients who received compression therapy had $15 \%$ less irreversible skin signs at 3 months, compared to those who did not receive immediate compression. Moreover, after 6 months, less obstructive vein occlusion was seen in patients who received immediate compression and that showed to be significantly related to less PTS (chapter 6). The relevance of our research question is that less PTS as a consequence of immediate compression therapy could mean less healthcare costs and better quality of life. As a third research angle we aimed to a better identification of patients at risk of PTS through development of a clinical risk score for PTS (Chapter 3 ). This is relevant because being able to estimate the individual patient risk of PTS development can result in patient specific and hence more effective therapy.

\section{Relevance for stakeholders}

\section{Patients}

Our findings will benefit the patients in several ways. In the acute phase of DVT patients now can be offered more adequate therapy that will result in better outcome (less PTS). We have shown that therapy can safely be adjusted according to the need of the individual patient. Not all patients are required to wear ECS for 2 years which will result in better quality of life and more autonomy, as not all patient are able to apply and remove the ECS independently. Moreover, wearing ECS can cause (esthetic) inconvenience and should therefore only be prescribed for prolonged duration in case the patient has a high risk of PTS development. Thus, the patients know that no unnecessarily therapy is offered.

\section{Health care providers}

We developed a clear-cut stepwise management strategy for PTS that can be easily applied in practice by health care providers. As step one, we recommend prescribing immediate compression therapy in form of compression hosiery, 
rather than the much expensive and inconvenient multilayer compression bandaging, to all patients with DVT in the acute phase. Step two is to estimate the individual patient risk of PTS development so that further therapy could be adjusted accordingly. To this end, we developed an easy applicable clinical risk score for PTS that uses only baseline clinical and demographic characteristics as predictors. As an internally and externally validated prediction rule, it is the first one that can be clinically applied. Step three is to individually tailor the duration of ECS based on the clinical signs and symptoms.

\section{Researchers}

By showing that immediate compression therapy reduces occurrence of residual vein obstruction and consequently PTS, the results of the present thesis contributed to the confirmation of the "open vein hypothesis" that assumes that early thrombus resolution will result in less PTS because there is less vein wall damage due to the shorter duration that the thrombus is adjacent to the vessel wall. Moreover, our findings confirmed the effectiveness of ECS as such. This is an important finding because the effectiveness of compression therapy in PTS prevention had become a matter of debate. We compared a subgroup of patients without complaints and with excellent adherence to ECS therapy from the individualized strategy who were instructed to stop treatment with similar patients from the standard treatment strategy that continued treatment for 2 years. It was observed that in patients who continued ECS less PTS occurred which lead to the conclusion that compression therapy prevents PTS in general.

\section{Policy makers}

Offering individualized instead of one size fits all therapy to patients suggests adequate patient oriented treatment, better health related quality of life and costs savings. We performed a cost-effectiveness analysis and found that individually tailored duration of ECS in the Netherlands would result in cost savings of 88 million euros ( $95 \% \mathrm{Cl} 31$ to 144 million) measured over two years, based on 25000 cases of DVT annually. Further analysis showed that the 
probability that the investigated strategy is indeed cost-effective is nearly $100 \%$, implying that from an economic perspective too, ECS therapy should be individualized.

\section{Innovativeness}

The present thesis was the first to touch upon several aspects in the management of PTS. We were the first to develop a clinically applicable risk score for PTS, to show that shortened duration of ECS is safe and feasible and to assess the effect of several forms of immediate compression therapy in the acute phase of DVT and the relation between immediate compression therapy and the occurrence residual vein occlusion and PTS, in a large study population. Additionally, as the first group we performed a cost-effectiveness analysis of individualized duration of compression therapy and contributed to the credibility of PTS pathophysiology. As such, our findings have redirected the current clinical practice in PTS prevention; patients with DVT are now prescribed immediate compression therapy in form of compression hosiery and the duration of ECS is being individualized.

\section{Knowledge and products}

The current thesis resulted in six published articles in the medical journals Phlebology, JTH, TH, Blood and two articles in the Lancet Haematology. The first article was a narrative review explaining the theoretical background. The second article provided the first clinical risk score for PTS. The third article provided evidence for shorter duration of ECS with all the related benefits. The fourth article showed the monetary benefits of shorter duration of ECS. Article five established that all patients should have immediate compression therapy and that a compression hosiery instead of multilayer bandaging should be used. The 
final article provided new insights in the relation between immediate compression therapy and residual vein obstruction. All results combined, we established a clear-cut and easily applicable personalized, predictive, preventive and cost-effective management approach for PTS. 


\section{References}

1. Naess IA, Christiansen SC, Romundstad P, Cannegieter SC, Rosendaal FR, Hammerstrom J. Incidence and mortality of venous thrombosis: a population-based study. Journal of thrombosis and haemostasis : JTH. 2007;5(4):692-9.

2. Brandjes DP, Buller HR, Heijboer $H$, Huisman MV, de Rijk $M$, Jagt $H$, et al. Randomised trial of effect of compression stockings in patients with symptomatic proximal-vein thrombosis. Lancet (London, England). 1997;349(9054):759-62.

3. Prandoni $P$, Lensing $A W$, Prins $M H$, Frulla $M$, Marchiori $A$, Bernardi $E$, et al. Below-knee elastic compression stockings to prevent the post-thrombotic syndrome: a randomized, controlled trial. Annals of internal medicine. 2004;141(4):249-56.

4. Kahn SR, Ducruet T, Lamping DL, Arsenault L, Miron MJ, Roussin A, et al. Prospective evaluation of health-related quality of life in patients with deep venous thrombosis. Archives of internal medicine. 2005;165(10):1173-8.

5. Bergqvist D, Jendteg S, Johansen L, Persson U, Odegaard K. Cost of long-term complications of deep venous thrombosis of the lower extremities: an analysis of a defined patient population in Sweden. Annals of internal medicine. 1997;126(6):454-7.

6. Caprini JA, Botteman MF, Stephens JM, Nadipelli V, Ewing MM, Brandt S, et al. Economic burden of long-term complications of deep vein thrombosis after total hip replacement surgery in the United States. Value in health : the journal of the International Society for Pharmacoeconomics and Outcomes Research. 2003;6(1):59-74.

7. Amin EE, Ten Cate-Hoek AJ, Bouman AC, Meijer K, Tick L, Middeldorp S, et al. Individually shortened duration versus standard duration of elastic compression therapy for prevention of post-thrombotic syndrome: a cost-effectiveness analysis. The Lancet Haematology. 2018;5(11):e512-e9. 
List of Publications 


\section{Published papers}

1. Amin E, Joore MA, ten Cate-Hoek AJ. Compression to prevent PTS: $a$ controversy? Phlebology. 2016 Mar;31(1 Suppl): 41-7.

2. Amin EE, van Kuijk SMJ, Prandoni $P$, ten Cate $H$, ten Cate-Hoek AJ. Development and validation of a practical two-step prediction model and clinical risk score for post-thrombotic syndrome. Thrombosis and Haemostasis. 2018 Jul; 118(7):1242-1249.

3. Ten Cate-Hoek AJ, Amin EE, Bouman AC, Meijer K, Tick LW, Middeldorp S, Mostard GJM, ten Wolde M, van den Heiligenberg SM, van Wissen S, van de Poel MHW, Villalta S, Serné EH, Otten HM, Klappe EH, Bistervels IM, Lauw $\mathrm{MN}$, Piersma-Wichers $\mathrm{M}$, Prandoni $\mathrm{P}$, Joore $\mathrm{MA}$, Prins $\mathrm{MH}$, ten Cate $\mathrm{H}$ for the IDEAL DVT investigators. Individualised versus standard duration of elastic compression therapy for prevention of post-thrombotic syndrome (IDEAL DVT): a multicentre, randomised, single-blind, allocation-concealed, noninferiority trial. The Lancet Haematology. 2018 Jan;5(1):e25-e33.

4. Amin EE, ten Cate-Hoek AJ, Bouman AC, Meijer K, Tick LW, Middeldorp S, Mostard GJM, ten Wolde M, van den Heiligenberg SM, van Wissen S, van de Poel MHW, Villalta S, Serné EH, Otten HM, Klappe EH, Prandoni P, Prins MH, ten Cate $\mathrm{H}$ and Joore MA. Cost-effectiveness of individualised versus standard duration of elastic compression therapy for prevention of post-thrombotic syndrome. The Lancet Haematology. 2018 Nov;5(11):e512-e519.

5. Amin EE, Joore MA, ten Cate H, Meijer K, Tick LW, Middeldorp S, Mostard GJM, ten Wolde $M$, van den Heiligenberg SM, van Wissen $S$, van de Poel MHW, Villalta S, Serné EH, Otten HM, Klappe EH, Prandoni P and ten CateHoek AJ. Clinical and economic impact of compression in the acute phase of DVT. Journal of Thrombosis and Haemostasis. Jun 1. doi: 10.1111/jth.14163.

6. Amin EE, Bistervels IM, Meijer K, Tick LW, Middeldorp S, Mostard GJM, van de Poel MHW, Serné EH, Otten HM, Klappe EH, Joore MA, ten Cate H, ten Wolde and ten Cate-Hoek AJ. Residual vein occlusion in relation to immediate compression and post-thrombotic syndrome in deep vein thrombosis. Blood. 2018 Nov 22;132(21):2298-2304. 


\section{About the Author}

The author of the thesis finished her pre-university education (VWO) at Porta Mosana College in Maastricht. Afterwards she attended Maastricht University and received Bachelor's degrees in Health Sciences, in European Studies and in Medicine, and Master's degrees in Epidemiology and in Medicine. From 2015 until 2018 she performed her PhD thesis at the department of Clinical Epidemiology and Medical Technology Assessment (KEMTA), and department of Internal Medicine (Biochemistry) at Maastricht University Medical Centre. As of March 2019 she works as a medical doctor at the department of General Surgery at Maastricht University Medical Centre. 
Acknowledgements 
Hartelijk dank aan iedereen die heeft bijgedragen aan mijn werk gedurende mijn promotietraject.

Mijn promotieteam; Hugo, Manuela en Arina, ik wil jullie graag bedanken voor het feit dat jullie mij hebben aangenomen als promovendus op de IDEAL DVT studie. Ik vond mijn werk bijzonder leuk en leerzaam en dank jullie voor het vertrouwen en de gestructureerde begeleiding. Het is een heel mooi boekje geworden.

De beoordelingscommissie en de corona dank ik voor hun bereidheid om mijn thesis te lezen. Alle medeauteurs en IDEAL onderzoekers bedankt voor jullie bijdrage.

Dank aan alle collega's van de afdeling KEMTA (Andrea, Bianca, Bram, Brigitte, Carmen, Daisy, Dorthe, Irene, Maarten, Marije, Martijn, Merel, Monique, Nicole, Sabine, Sander, Stella, Svenja, Willem, Xavier, Yvonne) voor de fijne sfeer op de afdeling en dat ik jullie om hulp kon vragen wanneer dat nodig was. Mijn onderzoeksassistente en kamergenoot Roos dank ik voor haar zelfstandigheid en de gezelligheid. Alle andere kamergenoten (bij KEMTA en CTH) Dorthe, Minka, Suzanne, Jens, Maarten, Daisy en Irene dank ik voor de gezelligheid, het feit dat jullie mijn klaagzang wilden aanhoren en helpen wanneer ik dat nodig had. Voor deze dingen dank ik natuurlijk ook Sander. Veder dank aan Dorthe dat ze ook mijn paranimf wilde zijn.

Collega's van CTH lab dank ik voor al hun inbreng tijdens de dinsdagochtend besprekingen en Renske verder ook dank voor haar hulp met de poli. Suzanne en Bram bedankt voor het overnemen van de onderwijspoli wanneer nodig.

Dank aan Elsa die mijn paranimf wilde zijn en Hesam voor alle hulp bij het bewerken van de cover picture en de lay-out van het boekje. Bedankt dat ik altijd op jullie kan rekenen.

Speciale dank aan mijn moeder voor het feit dat ze mijn grootste steun en toeverlaat is.

Nogmaals, beste allen die op één of ander manier betrokken waren bij mijn promotietraject en al dan niet zijn genoemd;

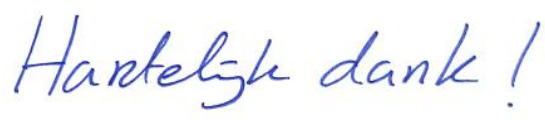

